\title{
Challenging the limits of endovascular abdominal aortic aneurysm repair
}

Citation for published version (APA):

Broos, P. P. H. L. (2015). Challenging the limits of endovascular abdominal aortic aneurysm repair.

[Doctoral Thesis, Maastricht University]. Maastricht University. https://doi.org/10.26481/dis.20151208pb

Document status and date:

Published: 01/01/2015

DOI:

10.26481/dis.20151208pb

Document Version:

Publisher's PDF, also known as Version of record

\section{Please check the document version of this publication:}

- A submitted manuscript is the version of the article upon submission and before peer-review. There can be important differences between the submitted version and the official published version of record.

People interested in the research are advised to contact the author for the final version of the publication, or visit the DOI to the publisher's website.

- The final author version and the galley proof are versions of the publication after peer review.

- The final published version features the final layout of the paper including the volume, issue and page numbers.

Link to publication

\footnotetext{
General rights rights.

- You may freely distribute the URL identifying the publication in the public portal. please follow below link for the End User Agreement:

www.umlib.nl/taverne-license

Take down policy

If you believe that this document breaches copyright please contact us at:

repository@maastrichtuniversity.nl

providing details and we will investigate your claim.
}

Copyright and moral rights for the publications made accessible in the public portal are retained by the authors and/or other copyright owners and it is a condition of accessing publications that users recognise and abide by the legal requirements associated with these

- Users may download and print one copy of any publication from the public portal for the purpose of private study or research.

- You may not further distribute the material or use it for any profit-making activity or commercial gain

If the publication is distributed under the terms of Article $25 \mathrm{fa}$ of the Dutch Copyright Act, indicated by the "Taverne" license above, 
Challenging the limits of endovascular abdominal aortic aneurysm repair

Pieter Petrus Henricus Luciën Broos 
Financial support by the Dutch Heart Foundation for the publication of this thesis is gratefully acknowledged.

Additional financial support was generously provided by; Catharina Ziekenhuis Eindhoven, Fonds voor het hart, W.L. Gore \& Associates, Rabobank EindhovenVeldhoven, Krijnen Medical Innovations, Pie Medical Imaging.

Challenging the limits of endovascular abdominal aortic aneurysm repair Thesis, University of Maastricht, The Netherlands

Copyright $\odot 2015$ Pieter Broos, The Netherlands No part of this thesis may be reproduced, stored or transmitted without prior permission of the author.

Lay-out Eric Alberts, ericalberts.com

Printed by Ridderprint, Ridderkerk, The Netherlands

ISBN 978-94-6299-225-2 


\title{
Challenging the limits of endovascular abdominal aortic aneurysm repair
}

\author{
PROEFSCHRIFT \\ ter verkrijging van de graad van doctor \\ aan de Universiteit Maastricht, \\ op gezag van Rector Magnificus, prof. dr. L.L.G. Soete \\ volgens het besluit van het College van Decanen, \\ in het openbaar te verdedigen \\ op dinsdag 8 december 2015 om 16.00 uur
}

door

\section{Pieter Petrus Henricus Luciën Broos}




\section{Promotiecommissie}

\section{Promotor}

Prof. dr. J.A.W. Teijink

\section{Copromotoren}

Dr. M.R.H.M. van Sambeek (Catharina Ziekenhuis, Eindhoven)

Dr. Ph.W.M. Cuypers (Catharina Ziekenhuis, Eindhoven)

\section{Beoordelingscommissie}

Prof. dr. M.H. Prins (voorzitter)

Prof. dr. F.L. Moll (Universitair Medisch Centrum Utrecht, Utrecht)

Prof. dr. G.W.H. Schurink

Prof. dr. H.J.M. Verhagen (Erasmus Medisch Centrum, Rotterdam) 
Voor An en Lola 


\section{Contents}

Chapter 1 General introduction and outline of the thesis

PART ONE Evolution and long-term follow-up in EVAR patients

Chapter 2 Ten-year follow-up of talent stent grafts for endovascular

abdominal aortic aneurysm repair: a single-centre experience

Chapter 3 Long-term outcome of endovascular repair for elective and 37 ruptured abdominal aortic aneurysms; 15-year single centre experience

PART TWO Clinical experience and new insights in EVAR

Chapter 4 The effects of anesthesia type on perioperative outcome after endovascular aneurysm repair

Chapter 5 A ruptured abdominal aortic aneurysm requiring 75 preoperative cardiopulmonary resuscitation is not necessarily lethal

PART THREE Challenging anatomy in EVAR

Chapter 6 Endovascular treatment of ruptured abdominal aortic aneurysms with hostile aortic neck anatomy

Chapter 7 Performance of the endurant stent graft in challenging anatomy: 30-day and 1-year analyses

Chapter 8 Rationale and design of the eagle registry: EVAR with the endurant in challening anatomy 
PART FOUR Summary, general discussion and future perspectives

Chapter 10 Nederlandse samenvatting

Appendices Valorisatie addendum

Dankwoord

Curriculum vitae

List of publications

185 



\title{
Chapter 1 \\ General introduction and outline of the thesis
}

Partly published as Endovascular aneurysm repair in challenging anatomy

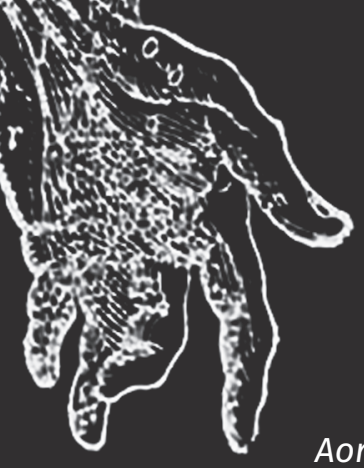

\author{
P.P.H.L. Broos \\ R.A. Stokmans \\ B.L.W. Bendermacher \\ Ph.W.M. Cuypers \\ M.R.H.M. van Sambeek \\ J.A.W. Teijink
}

Aortic Aneurysms: Risk factors, diagnosis, surgery \& repair. New York: Nova Science Publishers, 2013, ISBN: 978-1-62618-458-9 


\section{General introduction}

\section{Abdominal aortic aneurysms}

An abdominal aortic aneurysm is a localised, permanent dilatation of the abdominal aorta that exceeds the normal diameter by more than 50 percent. Abdominal aortic aneurysms (AAAs) are a significant health challenge with an estimated incidence of 20-40 cases per 100000 population per year. Initial treatment is aimed at preventing rupture.,2 There is a generally accepted indication for treatment if the threshold diameter of the AAA is reached $(55 \mathrm{~mm} / 50 \mathrm{~mm}$, measured by ultrasonography, in males/females respectively), if rapid aneurysm growth is observed (> $5 \mathrm{~mm} / 6$ months), or if the aneurysm becomes symptomatic. ${ }^{3}$

\section{Open aneurysm repair}

Since its first introduction in 1952 by Dubost et al., open aneurysm repair has undergone many improvements and has become the gold standard of AAA treatment. ${ }^{4}$ Based on long-term follow-up data, open repair remains a safe and durable option for the management of AAAs. ${ }^{5}$ However, open surgical aneurysm repair requires laparotomy and clamping of the aorta, which is frequently accompanied by substantial blood loss. Consequently, open repair is still associated with a perioperative mortality rate of $2 \%$ to $5 \%$ and significant morbidity.

\section{Endovascular aneurysm repair (EVAR)}

Over the last 25 years, the management of AAAs has changed dramatically. Independently of each other, Parodi et al. and Volodos et al. introduced endovascular aneurysm repair (EVAR) in 1991. ${ }^{6,7}$ Under X-ray fluoroscopic guidance, a minimally invasive approach is used to introduce a stent graft into the abdominal aorta and exclude the aneurysm sac from circulation. Initially, EVAR was an alternative treatment for patients with severe comorbidities, who were not suitable for open repair. Currently, however, EVAR has become the preferred treatment option for patients with an AAA in many centres. However, the main downside of EVAR is the risk of late complications and the subsequent need for secondary interventions. ${ }^{8}$ 


\section{Stent graft related complications}

Type-I endoleak

A type-I endoleak is defined as blood flow into the aneurysm due to an incomplete or ineffective seal at the stent graft ends. The blood flow is direct and under systemic pressure. The AAA is not excluded from circulation anymore and therefore at risk of continued expansion and rupture. AAAs with short, angulated and heavily calcified infrarenal necks are at increased risk. ${ }^{9}$ If type-I endoleaks are observed during the initial procedure, they should be corrected before the patient leaves the operating theatre. Intraoperative and late type-I endoleaks can be resolved through additional ballooning at the proximal attachment site, placement of balloon expandable stents, or stent-graft extension. ${ }^{10-13}$

\section{Type-Il endoleak}

The most common form of endoleaks after infrarenal EVAR are type-II endoleaks, which are defined as branch flow through a patent inferior mesenteric artery (IMA), lumbar artery, accessory renal artery, or hypogastric artery. Type-II endoleaks show an incidence of 15 to $20 \%$ perioperatively and at one month postoperatively. At 1-year follow-up, the incidence decreases to 5 to $10 \% .^{14}$ The most common source of type-II endoleaks is through lumbar arteries and via the inferior mesenteric artery (IMA). Nowadays, a much more conservative approach is accepted regarding type-II endoleak management, because many of them seems to be relatively benign. ${ }^{15}$ Some type-II endoleaks tend to resolve spontaneously, while others persist without causing clinical symptoms and a small proportion may cause significant increase in sac size. ${ }^{16}$ If reparation of a type-II endoleak is considered necessary, embolization may be executed with a transarterial approach or with direct endoleak puncture by means of a translumbar approach. ${ }^{17-19}$

\section{Type-III endoleak}

Type-III endoleaks are defined as mid-graft endoleaks that originate either from fabric holes or from an inadequate seal between endograft components. The incidence of type-III endoleaks is between 0.1 and 6.4 percent. To avoid inadequate seals, it is vital to use sufficient component overlap during the primary procedure, particularly in case of severe tortuosity of the iliac arteries or extreme neck angulation, which result in significantly increased forces on the overlap. A type-III 
endoleak can be eliminated by using additional stent graft components to bridge the defect. ${ }^{20}$

\section{Type-IV endoleak}

A type-IV endoleak is present if blood or fluid passes through the graft fabric due to porosity of the stent graft, a phenomenon that was recognized in the early period of stent grafting as generally taking place immediately after implantation. ${ }^{21}$ Type-IV endoleaks generally require no secondary intervention, as they are usually longer observed at the first surveillance CTA.

\section{Migration}

Stent graft migration is defined as stent graft movement of $>10 \mathrm{~mm}$ relative to anatomical landmarks or any migration leading to symptoms or requiring therapy. ${ }^{8}$ Risk of migration increases over time and can result in loss of device fixation proximally, distally, or at modular junctions. ${ }^{22}$ Stent graft migration may result in a type 1 endoleak with repressuration of the aneurysm sac, which can lead to rupture. Factors that contribute to migration are aortic neck and AAA morphology, insufficient accuracy of stent graft deployment, post-operative neck enlargement, proximal attachment failure, iliac fixation, and characteristics of stent grafts. ${ }^{3}$

The proximal type-I endoleak is the most important cause of AAA rupture after initial aneurysm exclusion with EVAR. Both type-I endoleaks and migration are the most common reasons for re-interventions. Complications can occur early or late during follow-up, therefore long-term follow-up is required after EVAR. ${ }^{23}$

\section{Anatomic limitations}

The success of EVAR, in terms of exclusion of the aneurysm and absence of perioperative and postoperative complications, is closely dependent on the morphology and dimensions of the AAA. ${ }^{24,25}$ For this reason, the instructions for use (IFU) of all commercially available stent grafts include strict guidelines regarding $A A A$ morphology and dimensions. If these guidelines were followed in daily practice, EVAR would be withheld from approximately $40 \%$ of patients with an AAA. Global registries show that EVAR is performed in patients whose anatomy is outside the recommended limits. ${ }^{26}$ 


\section{Evolution of stent grafts}

The first generation stent grafts led to significant problems during follow-up, including progressive neck dilatation, distal migration, modular separation, thrombosis, and loss of integrity. ${ }^{27,28}$ Substantial progress has been made with new generation devices to prevent such complications. ${ }^{29-32}$ This progress has continued up to the newest generation of stent grafts, which show good results in terms of perioperative and postoperative outcome, even in patients with a challenging anatomy. ${ }^{26,33}$

Stent graft manufacturers continue to refine both the stent graft and its delivery system. Besides, the physicians experience has increased over the past decades. Experienced vascular surgeons dare to take on aneurysms with short and angulated necks, thus allowing a wider range of patients to be treated with EVAR.

\section{Emergency EVAR}

EVAR has become the preferred treatment option in patients with a ruptured AAA in many centres worldwide. The technical success of EVAR depends on accurate preoperative planning, including aortic aneurysm sizing and adequate stent graft selection. In patients presenting with a ruptured AAA (RAAA), planning has to be done under pressure and in a limited time frame. Usually there is no time for extensive image reconstructions with a dedicated measuring programme. In addition, the stent graft will have to be selected from an available stock that will be at least relatively limited. Due to the nature of RAAAs and the concomitant hemodynamic instability, it is reasonable to assume that the interventionist will speed up the procedure to reach adequate haemostasis as soon as possible. All these factors can influence the procedure and can have an effect on the safety, durability and effectiveness of the stent graft in both short-term and long-term outcomes.

\section{AAA repair in very unstable patients}

A patient-specific treatment strategy may possibly improve the outcome if the selection criteria for the intervention are optimized. Scoring systems combining clinical findings and biochemical results were introduced as a means to predict survival for RAAA patients. For instance, the Hardman index uses a set of five 
parameters. Although this index is easily applicable, the outcome may also be determined by other factors. ${ }^{34}$ To date, there is no single system that allows for a proper preoperative selection of candidates who might optimally benefit from vascular surgery for RAAA. However, the necessity of preoperative cardiopulmonary resuscitation (CPR) reflects a dismal condition in an RAAA patient. Therefore, it is highly questionable whether RAAA patients requiring preoperative CPR should be offered surgical treatment at all. A slim body of low-level literature suggests that these patients are unlikely to survive. ${ }^{35-37}$

\section{Aim of the thesis}

- To assess the occurrence of graft-related complications and secondary interventions during a minimum of ten years of follow-up.

- To compare EVAR in patients with ruptured and non-ruptured AAAs in a retrospective, single-centre study.

- To assess the effects of anaesthesia type on the outcome of elective EVAR in a multi-centre, non-randomized, prospective observational study.

- To evaluate clinical outcome in RAAA patients who received cardiopulmonary resuscitation (CPR) prior to surgery.

- To assess the effect of challenging AAA morphology on the outcomes of elective EVAR in a multi-centre, non-randomized, prospective observational study.

- To assess the effects of challenging infrarenal aortic necks in patients with a RAAA treated with EVAR.

- $\quad$ To set up a protocol to prospectively collect real-world data on patients with challenging infrarenal aortic necks treated with the newest generation stent graft. 


\section{Outline of the thesis}

This thesis consists of three parts. Part I focuses on the outcomes of elective and emergency EVAR (chapters 2 and 3). The second part of this thesis contains studies on perioperative care and emergency EVAR in highly unstable patients (chapters 4 and 5). Once the clinical outcomes and new insights into perioperative management in EVAR have been described, part 3 focuses on the outcome of EVAR in patients with challenging proximal aortic neck anatomy (chapters 6, 7 and 8).

\section{PART ONE - Evolution and long-term follow-up in EVAR}

The main downside of EVAR is the risk of late complications and the need for secondary interventions. Therefore, lifelong surveillance is advised after EVAR. However, there is little evidence on long-term stent graft durability to support this intensive and costly follow-up recommendation. Chapter 2 reports 10-year followup data of elective cases of EVAR with the Talent infrarenal stent graft (Medtronic Vascular, Santa Rosa, CA, USA). To assess the need of lifelong surveillance after EVAR, we evaluated the occurrence of stent graft related complications and secondary interventions during a minimum of ten-year follow-up.

To evaluate and compare the technical performance of EVAR in both an elective as well as an emergency setting, we analysed outcomes of all EVAR procedures in the Catharina Hospital Eindhoven over a 15-year period. As described in Chapter 3, we evaluated technical operation success rates and compared the occurrence of secondary interventions after elective and emergency EVAR.

\section{PART TWO - Clinical experience and new insights regarding EVAR}

Chapter 4 presents an observational study that compared EVAR cases performed under different types of anaesthesia. The feasibility of EVAR with local and regional anaesthesia was already proven in $1999 .{ }^{38}$ Guidelines recommend the use of locoregional anaesthesia for EVAR if possible. ${ }^{3,39}$ Nevertheless, EVAR is still mainly performed under general anaesthesia..$^{40}$ Technical operation success and thirty-day outcomes were evaluated in this chapter.

Surgical repair of RAAAs is not always possible, due to existing comorbidities, anatomic unsuitability or a highly unstable patient condition at the time of 
admission. Chapter 5 evaluates the outcomes of RAAA in patients requiring preoperative cardiopulmonary resuscitation. Since EVAR is clearly less invasive than an open reconstruction, feasible under local anaesthesia, and certainly much quicker if performed by an experienced surgeon, we also analysed which technique appears to be superior in these patients.

\section{PART THREE - Challenging anatomy in EVAR}

Chapter $\mathbf{6}$ describes the outcome of endovascular treatment of RAAAs with short and angulated necks based on the experience of a single-centre. In contrast, Chapter $\mathbf{7}$ evaluates outcomes of EVAR by comparing three groups of patients with non-ruptured AAAs with different degrees of aortic neck complexity. To date, there are no prospective registries on patients treated with challenging aortic necks. For this reason, we initiated a multi-centre, prospective, non-randomized registry to collect global 'real-world' performance data of EVAR in anatomically challenging AAAs. Chapter 8 describes the rationale and design of the EAGLE registry (Endurant for challenging Anatomy: GLobal Experience).

\section{PART FOUR - Summary, general discussion and future perspectives}

Chapter 9 presents the main results and conclusions of this thesis. We discuss both the current knowledge and the remaining controversies and present the future perspectives. 


\section{References}

1. Melton LJ, 3rd, Bickerstaff LK, Hollier LH, et al.: Changing incidence of abdominal aortic aneurysms: a population-based study. Am J Epidemiol 1984; 120: 379-86

2. Lederle FA, Johnson GR, Wilson SE, et al.: Prevalence and associations of abdominal aortic aneurysm detected through screening. Aneurysm Detection and Management (ADAM) Veterans Affairs Cooperative Study Group. Ann Intern Med 1997; 126: 441-9

3. Moll FL, Powell JT, Fraedrich G, et al.: Management of abdominal aortic aneurysms clinical practice guidelines of the European society for vascular surgery. Eur J Vasc Endovasc Surg 2011; 41 Suppl 1: S1-S58

4. Dubost C, Allary M, Oeconomos $\mathrm{N}$ : Resection of an aneurysm of the abdominal aorta: reestablishment of the continuity by a preserved human arterial graft, with result after five months. AMA Arch Surg 1952; 64: 405-8

5. Conrad MF, Crawford RS, Pedraza JD, et al.: Long-term durability of open abdominal aortic aneurysm repair. J Vasc Surg 2007; 46: 669-75

6. Parodi JC, Palmaz JC, Barone HD: Transfemoral intraluminal graft implantation for abdominal aortic aneurysms. Ann Vasc Surg 1991; 5: 491-9

7. Volodos NL, Karpovich IP, Troyan VI, et al.: Clinical experience of the use of self-fixing synthetic prostheses for remote endoprosthetics of the thoracic and the abdominal aorta and iliac arteries through the femoral artery and as intraoperative endoprosthesis for aorta reconstruction. Vasa Suppl 1991; 33: 93-5

8. Chaikof EL, Blankensteijn JD, Harris PL, et al.: Reporting standards for endovascular aortic aneurysm repair. J Vasc Surg 2002; 35: 1048-60

9. Aburahma AF, Campbell JE, Mousa AY, et al.: Clinical outcomes for hostile versus favorable aortic neck anatomy in endovascular aortic aneurysm repair using modular devices. J Vasc Surg 2011; 54: $13-21$

10. Londero $\mathrm{H}$, Lev $\mathrm{G}$, Bertoni $\mathrm{H}$, et al.: Safety and feasibility of balloon-expandable stent implantation for the treatment of type I endoleaks following endovascular aortic abdominal aneurysm repair. Eurolntervention 2011; 6: 740-3

11. Arthurs ZM, Lyden SP, Rajani RR, et al.: Long-term outcomes of Palmaz stent placement for intraoperative type la endoleak during endovascular aneurysm repair. Ann Vasc Surg 2011; 25: $120-6$

12. Kim JK, Noll RE, Jr., Tonnessen BH, et al.: A technique for increased accuracy in the placement of the "giant" Palmaz stent for treatment of type IA endoleak after endovascular abdominal aneurysm repair. J Vasc Surg 2008; 48: 755-7

13. Rajani RR, Arthurs ZM, Srivastava SD, et al.: Repairing immediate proximal endoleaks during abdominal aortic aneurysm repair. J Vasc Surg 2011; 53: 1174-7 
14. Resch T, Dias N: Treatment of endoleaks: techniques and outcome. J Cardiovasc Surg (Torino) 2012; 53: 91-9

15. Rayt HS, Sandford RM, Salem M, et al.: Conservative management of type 2 endoleaks is not associated with increased risk of aneurysm rupture. Eur J Vasc Endovasc Surg 2009; 38: 718-23

16. Silverberg D, Baril DT, Ellozy SH, et al.: An 8-year experience with type II endoleaks: natural history suggests selective intervention is a safe approach. J Vasc Surg 2006; 44: 453-9

17. Stavropoulos SW, Park J, Fairman R, et al.: Type 2 endoleak embolization comparison: translumbar embolization versus modified transarterial embolization. J Vasc Interv Radiol 2009; 20: 1299-302

18. Nevala T, Biancari F, Manninen $\mathrm{H}$, et al.: Type II endoleak after endovascular repair of abdominal aortic aneurysm: effectiveness of embolization. Cardiovasc Intervent Radiol 2010; 33: 278-84

19. Sarac TP, Gibbons C, Vargas L, et al.: Long-term follow-up of type II endoleak embolization reveals the need for close surveillance. J Vasc Surg 2012; 55: 33-40

20. Subramanian K, Woodburn KR, Travis SJ, et al.: Secondary interventions following endovascular repair of abdominal aortic aneurysm. Diagn Interv Radiol 2006; 12: 99-104

21. Buth J, Harris PL, van Marrewijk C, et al.: The significance and management of different types of endoleaks. Semin Vasc Surg 2003; 16: 95-102

22. Zarins CK, Bloch DA, Crabtree T, et al.: Stent graft migration after endovascular aneurysm repair: importance of proximal fixation. J Vasc Surg 2003; 38: 1264-72; discussion 1272

23. Donas KP, Torsello G: Complications and reinterventions after EVAR: are they decreasing in incidence? J Cardiovasc Surg (Torino) 2011; 52: 189-92

24. Ouriel K, Tanquilut E, Greenberg RK, et al.: Aortoiliac morphologic correlations in aneurysms undergoing endovascular repair. J Vasc Surg 2003; 38: 323-8

25. Schanzer A, Greenberg RK, Hevelone N, et al.: Predictors of abdominal aortic aneurysm sac enlargement after endovascular repair. Circulation 2011; 123: 2848-55

26. Stokmans RA, Teijink JA, Forbes TL, et al.: Early results from the ENGAGE registry: real-world performance of the Endurant Stent Graft for endovascular AAA repair in 1262 patients. Eur J Vasc Endovasc Surg 2012; 44: 369-75

27. Katzen BT, MacLean AA: Complications of endovascular repair of abdominal aortic aneurysms: a review. Cardiovasc Intervent Radiol 2006; 29: 935-46

28. Lifeline registry of endovascular aneurysm repair: long-term primary outcome measures. J Vasc Surg 2005; 42: 1-10

29. Prinssen $\mathrm{M}$, Verhoeven EL, Buth J, et al.: A randomized trial comparing conventional and endovascular repair of abdominal aortic aneurysms. N Engl J Med 2004; 351: 1607-18

30. Blankensteijn JD, de Jong SE, Prinssen M, et al.: Two-year outcomes after conventional or endovascular repair of abdominal aortic aneurysms. N Engl J Med 2005; 352: 2398-405

31. Endovascular aneurysm repair versus open repair in patients with abdominal aortic aneurysm (EVAR trial 1): randomised controlled trial. Lancet 2005; 365: 2179-86 
32. Greenhalgh RM, Brown LC, Powell JT, et al.: Endovascular versus open repair of abdominal aortic aneurysm. N Engl J Med 2010; 362: 1863-71

33. Bastos Goncalves F, de Vries JP, van Keulen JW, et al.: Severe proximal aneurysm neck angulation: early results using the Endurant stentgraft system. Eur J Vasc Endovasc Surg 2011; 41: 193-200

34. Hardman DT, Fisher CM, Patel MI, et al.: Ruptured abdominal aortic aneurysms: who should be offered surgery? J Vasc Surg 1996; 23: 123-9

35. Greeven AP, Bouwman LH, Smeets HJ, et al.: Outcome of patients with ruptured abdominal aortic aneurysm after cardiopulmonary resuscitation. Acta Chir Belg 2011; 111: 78-82

36. Urwin SC, Ridley SA: Prognostic indicators following emergency aortic aneurysm repair. Anaesthesia 1999; 54: 739-44

37. Johansen K, Kohler TR, Nicholls SC, et al.: Ruptured abdominal aortic aneurysm: the Harborview experience. J Vasc Surg 1991; 13: 240-5; discussion 245-7

38. Henretta JP, Hodgson KJ, Mattos MA, et al.: Feasibility of endovascular repair of abdominal aortic aneurysms with local anesthesia with intravenous sedation. J Vasc Surg 1999; 29: 793-8

39. Chaikof EL, Brewster DC, Dalman RL, et al.: The care of patients with an abdominal aortic aneurysm: the Society for Vascular Surgery practice guidelines. J Vasc Surg 2009; 50: S2-49

40. Ruppert V, Leurs LJ, Steckmeier B, et al.: Influence of anesthesia type on outcome after endovascular aortic aneurysm repair: an analysis based on EUROSTAR data. J Vasc Surg 2006; 44: 16-21; discussion 21 

Chapter 2

\title{
Ten -year follow-up of talent stent grafts for endovascular abdominal aortic aneurysm repair; a single- centre experience
}

\author{
Y.W. 't Mannetje \\ P.P.H.L. Broos \\ R.F.A. van Poppel \\ M.R.H.M. van Sambeek \\ J.A.W. Teijink \\ Ph.W.M. Cuypers
}




\section{Abstract}

Objective: Yearly lifelong surveillance is advised after endovascular abdominal aortic aneurysm repair (EVAR) for abdominal aortic aneurysms (AAA). However, this follow-up requires a substantial amount of healthcare resources. The aim of this paper was to assess the occurrence of stent graft related complications and secondary interventions during a minimum of ten-year follow-up after elective EVAR.

Methods: Patients treated in a high-volume endovascular centre in the Netherlands with the Talent infrarenal stent graft (Medtronic Vascular, Santa Rosa, CA, USA) between June 1999 and February 2005 were included. Patients with previous aortic surgery, aortic fistula's or ruptured AAAs were excluded for this analysis. Our primary outcome was clinical success up to 10-years. Secondary endpoints were technical success and survival.

Results: A total of 149 patients were included in this study, $91.9 \%$ male with a mean age of $70.2 \pm 7.8$ years. A stent graft was implanted in $98 \%$ of patients; technical success was $89.3 \%$. Clinical success at 30-days, 1, 5 and 10-years was $81.1 \%, 74.3 \%, 70.3 \%$ and $65.5 \%$, respectively. A total of $30(20.7 \%)$ patients required a secondary intervention, $80.0 \%$ of first secondary interventions occurred within the first 5 years. Six late conversions were necessary due to; stent graft infection (2), migration (2), and persisting endoleak (2). The 5 and 10-year overall survival rates were $55.2 \%$ and $38.6 \%$, respectively.

Conclusion: The risk of EVAR related complication is the highest in the first 5-years. The main focus must be on that period, further follow-up must not be neglected as complications occur up to 10 -years after treatment. 


\section{Introduction}

The treatment of aneurysms has changed drastically with the introduction of endovascular abdominal aortic aneurysm repair (EVAR) by Parodi et al. in 1991. EVAR has become the preferred method to treat abdominal aortic aneurysms (AAA), mainly supported by positive short-term results as opposed to open repair.2, ${ }^{3}$ The main downside of EVAR is the risk of late complications and the subsequent need for secondary interventions. Endoleaks, stent graft migration, stent fractures and stent graft occlusions may lead to secondary interventions., ${ }^{4,5}$ The long-term risks require intensive follow-up with yearly visits and imaging of the stent graft.

The evolution of stent graft systems improved applicability and reduced stent graft related complications. ${ }^{6}$ However, current guidelines advise a lifelong surveillance, also in modern stent grafts, to timely detect EVAR related complications. ${ }^{7}$ This implies that a young patient would need up to 20 years of follow-up. To date there is little evidence on long-term stent graft durability to support these intensive and costly follow-up recommendations. We report on a cohort treated ten years ago, with a widely used, commercially available, 3rd generation, stent graft.

The aim of this paper is to assess the occurrence of stent graft related complications and secondary interventions during a minimum of ten-years of follow-up.

\section{Methods}

\section{Study population}

This study included patients primarily treated with a Talent Abdominal Stent Graft (Medtronic Vascular, Santa Rosa, CA, USA) between June 1999 and February 2005, in a tertiary centre for cardiovascular disease in the Netherlands. Only patients scheduled for the implantation of a Talent main body, either bifurcated, tube or Aortic- Uni-Iliac stent graft, were eligible for inclusion. All data were checked against the implantation logbook in order to avoid missing patients. Elective and symptomatic patients were included for analysis. Patients with previous aortic surgery, aortic fistula's or ruptured AAAs were excluded for this analysis. 


\section{Data collection}

Demographics, preoperative characteristics, comorbidities, and procedure details were collected from a prospectively maintained database. The date of death was retrieved from hospital records, if absent, the municipal personal records were consulted. Additional data was retrieved through referring hospitals or the general practitioner was contacted.

\section{Outcomes}

The outcomes are defined based on the reporting standards published by Chaikof et al.. ${ }^{4}$ The primary outcome is clinical success up to 10 -years on an intention-totreat basis. Clinical success is defined as the absence of aneurysm related death, graft stenosis, occlusion or infection, type-I and III endoleak, aneurysm expansion, aneurysm rupture, or conversion to open repair (OR). Graft failure in the form of migration, type IV endoleak or other graft integrity disruptions, is regarded as clinical failure. Stent graft migration defined as movement of $>10 \mathrm{~mm}$. Secondary endpoints were technical success and overall survival. Technical success is defined as a successful introduction and deployment and the absence of type-I or III endoleaks at completion angiography. Aneurysm related mortality included 30day mortality and death, either caused by rupture or as the result of a secondary intervention. Death after 30-days is reported as late aneurysm related mortality. Secondary interventions are defined as all surgical or endovascular interventions performed after the index procedure to resolve stent graft related complications. Secondary intervention data were analysed on a per protocol basis.

\section{Statistical analysis}

Statistical analyses were performed using SPSS version 21 for MAC (IBM Corporation, Armonk, NY, USA). Categorical variables are presented as frequencies with percentages. Continuous variables are presented as mean \pm standard deviation or as median and interquartile range (IQR) in case of skewed data. The X2 or Fisher's exact test were used for categorical variables according to sample size. Incidence rates with $95 \%$ confidence intervals were determined. A p-value $<.05$ was considered statistically significant. Factors influencing 10-year survival were identified using a multivariate regression analysis. 


\section{Results}

A total 318 stent grafts were implanted between June 1999 and February 2005. In 202 cases a Talent stent graf was implanted, because of ruptures, previous aortic surgery, iliac limbs only and aortic fistulas 53 patients were excluded. The baseline characteristics of the 149 included patients are outlined in table 1. Patient demographics were typical for an AAA population. A total of $91.9 \%$ were male with a mean age of $70.2 \pm 7.8$ years. Survival and secondary intervention data on 145 patients were available and comprise the basis for further analysis; there were three intraoperative conversions and one patient was lost to follow-up. This patient was not included in clinical success analysis.

Table 1. Baseline characteristics.

\begin{tabular}{lcccc}
\hline Variable & $\begin{array}{c}\text { Overall } \\
\%(\mathrm{n} / \mathrm{N})^{\mathrm{a}} \\
\mathrm{N}=149\end{array}$ & $\begin{array}{c}\text { Survival } \\
<10 \text { years }^{\mathrm{b}} \\
\mathrm{N}=89\end{array}$ & $\begin{array}{c}\text { Survival } \\
>10 \text { years }^{\mathrm{b}} \\
\mathrm{N}=56\end{array}$ & $\mathrm{p}$-value \\
\hline Age (years) (Mean $\pm \mathrm{SD})$ & $70.2 \pm 7.8$ & $73.8 \pm 7.6$ & $67.5 \pm 6.3$ & $<.001$ \\
Male & $91.9 \%(139 / 149)$ & $93.3 \%(84 / 89)$ & $92.9 \%(52 / 56)$ & $\mathrm{NS}$ \\
Max AAA diameter (mm) & $59[55-68]$ & $60[55-68]$ & $58[54-65]$ & $\mathrm{NS}$ \\
Tobacco use & $33.8 \%(50 / 148)$ & $30.7 \%(27 / 88)$ & $39.3 \%(22 / 56)$ & $\mathrm{NS}$ \\
Hypertension & $58.8 \%(87 / 148)$ & $64.4 \%(56 / 87)$ & $37.5 \%(21 / 56)$ & .002 \\
Renal insufficiency & $16.7 \%(25 / 149)$ & $20.2 \%(18 / 89)$ & $7.1 \%(4 / 56)$ & $\mathrm{NS}$ \\
Cardiac disease & $60.1 \%(89 / 148)$ & $66.3 \%(59 / 89)$ & $50.0 \%(28 / 56)$ & .051 \\
ASA classification & & & & $<.001$ \\
Class I & $18.2 \%(25 / 137)$ & $13.6 \%(11 / 81)$ & $26.4 \%(14 / 53)$ & \\
Class II & $46.7 \%(64 / 137)$ & $33.3 \%(27 / 81)$ & $64.2 \%(33 / 53)$ & \\
Class III & $20.4 \%(28 / 137)$ & $28.4 \%(23 / 81)$ & $9.4 \%(5 / 53)$ & \\
Class IV & $14.6 \%(20 / 137)$ & $24.7 \%(20 / 81)$ & $0 \%(0 / 53)$ & \\
\hline
\end{tabular}

a Values are reported as mean \pm standard deviation, median [IQR], or as frequencies $(\%)(n / N)$. Denominator differs when there are missing values.

${ }^{b}$ Groups corrected for conversions and lost to follow-up

AAA, Abdominal Aortic Aneurysm

ASA, American Society of Anaesthesiologists 


\section{Technical success}

Intraoperative data is depicted in table 2. The stent graft was successfully implanted in $98 \%(146 / 149)$ of the patients. There was an inability to deliver the device due to access difficulties in two female patients, resulting in one direct and one delayed conversion to OR. In the third patient, there was a detachment of the radiopaque ring from the sheath requiring conversion to OR. Primary assisted technical success was achieved in $89.3 \%(133 / 149)$ of the procedures. A total of 13 patients ( $8.7 \%$ ) had a persisting endoleak (12 type-I and one type-III) that was accepted on completion angiography. There were no deaths within 24 hours after implantation.

Table 2. Perioperative outcomes

\begin{tabular}{lc}
\hline Variable & $\%(\mathrm{n} / \mathrm{N})^{\mathrm{a}}$ \\
\hline Primary assisted technical success & $89.3 \%(133 / 149)$ \\
Type I endoleak & $8.0 \%(12 / 149)$ \\
Type III endoleak & $0.7 \%(1 / 149)$ \\
No implant & $2.0 \%(3 / 149)$ \\
Configuration & \\
Bifurcated & $82.2 \%(120 / 146)$ \\
AUI & $15.1 \%(22 / 146)$ \\
Tube & $1.4 \%(2 / 146)$ \\
Bifurcated converted to AUI & $1.4 \%(2 / 146)$ \\
Duration of procedure (mins) & $120[105-150]$ \\
LOS (days) & $4[3-5]$ \\
30-day mortality & $4.7 \%(7 / 1489)$ \\
\hline a Values are reported as median [IQR], or as frequencies $(\%)(\mathrm{n} / \mathrm{N})$. Denominator \\
differs when there are missing values. \\
AUI, Aortic-Uni-Iliac graft
\end{tabular}

\section{Clinical success}

A 30-day clinical success was achieved in $81.1 \%$ (120/148) of patients. The 30-day mortality was $4.7 \%$ (7/148); four cardiac, one renal insufficiency, one sepsis after necrotic cholecystitis and one unknown cause. These patients were significantly older ( $80.3 \pm 4.5$ vs. $71.1 \pm 7.7 p=.001)$, more frequently suffered from cardiac disease (100\% vs. $58 . \% \mathrm{p}=.042$ ) and renal insufficiency (57.1\% vs. $14.2 \% \mathrm{p}=.014)$. 
The operative endoleaks resolved spontaneously on the first follow-up imaging in $76.9 \%(10 / 13)$ of patients. One endoleak required a secondary intervention and two patients with an operative endoleak died of cardiac complications within 30 -days. The 1, 5 and 10-year clinical success rates were $74.3 \%, 70.3 \%$ and $65.5 \%$, respectively.

\section{Secondary interventions}

The freedom from secondary interventions is presented in a Kaplan-Meier curve (Figure 1). Freedom from secondary intervention at 1, 5 and 10-year was $90.5 \%, 83.3 \%$ and $80.6 \%$ respectively. During the complete follow-up, a total of 38 secondary interventions were required in 30 patients. In $73.7 \%$ of the cases, patients were asymptomatic, which means regular follow-up detected the majority of complications. Secondary interventions were mainly required for endoleaks, and occlusion/stenosis, $57.9 \%, 15.8 \%$ respectively. The need for the initial secondary intervention within 1, 5 and 10-years was $60.0 \%, 80.0 \%$ and $100 \%$ respectively. Three patients required a secondary intervention within 30-days, one for an iliac stenosis; one patient had an iliac limb occlusion and one for a type-III endoleak. All specific interventions and indications are depicted in table 3. A total of six patients were converted to OR during follow-up. The reason for conversion was; two stent graft infections, two migrations and two persisting endoleaks (a type-I and a type-III). A single patient required two revisions of a fem-fem crossover due to a graft infection. 
Figure 1. Kaplan-Meier curve representing the ten-year freedom from secondary procedures.

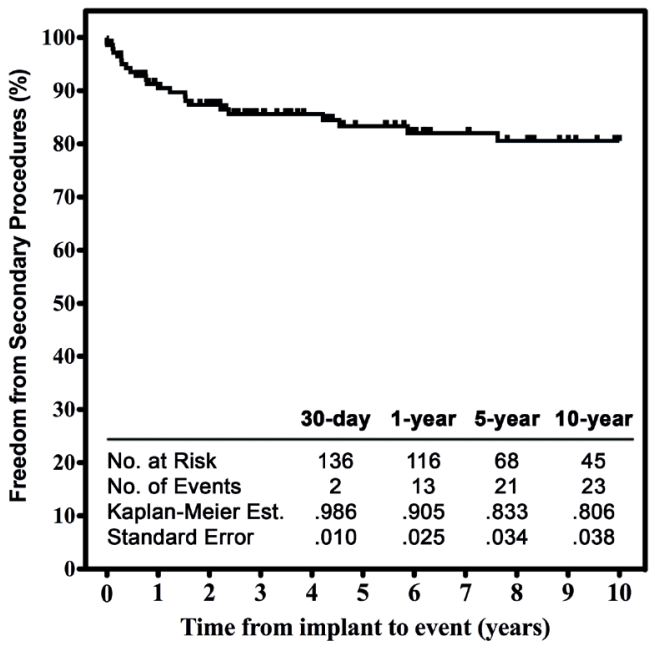

Table 3. Secondary interventions.

\begin{tabular}{lc}
\hline Variable & Cases $(\mathrm{N})$ \\
\hline Indication for intervention & 22 \\
Endoleak & 10 \\
Type IA & 3 \\
Type IB & 4 \\
Type II & 4 \\
Type III & 1 \\
Type V & 6 \\
Iliac occlusion/stenosis & 1 \\
Short distal sealing & 3 \\
Migration, no endoleak & 4 \\
Infection & 2 \\
Rupture & \\
Secondary interventions & 3 \\
Proximal cuff & 1 \\
Ballooning & 3 \\
Proximal BMS & 7 \\
Endolining & 6 \\
Iliac extension & 4 \\
Coiling/Ligation & 6 \\
Fem-fem crossover & 2 \\
Thrombectomy/PTA & 6 \\
Explantation & \\
\hline
\end{tabular}

AUI, Aortic-Uni-Iliac graft

PTA, Percutaneous Transluminal Angioplasty

BMS, Bare Metal Stent 


\section{Survival}

The overall survival is presented is presented in figure 2. There was a median overall survival of 74.2 months. A total of 89 patients (61.4\%) died within 10-years. The 1, 5 and 10-year survival rates were $88.3 \%, 55.2 \%$ and $38.6 \%$, respectively. During follow-up three (2.9\%) late aneurysm-related deaths occurred in the 140 patients with a stent graft after 30-days. Two deaths were the result of a rupture and one patient died after excessive perioperative blood loss during a secondary intervention.

Figure 2. Kaplan-Meier curves representing the ten-year freedom from all-cause mortality.

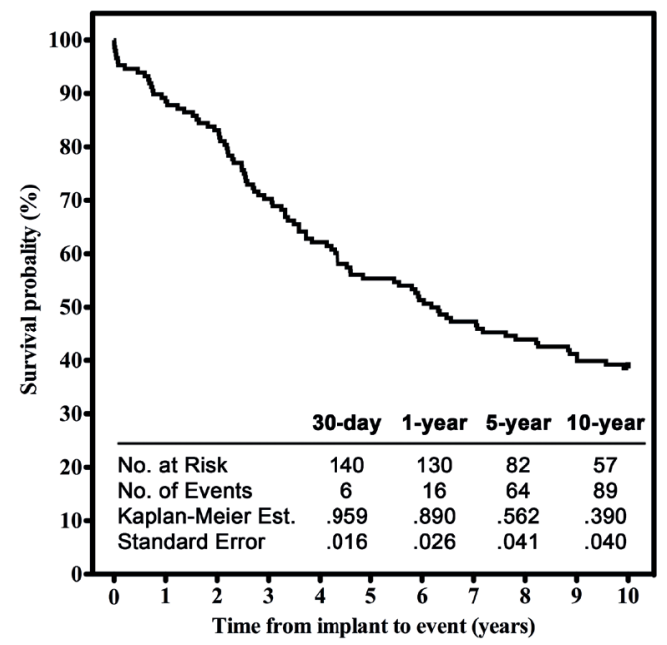

\section{Survivors vs. non-survivors}

A total of 56 patients (38.6\%) were alive after 10-years ("Survivors"). Age, hypertension, cardiac risk and an American Society of Anaesthesiologists (ASA) classification were significantly different between survivors and non-survivors. In a multivariate regression analysis an ASA classification of three or higher (hazard ratio (HR) 9.9; 95\% confidence interval (Cl) 3.2-30.7), age (HR 1.1; 95\% Cl 1.0-1.2) and hypertension (HR 2.7; 95\% Cl 1.1-6.5) showed to have a significant influence on 10year mortality. No difference in the number of secondary interventions between survivors and non-survivors were recorded (19.6\% vs. $21.3 \%, p=.080$ ). 


\section{Discussion}

Current guidelines advise lifelong surveillance after EVAR due to the high rate of late complications. ${ }^{7}$ Previously published reports often describe the 10-year experience and estimated outcomes. Our paper describes the long-term outcome of a widely applied stent graft more accurately, and gives insight in the distribution of complications.

The occurrence of graft and aneurysm related complications are the main downside of EVAR. In our population, the 30-day, 1, 5 and 10-year clinical success rates were $81.1 \%, 75.0 \%, 70.2 \%$ and $65.5 \%$ respectively. This result is difficult to compare because many publications use a variety of definitions for clinical success opposed to reporting standards of Chaikof et al.. ${ }^{4}$ Although a clinical success rate clearly describes deviations from ideal treatment, it does not reflect the impact of these deviations. In this study, the initial clinical success is largely influenced by the existence of type-I or III endoleaks at completion angiography. The relevance of in particular small type-I endoleaks is widely debated. It has been shown that these endoleaks may seal spontaneously, similar to our results.", ${ }^{9}$ Although, the initial clinical success is highly influenced by endoleaks of limited clinical relevance, the success rate does decline steadily during 10-years of followup. This decline indicates that new complications occur throughout the complete follow-up period, however the rate is rapidly reduced after one year.

In total, $20.0 \%(30 / 145)$ of patients required at least one secondary intervention during a minimum of 10-year follow-up. The secondary intervention rates and indications reported in this study are comparable with previous reports., 10 The physiological impact of the interventions is limited, $64.9 \%$ could be resolved endovascularly and in $16.2 \%$ of cases a laparotomy was required. The secondary interventions were performed during the complete 10-year period. Although the rate of secondary interventions seems to stabilize after 1-year of follow-up, $20.7 \%$ of the initial secondary interventions were performed after five years (Figure 2). In $70 \%$ of secondary interventions, patients did not experience any complaints, which is an important factor. Our data consequently show EVAR-related complications occur during the entire follow-up period. Regular follow-up imaging is required, 
as the majority of complications do not cause symptoms. However, the follow-up schedule must be organized efficiently.

Lifelong follow-up requires a great investment of time and resources, especially considering that $80 \%$ of patients require no secondary intervention. Guidelines propose a CTA at 30-days, 6-months and 1-year. The CTA at 6-months could be omitted if 30-day results are satisfying. It also states that a duplex ultrasound in combination with plain radiographs should be performed yearly after 1-year. ${ }^{7}$ The development of EVAR results in a better treatment outcome, and a decline in the need for secondary interventions. ${ }^{6}$ The follow-up strategy might be adjusted to better comply with current needs. In this study, no device integrity failures were recorded and four cases of graft migration without an endoleak. The value of plain radiographs in migration is questionable, aortic changes can mimic migration and not all changes are clinically relevant.11 Therefore, it is justifiable to only perform a duplex ultrasound in modern stent grafts.

Secondly, the timing of follow-up visits is important. As our results show the majority of complications arise in the first 5-years after implantation. The intensity of follow-up after five years could be reduced if patients experienced no adverse events. One possibility to design an efficient protocol is to allocate patients in risk groups based on baseline, perioperative and early follow-up data. Developments like the the "St George's Vascular Institute (SGVI) risk score", are essential to rationalize follow-up.12 The increasing quality of stent grafts, but also new approaches to EVAR like endovascular aneurysm sealing (EVAS) or polymer filled sealing rings, require reconsideration of follow-up strategies. ${ }^{13,14}$ In addition, aneurysm shrinkage is also associated with a reduced likelihood for secondary interventions. ${ }^{15}$ Therefore, a combination of data acquired pre-, periand postoperatively, is needed to compose a follow-up strategy that is safe, economical and acceptable for patients.

The main benefit of EVAR is the low perioperative mortality. The DREAM and EVAR1 trials reported perioperative mortality for EVAR of $1.2 \%$ and $1.6 \%$, respectively. ${ }^{2}$, ${ }^{3}$ This paper reports a perioperative mortality of $4.7 \%$ in patients treated in the same period as these landmark trials. Other series reporting on the Talent stent 
graft reported a 30-day mortality of $1.1-3.9 \% .^{9,10,16,17}$ The variability of mortality rates might be explained by the EVAR-2 trial, which included patients not eligible for open repair based on comorbidities, and reported a perioperative mortality of $9 \% .^{18} \mathrm{~A}$ closer analysis of our results showed that patients who died within 30-days were older and had more cardiac and renal disease than those who survived. As this study included all patients, fit or unfit for OR, the results resemble the current day-to-day practice.

The short-term survival benefits of EVAR are not sustained in the long-term outcome. The overall long-term survival was $55.9 \%$ and $38.6 \%$ for 5 and 10 -years, respectively. Other studies show an overall 5-year survival of $61 \%-78 \%$ for endovascular treated AAAs. ${ }^{9}, 10,17,19-21$ Wibmer et al. reported a similar 10-year survival rate of $37.7 \% .{ }^{19}$ A comparison of overall survival would be best performed in a RCT with patients that are suitable for both OR and EVAR. The best available evidence from DREAM and EVAR-1 suggests that the type of surgery does not influence overall long-term survival. ${ }^{22,}{ }^{23}$ Similar secondary intervention rate for OR and EVAR in young patiënts have been reported. However, there is a significant difference in the indication where OR shows more wound related problems as opposed to graft related problems in EVAR. ${ }^{24}$ Factors that do predict long-term survival are age and comorbidities. ${ }^{10,25}$ Therefore, OR should always be considered in young and healthy patients.

The indication for secondary interventions after EVAR suggests an increased risk of aneurysm rupture, and subsequently aneurysm related mortality. In this cohort the total aneurysm related mortality was $7.3 \%$, the late aneurysm-related mortality was $2.9 \%(3 / 140)$. These rates are not significantly different from other studies with a follow-up of at least 5-years. ${ }^{9,26,27}$ Caution is advised when interpreting these results, as post-mortem examination is not common practice in the Netherlands and aneurysm related death could be underestimated.

The retrospective nature of this paper brings forth several limitations. The database was not designed to identify factors influencing clinical success and survival. The reported population cannot be compared to an open repair population, a number of patients were not eligible for OR. The cohort therefore, does provide a 
real-world population that resembles current EVAR oriented era population. This study reports on a single type of stent graft making the data, regarding technical outcome, not transferable to other stent grafts.

\section{Conclusion}

The risk of EVAR related complication is the highest in the first 5-years. The main focus must be on that period, further follow-up must not be neglected as complications occur up to 10 -years after treatment. 


\section{References}

1. Parodi JC, Palmaz JC, Barone HD. Transfemoral intraluminal graft implantation for abdominal aortic aneurysms. Ann Vasc Surg. 1991;5(6):491-9.

2. Greenhalgh RM, Brown LC, Kwong GP, Powell JT, Thompson SG. Comparison of endovascular aneurysm repair with open repair in patients with abdominal aortic aneurysm (EVAR trial 1), 30day operative mortality results: randomised controlled trial. Lancet. 2004;364(9437):843-8.

3. Prinssen M, Verhoeven EL, Buth J, Cuypers PW, van Sambeek MR, Balm R, et al. A randomized trial comparing conventional and endovascular repair of abdominal aortic aneurysms. N Engl J Med. 2004;351(16):1607-18.

4. Chaikof EL, Blankensteijn JD, Harris PL, White GH, Zarins CK, Bernhard VM, et al. Reporting standards for endovascular aortic aneurysm repair. J Vasc Surg. 2002;35(5):1048-60.

5. Torsello GB, Klenk E, Kasprzak B, Umscheid T. Rupture of abdominal aortic aneurysm previously treated by endovascular stentgraft. J Vasc Surg. 1998;28(1):184-7.

6. Tadros RO, Faries PL, Ellozy SH, Lookstein RA, Vouyouka AG, Schrier R, et al. The impact of stent graft evolution on the results of endovascular abdominal aortic aneurysm repair. J Vasc Surg. 2014;59(6):1518-27.

7. Moll FL, Powell JT, Fraedrich G, Verzini F, Haulon S, Waltham M, et al. Management of abdominal aortic aneurysms clinical practice guidelines of the European society for vascular surgery. Eur J Vasc Endovasc Surg. 2011;41 Suppl 1:S1-S58.

8. Bastos Goncalves F, Verhagen HJ, Vasanthananthan K, Zandvoort HJ, Moll FL, van Herwaarden JA. Spontaneous delayed sealing in selected patients with a primary type-la endoleak after endovascular aneurysm repair. Eur J Vasc Endovasc Surg. 2014;48(1):53-9.

9. Verhoeven BA, Waasdorp EJ, Gorrepati ML, van Herwaarden JA, Vos JA, Wille J, et al. Long-term results of Talent endografts for endovascular abdominal aortic aneurysm repair. J Vasc Surg. 2011;53(2):293-8.

10. Torsello G, Osada N, Florek HJ, Horsch S, Kortmann H, Luska G, et al. Long-term outcome after Talent endograft implantation for aneurysms of the abdominal aorta: a multicenter retrospective study. J Vasc Surg. 2006;43(2):277-84; discussion 84.

11. Litwinski RA, Donayre CE, Chow SL, Song TK, Kopchok G, Walot I, et al. The role of aortic neck dilation and elongation in the etiology of stent graft migration after endovascular abdominal aortic aneurysm repair with a passive fixation device. J Vasc Surg. 2006;44(6):1176-81.

12. Karthikesalingam A, Holt PJ, Vidal-Diez A, Choke EC, Patterson BO, Thompson LJ, et al. Predicting aortic complications after endovascular aneurysm repair. Br J Surg. 2013;100(10):1302-11.

13. Bockler D, Holden A, Thompson M, Hayes P, Krievins D, de Vries JP, et al. Multicenter Nellix EndoVascular Aneurysm Sealing system experience in aneurysm sac sealing. J Vasc Surg. 2015;10.1016/j.jvs.2015.03.031. 
14. Mehta M, Valdes FE, Nolte T, Mishkel GJ, Jordan WD, Gray B, et al. One-year outcomes from an international study of the Ovation Abdominal Stent Graft System for endovascular aneurysm repair. J Vasc Surg. 2014;59(1):65-73 e1-3.

15. Soler RJ, Bartoli MA, Mancini J, Lerussi G, Thevenin B, Sarlon-Bartoli G, et al. Aneurysm sac shrinkage after endovascular repair: predictive factors and long-term follow-up. Ann Vasc Surg. 2015;29(4):770-9.

16. Espinosa G, Ribeiro Alves M, Ferreira Caramalho M, Dzieciuchowicz L, Santos SR. A 10-year singlecenter prospective study of endovascular abdominal aortic aneurysm repair with the talent stentgraft. J Endovasc Ther. 2009;16(2):125-35.

17. Turnbull IC, Criado FJ, Sanchez L, Sadek M, Malik R, Ellozy SH, et al. Five-year results for the Talent enhanced Low Profile System abdominal stent graft pivotal trial including early and long-term safety and efficacy. J Vasc Surg. 2010;51(3):537-44, 44 e1-2.

18. participants Et. Endovascular aneurysm repair and outcome in patients unfit for open repair of abdominal aortic aneurysm (EVAR trial 2): randomised controlled trial. Lancet. 2005;365(9478):218792.

19. Wibmer A, Nolz R, Teufelsbauer H, Kretschmer G, Prusa AM, Funovics M, et al. Complete ten-year follow-up after endovascular abdominal aortic aneurysm repair: survival and causes of death. Eur J Radiol. 2012;81(6):1203-6.

20. Mertens J, Houthoofd S, Daenens K, Fourneau I, Maleux G, Lerut P, et al. Long-term results after endovascular abdominal aortic aneurysm repair using the Cook Zenith endograft. J Vasc Surg. 2011;54(1):48-57 e2.

21. Mani K, Bjorck M, Lundkvist J, Wanhainen A. Improved long-term survival after abdominal aortic aneurysm repair. Circulation. 2009;120(3):201-11.

22. De Bruin JL, Baas AF, Buth J, Prinssen M, Verhoeven EL, Cuypers PW, et al. Long-term outcome of open or endovascular repair of abdominal aortic aneurysm. N Engl J Med. 2010;362(20):1881-9.

23. United Kingdom ETI, Greenhalgh RM, Brown LC, Powell JT, Thompson SG, Epstein D, et al. Endovascular versus open repair of abdominal aortic aneurysm. N Engl J Med. 2010;362(20):186371.

24. Lee K, Tang E, Dubois L, Power AH, DeRose G, Forbes TL. Durability and survival are similar after elective endovascular and open repair of abdominal aortic aneurysms in younger patients. J Vasc Surg. 2015;61(3):636-41.

25. Wisniowski B, Barnes M, Jenkins J, Boyne N, Kruger A, Walker PJ. Predictors of outcome after elective endovascular abdominal aortic aneurysm repair and external validation of a risk prediction model. J Vasc Surg. 2011;54(3):644-53.

26. Piffaretti G, Mariscalco G, Riva F, Fontana F, Carrafiello G, Castelli P. Abdominal aortic aneurysm repair: long-term follow-up of endovascular versus open repair. Arch Med Sci. 2014;10(2):273-82.

27. Pitton MB, Scheschkowski T, Ring M, Herber S, Oberholzer K, Leicher-Duber A, et al. Ten-year follow-up of endovascular aneurysm treatment with Talent stent-grafts. Cardiovasc Intervent Radiol. 2009;32(5):906-17 

Chapter 3

\title{
Long-term outcome of endovascular repair for elective and ruptured abdominal aortic aneurysms; 15 year single-centre experience
}

\author{
P.P.H.L. Broos \\ R.A. Stokmans \\ S. Houterman \\ G. Corte \\ J.A.W. Teijink \\ Ph.W.M. Cuypers \\ M.R.H.M. van Sambeek
}

Submitted; July 2015 Journal of Endovascular Therapy 


\section{Abstract}

Purpose: This study evaluates the differences in technical outcomes and secondary interventions between elective-EVAR (E-EVAR) and ruptured-EVAR (R-EVAR) procedures.

Methods: All primary EVAR cases for infrarenal aortic and aorto-iliac aneurysms conducted in our hospital from January 1998 until July 2012 were included. The E-EVAR group consisted of patients with asymptomatic and symptomatic AAA. The primary study endpoint was technical success. Secondary endpoints included freedom from secondary interventions and late survival.

Results: Among the 863 patients admitted in the current study, the E-EVAR group included $773(89,6 \%)$ patients and the R-EVAR group included 90 (10.4\%) patients. At baseline, R-EVAR patients had larger aneurysms on average $(p<.001)$ compared to E-EVAR patients. Operation technical success was comparable $(p=.052)$, but there were more type IA endoleaks at completion angiography in R-EVAR ( $p=$ .038). As anticipated more patients died in the first month in the R-EVAR group compared to the E-EVAR group ( $18.9 \%$ vs. $2.2 \%, p<.001$ ). At five-year, there was an overall survival of $65.1 \%$ for E-EVAR and $48.1 \%$ for R-EVAR $(p<.001)$. Five-year freedom form type I/III endoleaks was significantly lower for R-EVAR compared to E-EVAR (78.7\% vs. 90.0\%, $p=.003)$. Five-year secondary intervention free survival was not significantly different (E-EVAR $84.2 \%$ vs. R-EVAR 78.2\%, $p=.064$ ).

Conclusion: Within our cohort of primary EVAR patients, R-EVAR cases showed comparable stent-graft related technical outcome in both short and long-term. There is a higher incidence of Type IA endoleaks in the R-EVAR group, but not all Type IA endoleaks required a secondary intervention 


\section{Introduction}

Endovascular aneurysm repair (EVAR) has become the preferred treatment of elective and ruptured abdominal aortic aneurysms (AAAs). The endovascular approach of AAAs is less invasive compared to open surgical repair (OR) and demonstrates decreased early mortality and morbidity. ${ }^{1,2}$ EVAR is however associated with increased rates of endograft-related complications, requiring more extensive follow-up and secondary interventions. ${ }^{3}$

The technical success of EVAR is dependent on accurate preoperative planning including aneurysm measurements and adequate endograft selection. In patients presenting with a ruptured AAA (RAAA), planning has to be done under pressure and in a limited time frame. Usually, there is no time for extensive image reconstructions with a dedicated measuring programme. In addition, the endograft will be selected from the limited available stock. Due to the nature of RAAAs it is reasonable to assume that the interventionist will speed up the procedure to reach adequate haemostasis. All these factors can influence the procedure and this can hypothetically have an effect on the safety, durability and effectiveness of the endograft in both short and long-term outcome.

This study was performed to describe the short and long-term outcome of EVAR in a consecutive cohort of patients treated in a high-volume centre, and to evaluate the differences between elective EVAR (E-EVAR) and ruptured EVAR (R-EVAR).

\section{Methods}

\section{Patient population}

In this study we used our hospital database for a retrospective analysis. The Catharina Hospital is a high-volume and tertiary centre for vascular surgery. Being one of the first centres in the Netherlands performing EVAR, our vascular unit gained a long experience and is considered a referral hospital for complex AAA cases. Since the first EVAR procedure was performed in our clinic in 1995, patients were prospectively enrolled in a database and follow-up was conducted. For this 
study we selected only primary EVAR procedures conducted in our hospital from September 1998 until July 2012, in patients with aneurysms of the infrarenal aorta and iliac arteries. Patients primarily treated in other hospitals or treated with OR were left out of this analysis. Patients who were treated with the first generation of endovascular stent grafts, which were held off-market quickly, were excluded for this analysis (mainly before 1998).

Follow-up for all patients was completed as up to February 2013, by intensive patient file reviewing and by consulting the national mortality registry. Whenever follow-up data was missing, we contacted general practitioners and local hospitals, and requested for insight in patient records.

\section{Definitions and outcomes}

For this study we divided our cohort of patients in two groups: E-EVAR and R-EVAR. Patients were assigned into the R-EVAR group if blood outside the aortic wall was present on computed tomography angiography (CTA). The E-EVAR group included patients with asymptomatic and symptomatic AAAs. In our experience, the management of symptomatic AAAs is comparable with asymptomatic AAAs; specifically there was reasonable time to perform adequate procedure planning. $A$ variety of endografts were used, including AneuRx, Talent and Endurant (Medtronic, Santa Rosa, California, USA), Excluder (W.L. Gore and Assoc, Flagstaff, Arizona, USA), Zenith (Cook, Bloomington, USA), Endologix (Endologix PowerLink System, Irvine, USA), LifePath (Edwards Lifesciences LLC, Irvine, USA) and Fortron (Cordis Corp./ Johnson \& Johnson Inc, Miami Lakes, USA). The selection for a particular type of stent graft was at the surgeon's discretion and based on device's availability. Postoperative follow-up included clinical examination at discharge and imaging at 1, 6 and 12 months, and yearly thereafter.

The primary endpoint is the initial technical success. Technical success was defined as successful delivery and deployment of the endograft, without unintentional coverage of renal arteries, internal iliac arteries or visceral branches, with absence of either a type I or type III endoleak, followed by successful removal of the delivery system. ${ }^{4}$ The secondary endpoints are represented by the evaluation of early and late outcomes through analysis of perioperative mortality, overall 
survival, incidence of late complications, need for secondary procedures and the freedom from these. We analysed the perioperative mortality defined as mortality from any cause occurring within 30 days of surgery. Aneurysm-related mortality included all deaths due to aneurysm rupture, a primary or secondary procedure, or surgical conversion. A secondary procedure was defined as an endovascular or open surgical intervention performed after the initial EVAR in order to maintain the function or patency of the endograft and to treat the most common complications of EVAR procedures: endoleaks, endograft migration and graft limb stenosis/ occlusion. Endograft obstruction included endograft related occlusion, stenosis, kinking and migration. Device migration after EVAR is endograft movement of $>10$ $\mathrm{mm}$ relative to anatomic landmarks on CTA or any migration causing symptoms or requiring intervention. ${ }^{5}$

\section{Statistical analysis}

Categorical variables are presented as frequencies with percentages. The $X^{2}$ test or Fisher's exact test was used to test significance for categorical variables according to sample size. Continuous variables are presented as mean \pm standard deviation (SD) or as median and interquartile range (IQR) in case of skewed data. The independent group t-test was used to test significance in mean differences and the Mann-Whitney $U$ test for median differences. Kaplan-Meier curves and log-rank tests were used to evaluate survival. Patients eventually not treated with EVAR were excluded for follow-up analysis. A p-value $<.05$ was considered statistically significant. All statistical analyses were performed using SPSS version 21 for MAC (IBM Corporation, Armonk, NY, USA).

\section{Results}

From September 1995 until July 2012, 907 patients were treated with primary EVAR in our clinic. The first R-EVAR patient was treated in March 1999. A total of 43 cases were excluded because a first generation device was implanted: 14 with Stentor (MinTec La Ciotat, France) and 29 with Vanguard (Boston Scientific Corporation, Natick, MA). Among the remaining 863 patients, the E-EVAR group included 773 (89.6\%) patients and the R-EVAR group included 90 (10.4\%) patients. 


\section{Baseline characteristics}

Patients' demographics and risk factors (Table 1) were typical for an AAA population, with a high prevalence of cardiovascular risk factors and co-morbidities. Patients were predominantly male. The mean age was $72.2 \pm 7.7$ years for E-EVAR and 73.4 \pm 8.5 years for R-EVAR $(p=.189)$. Mean maximum AAA diameter was significantly smaller for E-EVAR compared to R-EVAR (E-EVAR $59 \pm 12 \mathrm{~mm}$ vs. R-EVAR $70 \pm 18 \mathrm{~mm}$, $\mathrm{p}<.001)$.

Table 1. Patient demographics and risk factors stratified by operative indication.

\begin{tabular}{|c|c|c|c|}
\hline Variable & $\begin{array}{l}\text { E-EVAR } \\
\mathrm{N}=773^{\mathrm{a}}\end{array}$ & $\begin{array}{l}\text { R-EVAR } \\
N=90^{a}\end{array}$ & $p$-value \\
\hline Age (years) & $72.2 \pm 7.7$ & $73.4 \pm 8.5$ & .189 \\
\hline Gender & & & .009 \\
\hline Male & $90.2 \%(697)$ & $81.1 \%(73)$ & \\
\hline Female & $9.8 \%(76)$ & $18.9 \%(17)$ & \\
\hline $\mathrm{AAA}^{\mathrm{b}}$ diameter $(\mathrm{mm})$ & $59 \pm 12$ & $70 \pm 18$ & $<.001$ \\
\hline Smoker & $23.4 \%(181)$ & $14.4 \%(13)$ & .054 \\
\hline Hypertension & $65.7 \%(508)$ & $64.4 \%(58)$ & .810 \\
\hline Hyperlipidaemia & $40.1 \%(310)$ & $48.9 \%(44)$ & .109 \\
\hline Diabetes mellitus & $10.7 \%(83)$ & $7.8 \%(7)$ & .385 \\
\hline Cardiac disease & $38.3 \%(296)$ & $43.3 \%(39)$ & .353 \\
\hline Pulmonary disease & $14.9 \%(115)$ & $12.2 \%(11)$ & .500 \\
\hline Renal disease & $4.8 \%(37)$ & $7.8 \%(7)$ & .222 \\
\hline Carotid artery disease & $7.8 \%(60)$ & $7.8 \%(7)$ & .996 \\
\hline
\end{tabular}

a Values are reported as mean \pm standard deviation or as frequencies (\%) (n).

${ }^{\mathrm{b}}$ Abdominal aortic aneurysm

\section{Intra-operative results}

Table 2 describes the variety of endografts used. The most commonly used endograft was the Talent (E-EVAR:30.8\%; R-EVAR: 63.3\%) in both groups. A bifurcated endograft configuration was more frequently used in E-EVAR than R-EVAR $(90.9 \%$ vs. $45.6 \%, p<.001)$. Initial procedural data and evaluation are detailed in Table 3. 
Table 2. Endograft used for EVAR stratified by operative indication.

\begin{tabular}{lccc}
\hline Variable & E-EVAR & R-EVAR & \multirow{2}{*}{$\mathrm{N}$-value } \\
\hline Graft name $=773^{\mathrm{a}}$ & $\mathrm{N}=90^{\mathrm{a}}$ & \\
Aneurx & & & \\
Endologix & $8.0 \%(62)$ & $2.2 \%(2)$ & \\
Endurant & $1.4 \%(11)$ & $1.1 \%(1)$ & \\
Excluder & $30.7 \%(237)$ & $31.1 \%(28)$ & \\
Fortron & $7.2 \%(56)$ & $1.1 \%(1)$ & \\
Lifepath & $1.2 \%(9)$ & $0 \%(0)$ & \\
Talent & $0.9 \%(7)$ & $0 \%(0)$ & \\
Zenith & $30.8 \%(238)$ & $63.3 \%(57)$ & \\
Type of main device & $19.8 \%(153)$ & $1.1 \%(1)$ & $<.001$ \\
Bifurcated & & & \\
AUI ${ }^{\mathrm{b}}$ & $90.9 \%(703)$ & $45.6 \%(41)$ & \\
Tube & $8.3 \%(64)$ & $53.3 \%(48)$ & \\
\hline
\end{tabular}

a Values are reported as frequencies (\%) (n).

${ }^{\mathrm{b}}$ Aorto-uni-iliac

Table 3. Initial procedural data and evaluation stratified by operative indication.

\begin{tabular}{lccc}
\hline Variable & $\begin{array}{c}\text { E-EVAR } \\
\mathrm{N}=773^{\mathrm{a}}\end{array}$ & $\begin{array}{c}\mathrm{R} \text {-EVAR } \\
\mathrm{N}=90^{\mathrm{a}}\end{array}$ & $p$-value \\
\hline Procedural duration (mins) & $120(90-150)$ & $135(101-180)$ & .002 \\
Type anaesthesia used & & & $<.001$ \\
General & $34.8 \%(269 / 773)$ & $61.1 \%(55 / 90)$ & \\
Regional & $63.6 \%(492 / 773)$ & $18.9 \%(17 / 90)$ & \\
Local & $1.6 \%(12 / 773)$ & $20.0 \%(18 / 90)$ & \\
Completion angiography & & & \\
Type IA & $2.8 \%(20 / 757)$ & $6.9 \%(6 / 87)$ & .038 \\
Type IB & $0.1 \%(1 / 757)$ & $0 \%(0 / 87)$ & 1.000 \\
Type III & $0.3 \%(2 / 757)$ & $0 \%(0 / 87)$ & .631 \\
Basic outcome & & & \\
Success & $95.0 \%(734 / 773)$ & $90.0 \%(81 / 90)$ & .052 \\
Conversion & $1.6 \%(12 / 773)$ & $2.2 \%(2 / 90)$ & .650 \\
NO implant & $0.5 \%(4 / 773)$ & $1.1 \%(1 / 90)$ & .424 \\
Death & $0 \%(0)$ & $0 \%(0)$ & - \\
\hline
\end{tabular}

${ }^{a}$ Values are reported as median with interquartile range or as frequencies (\%) (n). Denominator differs when there are missing values.

${ }^{\mathrm{b}}$ Completion angiography was available in 757 E-EVAR patients and 87 R-EVAR patients. 
The median procedural duration was 120 (IQR: 90 - 150) min in E-EVAR and 135 (IQR: $101-180)$ min in R-EVAR ( $p=.002)$. Technical success was obtained in $95.0 \%$ of elective and $90.0 \%$ of ruptured cases $(p=.052)$. There was no significant difference in conversion to open surgery (E-EVAR $1.6 \%$ vs. R-EVAR $2.2 \%, p=.650$ ). There were no intra-operative deaths recorded.

\section{Intra-operative endoleaks}

The presence of a type IA endoleak at final angiogram was significantly higher for R-EVAR (6.9\% vs. 2.8\%, $p=.038$ ). Within 30 days, 16 type IA endoleaks resolved without any secondary intervention and one type IA endoleak resolved with placement of proximal extension. Three type IA endoleaks were persistent. All (6/6) type IA endoleaks at completion angiography in the R-EVAR group resolved without intervention. One type IB in the E-EVAR group endoleak was excluded with a distal extension. The two type III endoleaks in the E-EVAR group both resolved without intervention.

\section{Thirty-day outcomes and complications}

A total of 757 E-EVAR and 83 R-EVAR eventually underwent EVAR and were evaluated for 30-day outcome (Table 4). Median hospital stay was 3 days (IQR: 2-5) for E-EVAR and 9 days (IQR: 5-14) for R-EVAR ( $<$.001). From operation to hospital discharge, systemic complications (cardiac, pulmonary, cerebral, renal, bowel, and sepsis) were observed in 5.3\% E-EVAR versus $25.6 \%$ R-EVAR patients $(p<.001)$. Significantly more patients died in the first month in the R-EVAR group (18.9\% vs. $2.2 \%, p<.001)$. 
Table 4. Hospitalisation and complications within 30 days stratified by operative indication

\begin{tabular}{lccc}
\hline Variable & $\begin{array}{c}\text { E-EVAR } \\
\mathrm{N}=757^{\mathrm{a}}\end{array}$ & $\begin{array}{c}\mathrm{R} \text {-EVAR } \\
\mathrm{N}=87^{\mathrm{a}}\end{array}$ & -value \\
\hline $\begin{array}{l}\text { Postoperative stay (days) } \\
\text { Major systemic complications }\end{array}$ & $3(2-5)$ & $9(5-14)$ & $<.001$ \\
from operation to discharge & $5.3 \%(40 / 757)$ & $26.4 \%(23 / 87)$ & $<.001$ \\
Endoleak & $1.0 \%(7 / 711)^{\mathrm{b}}$ & $4.5 \%(3 / 66)$ & .014 \\
$\quad$ Type I & $1.0 \%(7 / 711)$ & $1.5 \%(1 / 66)$ & .683 \\
$\quad$ Type III & $1.2 \%(9 / 757)$ & $3.4 \%(3 / 87)$ & .092 \\
Secondary interventions & $0.4 \%(3 / 757)$ & $0 \%(0 / 87)$ & .556 \\
$\quad$ Endovascular procedure & $0 \%(0 / 757)$ & $3.4 \%(3 / 87)$ & $<.001$ \\
Extra-anatomical bypass & $2.0 \%(15 / 757)$ & $17.2 \%(15 / 87)$ & $<.001$ \\
$\quad$ Conversion & &
\end{tabular}

${ }^{a}$ Only implanted patients were analysed. Values are reported as median with interquartile range or as frequencies $(\%)(n / N)$. Denominator differs when there are missing values.

${ }^{\mathrm{b}}$ Including three type I endoleaks seen at completion angiography during index procedure.

There were significantly more type I endoleaks reported in the R-EVAR group (E-EVAR $1.0 \%$ vs. R-EVAR $4.5 \%, p=.014$ ) within the first 30 days. Among these endoleaks, three type I endoleaks in the E-EVAR group were also present at completion angiography. There was no difference in the incidence of type III endoleaks. Nine (1.2\%) E-EVAR patients versus three (3.4\%) R-EVAR patients underwent a secondary endovascular procedure in the first month, mainly to resolve endoleaks and occlusions of the endograft. Three patients underwent extra-anatomic bypass surgery to resolve progressive limb occlusion, all in the E-EVAR group. Within the first 30 days, three cases were converted to open surgery, all in the R-EVAR group. One patient had removal of an infected endograft. Another conversion was necessary because the endograft was blocking both renal arteries. The third patient was converted to open surgery because of a persistent type IA endoleak.

\section{Late outcomes and complications}

Median follow-up was 37.8 (IQR: 16.6-77.7) months for E-EVAR and 21.0 (IQR: 2.865.2) months for R-EVAR. Freedom from secondary procedures after 5 years was 84.2\% for E-EVAR and $78.2 \%$ for R-EVAR ( $p=.064$, Figure 1$)$. 
Figure 1. Kaplan-Meier curves representing the five-year freedom from secondary procedures in 773 E-EVAR and 90 R-EVAR patients. Log rank, $p=.064$.

\begin{tabular}{|c|c|c|c|c|c|c|c|c|}
\hline & \multicolumn{4}{|c|}{ E-EVAR } & \multicolumn{4}{c|}{ R-EVAR } \\
\cline { 2 - 9 } Months & $\begin{array}{c}\text { No. At } \\
\text { Risk }\end{array}$ & $\begin{array}{c}\text { No. Of } \\
\text { Events }\end{array}$ & $\begin{array}{c}\text { KM } \\
\text { Estimate }\end{array}$ & SE & $\begin{array}{c}\text { No. At } \\
\text { Risk }\end{array}$ & $\begin{array}{c}\text { No. Of } \\
\text { Events }\end{array}$ & $\begin{array}{c}\text { KM } \\
\text { Estimate }\end{array}$ & SE \\
\hline 12 & 603 & 61 & .914 & .011 & 46 & 11 & 0.842 & 0.045 \\
\hline 24 & 475 & 72 & .895 & .012 & 38 & 14 & 0.782 & 0.053 \\
\hline 36 & 389 & 80 & .884 & .013 & 27 & 14 & 0.782 & 0.053 \\
\hline 48 & 296 & 87 & .859 & .015 & 24 & 14 & 0.782 & 0.053 \\
\hline 60 & 235 & 92 & .842 & .016 & 20 & 14 & 0.782 & 0.053 \\
\hline
\end{tabular}

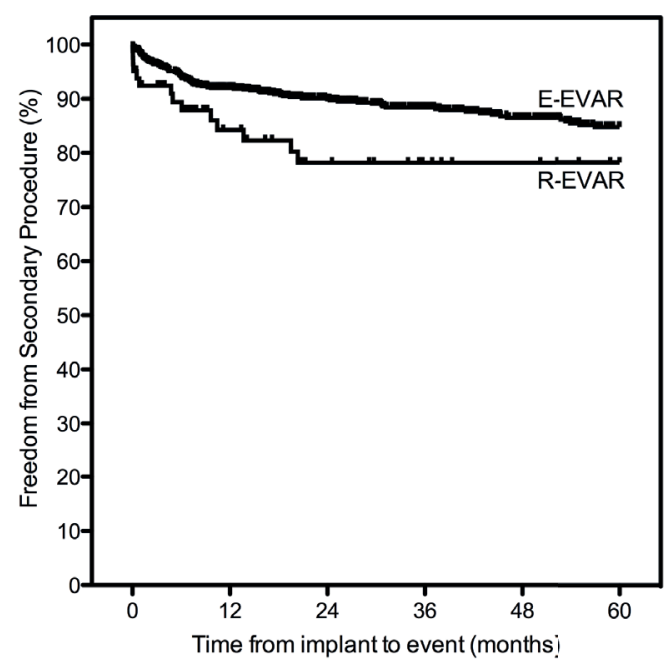

Figure 2 represents the freedom from type I/III endoleaks showing a significant lower rate of freedom from endoleaks in the R-EVAR group after 5-year follow-up (E-EVAR $90.0 \%$ vs. R-EVAR 78.7\%, $p=.003$ ). A total of 63 E-EVAR patients developed a type I/III endoleak, of which 32 were corrected with a secondary intervention, 28 resolved spontanously, and 4 were accepted and persisted during follow-up. There were 14 type I/III endoleak in the R-EVAR group, of which 9 were corrected with a secondary intervention and the remaining 5 resolved spontaneously. 
Figure 2. Kaplan-Meier curves representing the five-year freedom from type I/III endoleaks in 773 E-EVAR and 90 R-EVAR patients. Log rank, $p=.003$.

\begin{tabular}{|c|c|c|c|c|c|c|c|c|}
\hline & \multicolumn{4}{|c|}{ E-EVAR } & \multicolumn{4}{c|}{ R-EVAR } \\
\cline { 2 - 9 } Months & $\begin{array}{c}\text { No. At } \\
\text { Risk }\end{array}$ & $\begin{array}{c}\text { No. Of } \\
\text { Events }\end{array}$ & $\begin{array}{c}\text { KM } \\
\text { Estimate }\end{array}$ & SE & $\begin{array}{c}\text { No. At } \\
\text { Risk }\end{array}$ & $\begin{array}{c}\text { No. Of } \\
\text { Events }\end{array}$ & $\begin{array}{c}\text { KM } \\
\text { Estimate }\end{array}$ & SE \\
\hline 12 & 619 & 49 & .934 & .009 & 43 & 11 & .855 & .042 \\
\hline 24 & 476 & 53 & .927 & .010 & 32 & 14 & .787 & .054 \\
\hline 36 & 461 & 56 & .921 & .010 & 25 & 14 & .787 & .054 \\
\hline 48 & 298 & 61 & .907 & .012 & 23 & 14 & .787 & .054 \\
\hline 60 & 245 & 63 & .900 & .013 & 18 & 14 & .787 & .054 \\
\hline
\end{tabular}

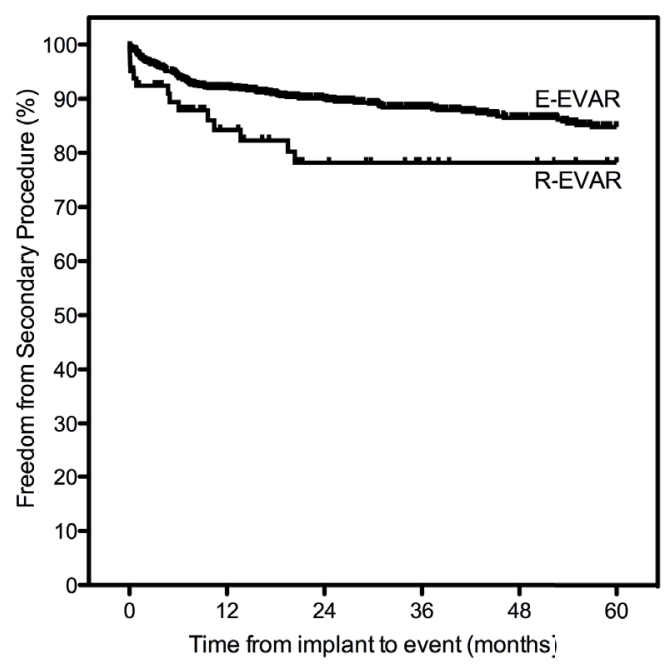

After 5 years of follow-up, there was no significant difference in freedom for endograft obstruction between groups (E-EVAR $91.9 \%$ vs. R-EVAR $87.0 \%, p=.073$, Figure 3). The survival rates for all cause mortality after 5-year were $65.2 \%$ for E-EVAR and $48.1 \%$ for R-EVAR $(\mathrm{p}<.001)$ and freedom from AAA-related mortality was $95.7 \%$ for E-EVAR and $71.0 \%$ for R-EVAR ( $p<.001$, Figure 4). 
Figure 3. Kaplan-Meier curves representing the five-year freedom from endograft obstruction including: occlusion, stenosis, kinking and migration in $773 \mathrm{E}-\mathrm{EVAR}$ and 90 R-EVAR patients. Log-rank, $\mathrm{p}=.073$.

\begin{tabular}{|c|c|c|c|c|c|c|c|c|}
\hline \multirow{2}{*}{ Months } & \multicolumn{4}{|c|}{ E-EVAR } & \multicolumn{4}{c|}{ R-EVAR } \\
\cline { 2 - 9 } & $\begin{array}{c}\text { No. At } \\
\text { Risk }\end{array}$ & $\begin{array}{c}\text { No. Of } \\
\text { Events }\end{array}$ & $\begin{array}{c}\text { KM } \\
\text { Estimate }\end{array}$ & SE & $\begin{array}{c}\text { No. At } \\
\text { Risk }\end{array}$ & $\begin{array}{c}\text { No. Of } \\
\text { Events }\end{array}$ & $\begin{array}{c}\text { KM } \\
\text { Estimate }\end{array}$ & SE \\
\hline 12 & 638 & 28 & .961 & .007 & 48 & 6 & .913 & .035 \\
\hline 24 & 516 & 36 & .947 & .009 & 41 & 8 & .870 & .044 \\
\hline 36 & 412 & 40 & .939 & .010 & 29 & 8 & .870 & .044 \\
\hline 48 & 325 & 46 & .922 & .011 & 27 & 8 & .870 & .044 \\
\hline 60 & 282 & 47 & .919 & .012 & 21 & 8 & .870 & .044 \\
\hline
\end{tabular}

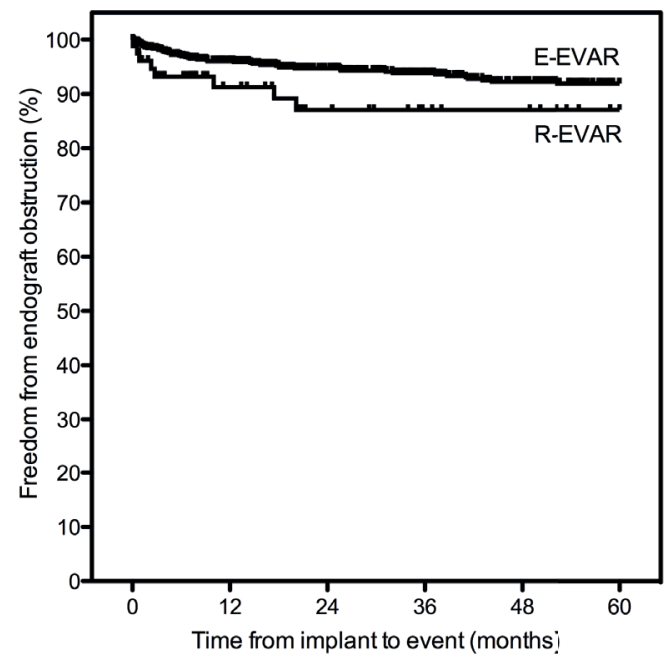


Figure 4. Kaplan-Meier curves representing the five-year freedom from all-cause and AAA related mortality in $773 \mathrm{E}-$ EVAR and 90 R-EVAR patients. Log-rank, all-cause mortality: $p<.001$, AAA-related mortality: $p<.001$.

\begin{tabular}{|c|c|c|c|c|c|c|c|c|}
\hline & \multicolumn{3}{|c|}{ E-EVAR (All-cause mortality) } & \multicolumn{3}{c|}{ R-EVAR (All-cause mortality) } \\
\cline { 2 - 9 } Months & $\begin{array}{c}\text { No. At } \\
\text { Risk }\end{array}$ & $\begin{array}{c}\text { No. Of } \\
\text { Events }\end{array}$ & $\begin{array}{c}\text { KM } \\
\text { Estimate }\end{array}$ & SE & $\begin{array}{c}\text { No. At } \\
\text { Risk }\end{array}$ & $\begin{array}{c}\text { No. Of } \\
\text { Events }\end{array}$ & $\begin{array}{c}\text { KM } \\
\text { Estimate }\end{array}$ & SE \\
\hline 12 & 644 & 61 & .917 & .010 & 51 & 31 & .646 & .051 \\
\hline 24 & 510 & 98 & .859 & .013 & 42 & 33 & .617 & .053 \\
\hline 36 & 405 & 148 & .769 & .017 & 35 & 36 & .570 & .056 \\
\hline 48 & 328 & 184 & .696 & .019 & 30 & 38 & .534 & .057 \\
\hline 60 & 270 & 203 & .652 & .020 & 27 & 41 & .481 & .059 \\
\hline
\end{tabular}

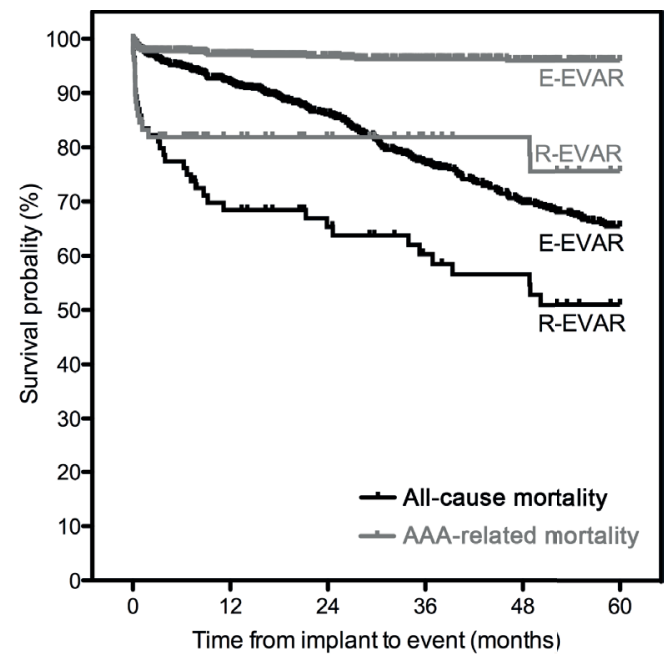




\section{Discussion}

Our 15-year single-centre experience shows that endovascular repair of elective and ruptured AAAs is a safe and feasible technique. Major differences comprised a higher overall mortality rate and a higher incidence of type I endoleaks in the R-EVAR group after 30-day and a higher incidence of type I/III endoleaks after five-year follow-up.

Since the first report in 1994 by Yusuf et al., the endovascular approach for RAAAs has been applied with increasing frequency. ${ }^{6,7}$ To improve the outcome and to ensure high quality R-EVAR care, Mehta et al. suggested a standardized multidisciplinary protocol. This protocol included the presence of an experienced staff consisting of vascular surgeons, anaesthesiologists, emergency room physicians and operating room personnel. The vascular surgeon must have a dedicated operating room and a sufficient stock of off-the shelf endografts at his disposal. ${ }^{8}$ Following such a protocol, anatomically suitable RAAAs are now primarily treated with EVAR with better outcome..$^{9-11}$

A theoretical reduction in technical success for R-EVAR could be explained by limited endograft availability, the need for rapid assessment of aneurysm morphology and swift endograft deployment. However, this study demonstrates excellent technical success rates of EVAR in both elective and emergency settings (95\% and $90 \%$, respectively). The need for conversion to open surgery was low in both groups and there were no intra-operative deaths reported. However, we did find a significant difference in the appearance of type IA endoleaks at completion angiogram between the two groups in favour of elective treated patients. Because of an increased risk of AAA rupture, aggressive management of intraoperative type IA endoleaks is recommended.12 If adjunctive intraoperative endovascular procedures are unsuccessful, only small type IA endoleaks in already stabilized RAAA patients can be accepted. In the first month, the majority of these type IA endoleaks resolved spontaneously without the need of a secondary procedure. The disappearance of type IA endoleaks after appropriate endograft sizing may result from improved graft-wall apposition and thrombosis of low-flow type IA endoleaks. ${ }^{13}$ Extensive image surveillance is advised in these patients, because 
high recurrence rates after spontaneous sealing of type IA have been reported ${ }^{14,15}$

Several studies have demonstrated that the Achilles's heel of EVAR is the high rate of secondary interventions after an initial advantage in terms of survival. The majority of secondary interventions in EVAR are performed to resolve endograft migration and type I and III endoleaks, which are independent risk factor for AAA rupture after EVAR. All delayed type I and III endoleaks should be treated because of a high risk for rupture. ${ }^{5,16}$

Despite significantly more Type I endoleaks in the R-EVAR group, our single-centre experience shows no significant differences in the need for endograft related secondary interventions between elective and emergency AAA repair at fiveyear. We also found that a large part of endoleaks resolved spontaneously. The anatomical fit between aortic anatomy and the stent graft could be considered as predictive factors for re-intervention. ${ }^{17,18}$ Therefore, accurate sizing is essential to select the most suitable endograft. This study also shows that swift anatomical assessment and the availability of a limited stock of endografts do not influence the outcome. In specialized vascular centres, the limited time seems to be sufficient to perform CTA imaging and to assess EVAR suitability in patients with a RAAA without increasing the mortality. ${ }^{19}$

We included a variety of endografts for this study and the risk for endograft related complications is considerably higher in patients treated with early generation stent grafts. ${ }^{20,21}$ For this reason we have excluded all patients treated with first generation endografts (Stentor and Vanguard). The evolution of endograft technology has resulted in a multitude of endograft configurations with modular components and lower profile delivery systems, which allows treatments of patients who may have been excluded previously. Partly due to these developments in EVAR, the complexity of aneurysms treated with EVAR has also increased over time.

In the early years of emergency EVAR, there was no consensus on whether to use bifurcated or aorto-uni-iliac (AUI) devices for the management of RAAAs. Some interventionists prefer the use of AUI devices because there is 
no need for cannulation of the contralateral limb, which may result in faster haemorrhage control. ${ }^{22}$ However, a major disadvantage of AUIs remains the need for a femorofemoral crossover bypass to vascularize the contralateral leg. This results in longer operating times and a higher risk of graft infection and graft thrombosis. In contrast to AUI devices, emergency EVAR with bifurcated devices can be performed under local anaesthesia. ${ }^{23}$ We reported a more frequent use of AUI devices for the treatment of RAAAs. This could be explained by the limited availability of bifurcated grafts in the early years of R-EVAR. ${ }^{24}$ In the last decade, with an increased stock of endografts, we prefer the use of bifurcated devices for the treatment of RAAAs.

\section{Study limitations}

The majority of data were collected prospectively and analysed retrospectively. Selection criteria for endovascular treatment have evolved during the inclusion period. This results in more challenging aortic morphologies treated in the more recent cases.

\section{Conclusion}

EVAR appears technically comparable in patients with non-ruptured and ruptured AAAs. Swift anatomical assessment and the availability of a limited stock of endografts do not influence the technical success and secondary intervention rate of EVAR. 


\section{References}

1. participants Et: Endovascular aneurysm repair versus open repair in patients with abdominal aortic aneurysm (EVAR trial 1): randomised controlled trial. Lancet 2005; 365: 2179-86

2. Prinssen $\mathrm{M}$, Verhoeven EL, Buth J, et al.: A randomized trial comparing conventional and endovascular repair of abdominal aortic aneurysms. N Engl J Med 2004; 351: 1607-18

3. United Kingdom ETI, Greenhalgh RM, Brown LC, et al.: Endovascular versus open repair of abdominal aortic aneurysm. N Engl J Med 2010; 362: 1863-71

4. Chaikof EL, Blankensteijn JD, Harris PL, et al.: Reporting standards for endovascular aortic aneurysm repair. J Vasc Surg 2002; 35: 1048-60

5. Moll FL, Powell JT, Fraedrich G, et al.: Management of abdominal aortic aneurysms clinical practice guidelines of the European society for vascular surgery. Eur J Vasc Endovasc Surg 2011; 41 Suppl 1: S1-S58

6. Yusuf SW, Whitaker SC, Chuter TA, et al.: Emergency endovascular repair of leaking aortic aneurysm. Lancet 1994; 344: 1645

7. Park BD, Azefor N, Huang CC, et al.: Trends in treatment of ruptured abdominal aortic aneurysm: impact of endovascular repair and implications for future care. J Am Coll Surg 2013; 216: 745-54; discussion 754-5

8. Mehta M, Taggert J, Darling RC, 3rd, et al.: Establishing a protocol for endovascular treatment of ruptured abdominal aortic aneurysms: outcomes of a prospective analysis. J Vasc Surg 2006; 44: 1-8; discussion 8

9. Moore R, Nutley M, Cina CS, et al.: Improved survival after introduction of an emergency endovascular therapy protocol for ruptured abdominal aortic aneurysms. J Vasc Surg 2007; 45: 443-50

10. Arya N, Makar RR, Lau LL, et al.: An intention-to-treat by endovascular repair policy may reduce overall mortality in ruptured abdominal aortic aneurysm. J Vasc Surg 2006; 44: 467-71

11. Sweeting MJ, Ulug P, Powell JT, et al.: Ruptured Aneurysm Trials: The Importance of Longer-term Outcomes and Meta-analysis for 1-year Mortality. Eur J Vasc Endovasc Surg 2015

12. Veith FJ, Baum RA, Ohki T, et al.: Nature and significance of endoleaks and endotension: summary of opinions expressed at an international conference. J Vasc Surg 2002; 35: 1029-35

13. Bastos Goncalves F, Verhagen HJ, Vasanthananthan K, et al.: Spontaneous delayed sealing in selected patients with a primary type-ia endoleak after endovascular aneurysm repair. Eur J Vasc Endovasc Surg 2014; 48: 53-9

14. Dias NV, Resch T, Malina M, et al.: Intraoperative proximal endoleaks during AAA stent-graft repair: evaluation of risk factors and treatment with Palmaz stents. J Endovasc Ther 2001; 8: 268-73

15. Sampaio SM, Panneton JM, Mozes GI, et al.: Proximal type I endoleak after endovascular abdominal aortic aneurysm repair: predictive factors. Ann Vasc Surg 2004; 18: 621-8 
16. Koole D, Moll FL, Buth J, et al.: Annual rupture risk of abdominal aortic aneurysm enlargement without detectable endoleak after endovascular abdominal aortic repair. J Vasc Surg 2011; 54: $1614-22$

17. Ohrlander T, Dencker M, Acosta S: Morphological state as a predictor for reintervention and mortality after EVAR for AAA. Cardiovasc Intervent Radiol 2012; 35: 1009-15

18. Wyss TR, Dick F, Brown LC, et al.: The influence of thrombus, calcification, angulation, and tortuosity of attachment sites on the time to the first graft-related complication after endovascular aneurysm repair. J Vasc Surg 2011; 54: 965-71

19. Boyle JR, Gibbs PJ, Kruger A, et al.: Existing delays following the presentation of ruptured abdominal aortic aneurysm allow sufficient time to assess patients for endovascular repair. Eur J Vasc Endovasc Surg 2005; 29: 505-9

20. Desai M, Eaton-Evans J, Hillery C, et al.: AAA stent-grafts: past problems and future prospects. Ann Biomed Eng 2010; 38: 1259-75

21. Tadros RO, Faries PL, Ellozy SH, et al.: The impact of stent graft evolution on the results of endovascular abdominal aortic aneurysm repair. J Vasc Surg 2014; 59: 1518-27

22. Peppelenbosch N, Geelkerken RH, Soong C, et al.: Endograft treatment of ruptured abdominal aortic aneurysms using the Talent aortouniiliac system: an international multicenter study. J Vasc Surg 2006; 43: 1111-1123; discussion 1123

23. Verhoeven EL, Prins TR, van den Dungen JJ, et al.: Endovascular repair of acute AAAs under local anesthesia with bifurcated endografts: a feasibility study. J Endovasc Ther 2002; 9: 729-35

24. Peppelenbosch N, Yilmaz N, van Marrewijk C, et al.: Emergency treatment of acute symptomatic or ruptured abdominal aortic aneurysm. Outcome of a prospective intent-to-treat by EVAR protocol. Eur J Vasc Endovasc Surg 2003; 26: 303-10 


Chapter 4 Effects of anesthesia type on
preoperative outcome after
endovascular aneurysm repair

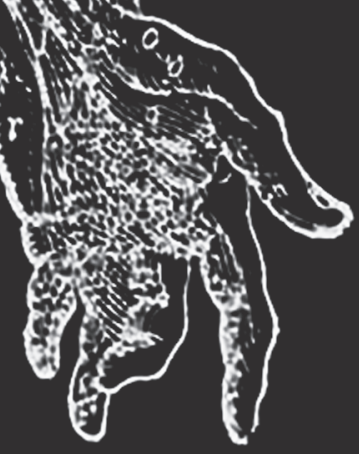

\author{
P.P.H.L. Broos \\ R.A. Stokmans \\ Ph.W.M. Cuypers \\ M.R.H.M. van Sambeek \\ J.A.W. Teijink
}

Journal of Endovascular Therapy 2015;55(5):770-7 


\section{Abstract}

Purpose: This study examined outcomes of endovascular aortic aneurysm repair (EVAR) using general, regional or local anesthesia.

Methods: From March 2009 to April 2011, patients were enrolled from 79 sites in 30 countries worldwide and treated with an Endurant Stent Graft System (Medtronic, Santa Rosa, CA, USA). Data were compared among three groups based on anesthesia type used. Multivariate logistic regression analysis was performed to adjust for possible confounding factors.

Results: General anesthesia (GA) was used in 785 patients (62\%), regional anesthesia (RA) in 331 patients (27\%), and 145 patients (11\%) received local anesthesia (LA). There were intercontinental differences in the distribution of type of anesthesia used for EVAR. Higher ASA classification was associated with predominant use of GA. Procedure time was reduced in LA (80.4 $\pm 40.0 \mathrm{~min})$ compared with RA ( 94.2 \pm 41.6 min, adjusted $P=.001)$ and $G A(105.346 .0$ min, adjusted $P<.001)$. ICU admission was less frequent for RA than for GA (adjusted OR $0.71,95 \% \mathrm{Cl} 0.53$ - 0.97) and LA (adjusted OR 0.51, 95\% Cl 0.33 - 0.79). Postoperative hospital stay was significantly shorter for RA and LA compared to GA (adjusted $\mathrm{P}=.003$ resp. adjusted $P=.100$ ). There were no significant differences in systemic and surgical complications. Mortality rates within 30-days did not differ between the groups.

Conclusions: Type of anesthesia used during EVAR has no influence on perioperative mortality and morbidity. The use of local or regional anesthesia during EVAR appeared to be beneficial concerning procedure time, ICU admission and postoperative hospital stay. 


\section{Introduction}

Since the introduction of endovascular aortic repair (EVAR) in 1991, there have been substantial changes in the treatment of abdominal aortic aneurysms (AAAs). ${ }^{1}$ With improved delivery technique and better technical features of the next generation stent grafts, EVAR shows lower intra-operative mortality and morbidity compared with the conventional open operation of AAA..$^{2-4}$

After 20 years, there is still no consensus about which type of anesthesia is most suitable for EVAR. Feasibility of local and regional anesthesia was proven in 1999. ${ }^{5}$ According to the guidelines of the European society of vascular surgery, the preferential use of local anesthesia for EVAR is feasible and appears to be well tolerated, restricting regional anesthesia or general anesthesia only to those with predefined contraindications. ${ }^{6}$ The Society for Vascular Surgery practice guidelines suggests the use of epidural and local anesthetic along with conscious sedation for patients undergoing EVAR. ${ }^{7}$ However, these guidelines are based on a low level of evidence and recommendation.

The main objective of this study was to compare different anesthesia techniques in a real-world setting. We used data from the prospective Endurant Stent Graft Natural Selection global Post-market Registry (ENGAGE) database for retrospective analysis.

\section{Methods}

\section{Patients and database}

Data from 1263 prospectively enrolled patients enrolled in the ENGAGE Registry were used for this analysis. The ENGAGE Registry was undertaken to quantify the performance of the Endurant Stent Graft System (Medtronic, Santa Rosa, CA, USA) within the context of contemporary, real-world use. The ENGAGE Registry is a multi-center, non-randomized, prospective observational study. The trial was conducted according to the Declaration of Helsinki and the International Conference on Harmonization (ICH) Good Clinical Practice (GCP) guidelines, and 
approved by local medical ethics committees. Ruptured AAAs were not considered for enrolment into ENGAGE. Stokmans et al. described full methodological details of the ENGAGE Registry in an earlier publication. ${ }^{8}$

\section{Definitions and outcome variables}

From the database we retrospectively selected three groups based on anesthesia type used during operation: local, regional and general anesthesia. Local anesthesia was defined as infiltration of local anesthetics into the groin whether or not in combination with sedation. Spinal anesthesia and epidural anesthesia were both defined as regional anesthesia. If multiple anesthesia techniques were used, patients were categorized in the group of most invasive anesthetic technique. Data about type of anesthesia were derived from operation and anesthesia reports. $A$ symptomatic AAA refers to any of a number of symptoms (e.g.: abdominal pain, back pain and limb ischemia) that can be attributed to the aneurysm. Pre-existing medical comorbidities and cardiovascular risk factors were recorded. Collection of this data has been described in a previous publication. ${ }^{9}$

The primary outcome was perioperative success defined as 30-day morbidity and mortality. Secondary outcome measures for this analysis included procedural data, adverse events and quality of life.

Initial technical success was defined as successful delivery and deployment of the Endurant endograft, without unintentional coverage of renal arteries, internal iliac arteries or visceral branches, with absence of either a type I or III endoleak, followed by successful removal of the delivery system. ${ }^{10}$ Duration of implant procedure was defined as the time between cut down or puncture and removal of the last guide catheter. Fluoroscopic time, volume of contrast, post-operative stay and possible intensive care unit (ICU) admission were documented. Thirtyday complications included all-cause mortality, cardiac complications, bowel ischemia, neurologic complications, renal failure, respiratory failure, and surgical complications. Thirty-day follow-up was completed for all patients.

Quality of life was assessed using the EuroQoL 5-Dimensions Questionnaire (EQ-5D) index score; a standardized instrument for use as a measure of health 
outcome in three different ways."11 The descriptive system has five dimensions (mobility, self-care, usual activity, pain/discomfort, and anxiety/depression) and three levels (no problems, some problems, extreme problems), which create 243 unique health states and can be converted into a single summary index (EQ-5D index) by applying scores from a set of general population preference weights. This study used the Dutch TTO value set to calculate the EQ-5D index. The third measure was a 0 to 100 visual analogue scale (VAS) for self-rating a patient's own health. Ratings took place at the first contact (baseline), at discharge, and at the 30-day outpatient visit.

\section{Data collection and statistical analysis}

Data collected were recorded on a web-based electronic case report form. $100 \%$ of the data were reviewed, and more than $40 \%$ of patients' source documentation was monitored randomly. ${ }^{8}$ Each site's Institutional Review Board approved data collection and analysis. Informed consent for authorization of data release was obtained in all patients.

Categorical variables are presented as frequencies with percentages. Continuous variables are presented as mean \pm standard deviation or as median and interquartile range in case of skewed data. Differences in baseline characteristics among the three study groups were analyzed using the $X^{2}$ test for discrete variables and the ANOVA or the Kruskal-Wallis test for continuous variables. Multivariate logistic and linear regression analyses were used to adjust for possible confounding factors. Multicollinearity was checked using the variance inflation factor (VIF) and the tolerance. A P-value $<0.05$ was considered statistically significant. However, we adjusted the $P$-value $(P<0.017)$ for multiple testing, because we performed three comparisons between groups in the regression analysis (Bonferroni correction). All statistical analyses were performed using SPSS ${ }^{\circledR}$ version 20 for MAC (SPSS, Chicago, Ill). 


\section{Results}

Among the 1263 consecutive patients enrolled in the ENGAGE registry, 145 (11.5\%) had local anesthesia (LA), 331 (26.2\%) had regional anesthesia (RA) and 785 (62.3\%) had general anesthesia (GA). The GA group includes 6 patients who scored both spinal and general anesthesia. Two patients were excluded from the study due to lack of recording the anesthesia type. Data for the remaining 1261 patients comprise the basis of this report. Figure 1 shows the distribution of anesthesia type used in ENGAGE. There were intercontinental differences in the distribution of type of anesthesia used for EVAR. Also, differences between regions in Europe were reported.

Figure 1. Distribution of anesthesia type by American Society of Anesthesiologists (ASA) classification. GA, general anesthesia; LA, local anesthesia; RA, regional anesthesia.

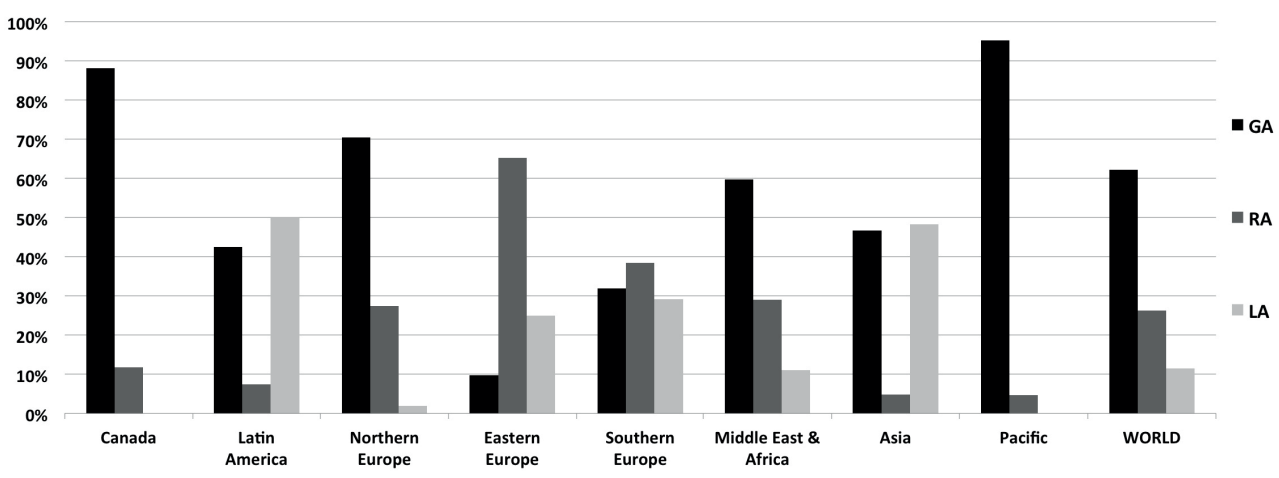

\section{Baseline characteristics}

Demographic data and baseline risk factors are presented in Table 1. On average, there was an overall significant difference in age in GA, RA and LA patients, respectively with a mean age of $73.6 \pm 8.1$ years, $72.3 \pm 8.1$ years and $72.3 \pm 7.7$ years $(P=.026)$. Patients were predominantly men and the distribution of sexes was comparable between the groups. Distribution in different American Society of Anesthesiologists (ASA) class was not equal ( $P=.002)$. ASA class IV was associated with predominant use of GA (Figure 2). Symptomatic presentation was lower in LA and RA patients compared to GA patients $(P=.004)$. Risk factors such as tobacco 
use, hyperlipidemia, coronary artery disease and cardiac revascularization were overall significantly different between groups.

Figure 2. Distribution of anesthesia type by geographic region. GA, general anesthesia; RA, regional anesthesia; LA, local anesthesia.

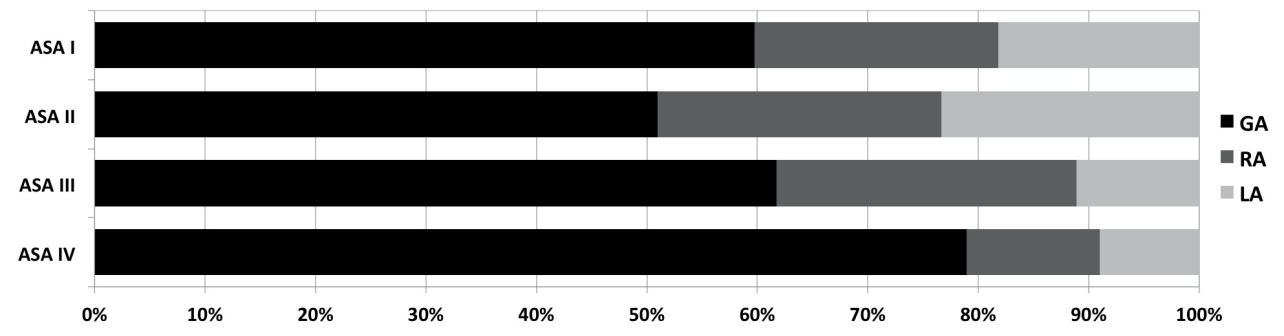

Table 1. Baseline characteristics according to anesthesia type

\begin{tabular}{|c|c|c|c|c|}
\hline Variables & $\begin{array}{c}\text { General (GA) } \\
\mathrm{N}=785^{\mathrm{a}}(\mathrm{n} / \mathrm{N})\end{array}$ & $\begin{array}{l}\text { Regional (RA) } \\
\mathrm{N}=331^{\mathrm{a}}(\mathrm{n} / \mathrm{N})\end{array}$ & $\begin{array}{c}\text { Local (LA) } \\
\mathrm{N}=145^{\mathrm{a}}(\mathrm{n} / \mathrm{N})\end{array}$ & p-value \\
\hline$\overline{\text { Age (years) (Mean } \pm \text { SD) }}$ & $73.6 \pm 8.1$ & $72.3 \pm 8.1$ & $72.3 \pm 7.7$ & $.026^{c}$ \\
\hline Gender & & & & .742 \\
\hline Male & $89.9 \%(706 / 785)$ & $88.5 \%(293 / 331)$ & $90.3 \%(131 / 145)$ & \\
\hline Female & $10.1 \%(79 / 785)$ & $11.5 \%(38 / 331)$ & $9.7 \%(14 / 145)$ & \\
\hline Baseline symptoms & & & & $.004^{c}$ \\
\hline Asymptomatic & $86.5 \%(679 / 785)$ & $80.7 \%(267 / 331)$ & $77.2 \%(112 / 145)$ & \\
\hline Symptomatic & $13.5 \%(106 / 785)$ & $19.3 \%(64 / 331)$ & $22.8 \%(33 / 145)$ & \\
\hline ASA $^{\mathrm{b}}$ classification & & & & $.002^{c}$ \\
\hline Class I & $5.9 \%(46 / 784)$ & $5.1 \%(17 / 331)$ & $9.7 \%(14 / 145)$ & \\
\hline Class II & $39.5 \%(310 / 784)$ & $47.1 \%(156 / 331)$ & $42.1 \%(61 / 145)$ & \\
\hline Class III & $41.2 \%(323 / 784)$ & $42.9 \%(142 / 331)$ & $40.0 \%(58 / 145)$ & \\
\hline Class IV & $13.4 \%(105 / 784)$ & $4.8 \%(16 / 331)$ & $8.3 \%(12 / 145)$ & \\
\hline \multicolumn{5}{|l|}{ Risk factors } \\
\hline Tobacco use & $46.5 \%(355 / 764)$ & $50.8 \%(164 / 323)$ & $60.8 \%(87 / 143)$ & $.006^{c}$ \\
\hline Hypertension & $76.0 \%(586 / 771)$ & $74.5 \%(246 / 330)$ & $74.1 \%(106 / 143)$ & .816 \\
\hline Hyperlipidemia & $63.0 \%(465 / 738)$ & $61.4 \%(191 / 311)$ & $44.9 \%(62 / 138)$ & $<.001^{c}$ \\
\hline Diabetes & $20.9 \%(161 / 772)$ & $17.1 \%(56 / 327)$ & $13.2 \%(19 / 144)$ & .060 \\
\hline Cancer & $19.7 \%(152 / 773)$ & $20.9 \%(68 / 325)$ & $23.9 \%(34 / 142)$ & .497 \\
\hline \multicolumn{5}{|l|}{ Cardiac disease } \\
\hline Myocardial infarction & $27.2 \%(205 / 754)$ & $26.1 \%(82 / 314)$ & $22.0 \%(31 / 141)$ & .435 \\
\hline Arrhythmia & $16.7 \%(128 / 768)$ & $16.2 \%(52 / 321)$ & $12.5 \%(18 / 144)$ & .457 \\
\hline Angina & $15.8 \%(121 / 764)$ & $16.0 \%(52 / 324)$ & $13.1 \%(19 / 145)$ & .681 \\
\hline Congestive heart failure & $5.1 \%(39 / 761)$ & $7.1 \%(23 / 322)$ & $6.2 \%(9 / 145)$ & .418 \\
\hline Coronary artery disease & $34.5 \%(261 / 756)$ & $39.0 \%(124 / 318)$ & $25.9 \%(37 / 143)$ & $.023^{c}$ \\
\hline Cardiac revascularization & $28.1 \%(216 / 770$ & $28.7 \%(94 / 328)$ & $18.6 \%(27 / 145)$ & $.049^{c}$ \\
\hline Pulmonary disease & $25.7 \%(198 / 771)$ & $24.0 \%(78 / 325)$ & $23.6 \%(34 / 144)$ & .774 \\
\hline Renal insufficiency & $15.3 \%(119 / 778)$ & $15.0 \%(49 / 327)$ & $15.2 \%(22 / 145)$ & .991 \\
\hline Cerebrovascular disease & $12.1 \%(95 / 784)$ & $14.2 \%(47 / 331)$ & $12.4 \%(18 / 145)$ & .631 \\
\hline
\end{tabular}

a Denominator differs when there are missing values.

${ }^{\mathrm{b}}$ American Society of Anaesthesiologists.

'Significantly different 
Baseline aneurysm characteristics are summarized in Table 2. There were no significant differences in AAA diameter $(P=.449)$. Distal iliac fixation site diameters, proximal non-aneurysmal neck length and angulation were significantly different between groups.

Table 2. Baseline aneurysm characteristics.

\begin{tabular}{|c|c|c|c|c|}
\hline Variable & $\begin{array}{c}\text { General (GA) } \\
N=785 \\
\text { (Mean } \pm \text { SD) }\end{array}$ & $\begin{array}{c}\text { Regional (RA) } \\
\mathrm{N}=331 \\
\text { (Mean } \pm \text { SD) }\end{array}$ & $\begin{array}{c}\text { Local (LA) } \\
\mathrm{N}=145 \\
\text { (Mean } \pm \mathrm{SD})\end{array}$ & $\begin{array}{c}p- \\
\text { value }\end{array}$ \\
\hline $\begin{array}{l}\text { Maximum } \text { AAA }^{\mathrm{a}} \text { diameter } \\
(\mathrm{mm})\end{array}$ & $60.5 \pm 11.9$ & $60.1 \pm 10.6$ & $59.3 \pm 12.6$ & .449 \\
\hline $\begin{array}{l}\text { Proximal neck diameter } \\
(\mathrm{mm})\end{array}$ & $23.7 \pm 3.5$ & $23.6 \pm 3.6$ & $24.3 \pm 3.9$ & .160 \\
\hline $\begin{array}{l}\text { Proximal non-aneurysmal } \\
\text { neck length }(\mathrm{mm})\end{array}$ & $27.5 \pm 12.5$ & $26.8 \pm 12.6$ & $24.7 \pm 11.0$ & $.045^{\mathrm{b}}$ \\
\hline \multicolumn{5}{|l|}{$\begin{array}{l}\text { Distal iliac fixation site } \\
\text { diameter }(\mathrm{mm})\end{array}$} \\
\hline Right & $14.4 \pm 3.6$ & $14.0 \pm 3.7$ & $13.4 \pm 3.0$ & $.017^{b}$ \\
\hline Left & $14.0 \pm 3.5$ & $13.6 \pm 4.0$ & $13.1 \pm 2.9$ & $.014^{b}$ \\
\hline Infrarenal neck angle $\left(^{\circ}\right)$ & $28.8 \pm 23.2$ & $33.2 \pm 24.7$ & $31.9 \pm 23.9$ & $.014^{b}$ \\
\hline Suprarenal neck angle $\left({ }^{\circ}\right)$ & $18.0 \pm 18.3$ & $19.1 \pm 18.5$ & $22.6 \pm 19.5$ & $.024^{\mathrm{b}}$ \\
\hline
\end{tabular}

\section{Intra-operative outcome}

Initial procedural data and evaluation are detailed in Table 3. The mean adjusted procedural duration was significantly shorter in LA $(80.4 \pm 40.0 \mathrm{~min})$ compared to RA $(94.2 \pm 41.6 \mathrm{~min}$, adjusted $\mathrm{P}=.001)$ and $\mathrm{GA}(105.3 \pm 46.0 \mathrm{~min}$, adjusted $\mathrm{P}<$ .001). There were no significant differences in type I and/or type III endoleaks at completion angiography between groups. Type of anesthesia used did not influence technical success rates. No intra-operative deaths occurred. Focusing on hospitalization, GA patients were significantly longer in the hospital than RA and LA patients (adjusted $\mathrm{P}=.003$ resp. adjusted $\mathrm{P}=.010$ ). GA and LA patients were admitted more frequently to the ICU than RA patients (adjusted OR $1.40,95 \% \mathrm{CI}$ $1.03-1.90$ resp. adjusted OR $0.51,95 \% \mathrm{Cl} 0.33-0.79$ ). 
Table 3. Initial procedural data and evaluation by anesthesia type.

\begin{tabular}{|c|c|c|c|c|c|c|}
\hline \multirow[b]{2}{*}{ Variables } & \multirow{2}{*}{$\begin{array}{c}\text { General (GA) } \\
N=785 \\
\text { Mean } \pm \text { SD }\end{array}$} & \multirow{2}{*}{$\begin{array}{c}\text { Regional (RA) } \\
N=331 \\
\text { Mean } \pm \text { SD }\end{array}$} & \multirow{2}{*}{$\begin{array}{l}\text { Local (LA) } \\
N=145 \\
\text { Mean } \pm \text { SD }\end{array}$} & \multicolumn{3}{|c|}{ Adjusted $p$-value ${ }^{a}$} \\
\hline & & & & GA vs. RA & GA vs. $L A$ & RA vs. $L A$ \\
\hline Duration of procedure (mins) & & & & $.002^{d}$ & $<.001^{d}$ & $.001^{d}$ \\
\hline Mean \pm SD & $105.3 \pm 46.0$ & $94.2 \pm 41.6$ & $80.4 \pm 40.0$ & & & \\
\hline Volume of contrast $(\mathrm{mL})$ & & & & $.001^{d}$ & .028 & $<.001^{d}$ \\
\hline Mean \pm SD & $130.9 \pm 71.2$ & $122.9 \pm 67.4$ & $148.4 \pm 71.9$ & & & \\
\hline Post-operative stay (days) & & & & $.003^{d}$ & $.010^{d}$ & .731 \\
\hline \multirow[t]{3}{*}{ Mean \pm SD } & $5.2 \pm 5.4$ & $4.3 \pm 4.8$ & $4.0 \pm 3.6$ & & & \\
\hline & & & & \multicolumn{3}{|c|}{ Adjusted $\mathrm{OR}^{\mathrm{a}, \mathrm{b}}(95 \% \mathrm{Cl})$} \\
\hline & $\%(n / N)$ & $\%(n / N)$ & $\%(n / N)$ & GA vs. $R A$ & GA vs. $L A$ & RA vs. LA \\
\hline$\overline{\text { Admission to } \mathrm{ICU}^{\mathrm{C}}}$ & $\begin{array}{c}35.8 \% \\
(279 / 780)\end{array}$ & $\begin{array}{c}27.0 \% \\
(89 / 330)\end{array}$ & $\begin{array}{c}42.1 \% \\
(61 / 145)\end{array}$ & $\begin{array}{c}1.40^{d} \\
(1.03-1.90)\end{array}$ & $\begin{array}{c}.72 \\
(.49-1.05)\end{array}$ & $\begin{array}{c}.51^{d} \\
(.33-.79)\end{array}$ \\
\hline $\begin{array}{l}\text { Type I endoleak at } \\
\text { completion angiography }\end{array}$ & $(8 / 785)$ & $(3 / 331)$ & $(2 / 145)$ & $\begin{array}{c}1.12 \\
(.28-4.52)\end{array}$ & $\begin{array}{c}.31 \\
(.06-1.74)\end{array}$ & $\begin{array}{c}.28 \\
(.04-1.93)\end{array}$ \\
\hline $\begin{array}{l}\text { Type III endoleak at } \\
\text { completion angiography } \\
\text { Evaluation }\end{array}$ & $(2 / 785)$ & $(2 / 331)$ & $(0 / 145)$ & - & - & - \\
\hline Intra-operative mortality & $0.0 \%(0)$ & $0.0 \%(0)$ & $0.0 \%(0)$ & - & - & - \\
\hline Conversion to open surgery & $0.5 \%(4)$ & $0.0 \%(0)$ & $0.0 \%(0)$ & - & - & - \\
\hline Clinical success & $\begin{array}{c}97.7 \% \\
(767 / 785)\end{array}$ & $\begin{array}{c}97.3 \% \\
(322 / 331)\end{array}$ & $\begin{array}{c}97.9 \% \\
(142 / 145)\end{array}$ & $\begin{array}{c}1.01 \\
(.41-2.53)\end{array}$ & $\begin{array}{c}1.06 \\
(.29-3.81)\end{array}$ & $\begin{array}{c}1.06 \\
(.26-4.24)\end{array}$ \\
\hline
\end{tabular}

${ }^{a}$ Adjusted for: Age; Baseline symptoms; ASA classification; Tobacco use; Hyperlipidemia; Coronary artery disease; Cardiac revascularization

${ }^{b}$ Odds ratio

c Intensive care unit

d Significantly different $(P<.017)$

\section{Mortality and morbidity}

Thirty-day outcome is summarized in Table 4. Within 30 days after implant, $11 \mathrm{GA}$ patients (1.4\%) died versus 3 RA patients (0.9\%, adjusted OR $1.42,95 \% \mathrm{Cl} 0.38$ 5.31) versus 2 LA patients (1.4\%, adjusted OR $0.80,95 \% \mathrm{Cl} 0.16-3.89)$. There were no significant differences for systemic and surgical complications. 
Table 4. Patient outcome within 30 days post implant by anesthesia type.

\begin{tabular}{|c|c|c|c|c|c|c|}
\hline \multirow[b]{2}{*}{ Variables } & \multirow{2}{*}{$\begin{array}{c}\text { General (GA) } \\
N=785 \\
\%(n / N) \\
\end{array}$} & \multirow{2}{*}{$\begin{array}{c}\text { Regional (RA) } \\
N=331 \\
\%(n / N) \\
\end{array}$} & \multirow{2}{*}{$\begin{array}{c}\text { Local (LA) } \\
N=145 \\
\%(n / N) \\
\end{array}$} & \multicolumn{3}{|c|}{ Adjusted $\mathrm{OR}^{\mathrm{a}, \mathrm{b}}(95 \% \mathrm{Cl})$} \\
\hline & & & & $\overline{G A}$ vs. RA & GA vs. LA & RA vs. LA \\
\hline One or more complications & $5.6 \%(44)$ & $4.8 \%(16)$ & $2.8 \%(4)$ & $\begin{array}{c}1.23 \\
(.65-2.31)\end{array}$ & $\begin{array}{c}2.79 \\
(.84-9.29)\end{array}$ & $\begin{array}{c}2.28 \\
(.63-8.18)\end{array}$ \\
\hline All-cause mortality & $1.4 \%(11)$ & $0.9 \%(3)$ & $1.4 \%(2)$ & $\begin{array}{c}1.52 \\
(.41-5.65)\end{array}$ & $\begin{array}{c}.91 \\
(.19-4.36)\end{array}$ & $\begin{array}{c}.60 \\
(.10-3.75)\end{array}$ \\
\hline Cardiac complications & & & & & & \\
\hline $\begin{array}{l}\text { One or more cardiac } \\
\text { complications }\end{array}$ & $2.3 \%(18)$ & $1.8 \%(6)$ & $1.4 \%(2)$ & $\begin{array}{c}1.12 \\
(.42-3.01)\end{array}$ & $\begin{array}{c}1.00 \\
(.21-4.65)\end{array}$ & $\begin{array}{c}.89 \\
(.17-4.69)\end{array}$ \\
\hline Cardiac death & $0.8 \%(6)$ & $0.3 \%(1)$ & $0.7 \%(1)$ & $\begin{array}{c}2.74 \\
(.32-23.50)\end{array}$ & $\begin{array}{c}.94 \\
(.10-8.80)\end{array}$ & $\begin{array}{c}.34 \\
(.02-5.95)\end{array}$ \\
\hline Myocardial infarction & $1.4 \%(11)$ & $0.3 \%(1)$ & $1.4 \%(2)$ & $\begin{array}{c}4.55 \\
(.56-36.70)\end{array}$ & $\begin{array}{c}.47 \\
(.09-2.48)\end{array}$ & $\begin{array}{c}.10 \\
(.01-1.27)\end{array}$ \\
\hline Cardiogenic shock & $0.3 \%(2)$ & $0.3 \%(1)$ & $0.0 \%(0)$ & $\begin{array}{c}.59 \\
(.05-6.98)\end{array}$ & - & - \\
\hline Arrhythmia & $0.4 \%(3)$ & $0.9 \%(3)$ & $0.0 \%(0)$ & $\begin{array}{c}.39 \\
(.07-2.09)\end{array}$ & - & - \\
\hline Other cardiac & $0.3 \%(2)$ & $0.3 \%(1)$ & $0.0 \%(0)$ & $\begin{array}{c}.03 \\
(0-5.76)\end{array}$ & - & - \\
\hline Renal failure & $0.4 \%(3)$ & $0.3 \%(1)$ & $0.0 \%(0)$ & $\begin{array}{c}1.74 \\
(.17-17.79)\end{array}$ & - & - \\
\hline Respiratory failure & $0.0 \%(0)$ & $0.0 \%(0)$ & $0.0 \%(0)$ & - & - & - \\
\hline Bowel ischemia & $0.4 \%(3)$ & $0.0 \%(0)$ & $0.0 \%(0)$ & - & - & - \\
\hline \multicolumn{7}{|l|}{ Neurologic } \\
\hline Paraplegia & $0.0 \%(0)$ & $0.0 \%(0)$ & $0.0 \%(0)$ & - & - & - \\
\hline Stroke & $0.3 \%(1)$ & $0.0 \%(0)$ & $0.7 \%(1)$ & - & - & - \\
\hline \multicolumn{7}{|l|}{ Surgical } \\
\hline Blood loss $\geq 1000 \mathrm{cc}$ & $2.0 \%(16)$ & $0.6 \%(2)$ & $0.0 \%(0)$ & $\begin{array}{c}3.28 \\
(.74-14.65)\end{array}$ & - & - \\
\hline Access site bleeding & $0.9 \%(7)$ & $0.9 \%(3)$ & $0.7 \%(1)$ & $\begin{array}{c}.76 \\
(.18-3.19)\end{array}$ & $\begin{array}{c}1.02 \\
(.12-9.09)\end{array}$ & $\begin{array}{c}1.36 \\
(.13-13.81)\end{array}$ \\
\hline Secondary intervention & $1.3 \%(10)$ & $2.1 \%(7)$ & $1.4 \%(2)$ & $\begin{array}{c}.77 \\
(.25-2.32)\end{array}$ & $\begin{array}{c}1.02 \\
(.21-4.85)\end{array}$ & $\begin{array}{c}1.32 \\
(.25-7.15) \\
\end{array}$ \\
\hline
\end{tabular}

a. Adjusted for: Age; Baseline symptoms; ASA classification; Tobacco use; Hyperlipidemia; Coronary artery disease; Cardiac revascularization b. Odds ratio

\section{Activities of daily living and quality of life}

Table 5 displays differences in quality of life data between groups at each of the three time points (intergroup differences) and within each group from preoperative baseline to discharge and 30 days (intragroup differences). At baseline, quality of life and the dimensions of health status were similar in the three groups. At discharge, the LA group scored significantly better on usual activities and selfcare. The change in EQ-5D index from baseline to discharge was negative in GA and RA patients $(-0.06 \pm 0.22$ and $-0.03 \pm 0.17$, respectively), no change was found in LA patients $(0.00 \pm 0.19)(P=.006)$. After 30 days, there is an overall significant difference in VAS-score between study groups $(P=.021)$ favoring LA patients. Changes in EQ-5D index from baseline to 30 days follow-up are positive for all groups and overall not significantly different $(P=.328)$. 
Table 5. Outcome of activities of daily living and quality of life by anesthesia type.

\begin{tabular}{|c|c|c|c|c|}
\hline Variables & General (GA) & Regional (RA) & Local (LA) & $p$-value \\
\hline Baseline & $n=750$ & $n=327$ & $n=130$ & \\
\hline Mobility & & & & .673 \\
\hline 1 (no problem) & $69.9 \%(524)$ & $69.1 \%(226)$ & $67.7 \%(88)$ & \\
\hline 2 (some problems) & $29.5 \%(221)$ & $30.6 \%(100)$ & $30.8 \%(40)$ & \\
\hline 3 (extreme problems) & $0.7 \%(5)$ & $0.3 \%(1)$ & $1.5 \%(2)$ & \\
\hline Self-care & & & & .953 \\
\hline 1 (no problem) & $90.1 \%(676)$ & $91.4 \%(299)$ & $90.0 \%(117)$ & \\
\hline 2 (some problems) & $8.5 \%(64)$ & $7.6 \%(25)$ & $8.5 \%(11)$ & \\
\hline 3 (extreme problems) & $1.3 \%(10)$ & $0.9 \%(3)$ & $1.5 \%(2)$ & \\
\hline Usual activities & & & & .848 \\
\hline 1 (no problem) & $79.5 \%(596)$ & $81.7 \%(267)$ & $82.3 \%(107)$ & \\
\hline 2 (some problems) & $17.9 \%(134)$ & $16.2 \%(53)$ & $16.2 \%(21)$ & \\
\hline 3 (extreme problems) & $2.7 \%(20)$ & $2.1 \%(7)$ & $1.5 \%(2)$ & \\
\hline Pain/discomfort & & & & .634 \\
\hline 1 (no problem) & $64.9 \%(487)$ & $63.9 \%(209)$ & $68.5 \%(89)$ & \\
\hline 2 (some problems) & $32.0 \%(240)$ & $33.9 \%(111)$ & $27.7 \%(36)$ & \\
\hline 3 (extreme problems) & $3.1 \%(23)$ & $2.1 \%(7)$ & $3.8 \%(5)$ & \\
\hline Anxiety/depression & & & & .201 \\
\hline 1 (no problem) & $73.5 \%(551)$ & $70.6 \%(231)$ & $70.8 \%(92)$ & \\
\hline 2 (some problems) & $24.1 \%(181)$ & $26.0 \%(85)$ & $23.1 \%(30)$ & \\
\hline 3 (extreme problems) & $2.4 \%(18)$ & $3.4 \%(11)$ & $6.2 \%(8)$ & \\
\hline Your own health state today $(0-100)$ & & & & .270 \\
\hline Mean \pm SD & $73.0 \pm 16.4$ & $72.1 \pm 16.9$ & $74.8 \pm 17.1$ & \\
\hline Median $(I Q R)^{a}$ & $75(65-85)$ & $75(60-85)$ & $80(60-90)$ & \\
\hline$E Q-5 D$ inde $x^{b}$ & & & & .492 \\
\hline Mean \pm SD & $0.84 \pm 0.21$ & $0.84 \pm 0.20$ & $0.82 \pm 0.22$ & \\
\hline Median $(I Q R)^{a}$ & $0.86(0.78-1)$ & $0.84(0.78-1)$ & $0.84(0.77-1)$ & \\
\hline At discharge & $n=641$ & $n=285$ & $n=118$ & \\
\hline EQ-5D index & & & & .128 \\
\hline Mean \pm SD & $0.78 \pm 0.22$ & $0.81 \pm 0.19$ & $0.81 \pm 0.17$ & \\
\hline Median $(I Q R)^{a}$ & $0.81(0.69-1)$ & $0.84(0.73-1)$ & $0.81(0.78-1)$ & \\
\hline Change from baseline to discharge & & & & $.006^{c}$ \\
\hline Mean \pm SD & $-0.06 \pm 0.22$ & $-0.03 \pm 0.17$ & $0.00 \pm 0.19$ & \\
\hline Median $(I Q R)^{a}$ & $0.00(-0.16-0.00)$ & $0.00(-0.12-0.00)$ & $0.00(-0.09-0.0)$ & \\
\hline After 30 days & $n=646$ & $\mathrm{n}=282$ & $n=125$ & \\
\hline EQ-5D index & & & & .978 \\
\hline Mean \pm SD & $0.85 \pm 0.19$ & $0.85 \pm 0.19$ & $0.86 \pm 0.19$ & \\
\hline Median $(I Q R)^{a}$ & $0.89(0.81-1)$ & $0.89(0.78-1)$ & $0.89(0.81-1)$ & \\
\hline Change from baseline to 30 days & & & & .328 \\
\hline Mean \pm SD & $0.08 \pm 0.21$ & $0.05 \pm 0.17$ & $0.04 \pm 0.17$ & \\
\hline Median $(I Q R)^{a}$ & $0.03(0.00-0.16)$ & $0.00(0.00-0.16)$ & $0.03(0.00-0.16)$ & \\
\hline
\end{tabular}

a. Inter Quartile Range.

b. Dutch TTO value set used to calculate EQ-5D index score.

c. Significantly different 


\section{Discussion}

The effect of different anesthetic techniques in EVAR is described in small studies with possible selection bias. Unprecedented in size, scope, and geographic representation, the ENGAGE Registry represents the collective experience of 79 centers in 30 countries across five different continents with the Endurant Stent Graft. Patients with a wide spectrum of comorbidities were included, resulting in a representation of everyday real-world clinical practice. ${ }^{8}$

According to the European and American guidelines, the use of local anesthesia for EVAR is preferred. ${ }^{6,7}$ Despite this consensus, EVAR is still mainly conducted under general anesthesia. ${ }^{12-15} \mathrm{~A}$ majority of the patients (62.3\%) in our study were treated under GA. However, we found an existence of large intercontinental differences for the primary choice of anesthetic. The differences between regions in Europe were even more remarkable. This could be explained by sustained regional customs of vascular surgeons and anesthesiologists. Another interesting finding is that patients in the GA group had a significant higher ASA score, which is not according the European guidelines. ${ }^{6}$ Unfortunately, the registry does not foresee in a specific explanation on the individual choice of anesthesia. We can therefor only speculate on individual preferences.

Geisbüsch et al. concluded in a cohort of 217 continuous patients that with a 'local anesthesia first strategy', LA could be applied in approximately $75 \%$ of patients undergoing elective EVAR. ${ }^{16}$ Lachat et al. published their first results of 100 consecutive patients treated percutaneously under local anesthesia in an outpatient setting, showing excellent results. ${ }^{17}$ We described a more frequently use of LA in our data compared to the EUROpean collaborators on Stent-graft Techniques for abdominal Aneurysm Repair (EUROSTAR) data (resp. $11.5 \%$ vs. $5.6 \%) .^{14}$ This could imply that nowadays more LA is applied.

EUROSTAR data indicated no differences in surgical outcome between types of anesthesia..$^{14}$ Our results are consistent with these findings, showing comparable rates of technical success and endoleaks between groups. In addition, we reported 
no significant differences in the need for secondary procedures within 30 days after implant.

LA and RA reported shorter operation time and hospital stay than GA. ${ }^{12,14,18,19}$ In contrast to previous reports, we reported a remarkable higher requirement for ICU admission in the LA group. . $14,18-21^{1}$ This difference might be caused by two centers that had $100 \%$ ICU admission in 38 LA patients (26.2\%). When we excluded this group, we found a significant lower ICU admission for LA (22.4\%) compared to GA (35.8\%, adjusted OR $0.55,95 \% \mathrm{Cl} 0.33-0.91)$.

LA and RA are proven to be feasible and safe as an alternative for general anesthesia during EVAR. ${ }^{22}$ All-cause mortality rates were low in all three groups and were comparable with other studies. ${ }^{14,15}$ We reported no differences in shortterm complications. We did see a trend that LA resulted in fewer complications, however a significant advantage for LA was not established. This is probably due to the low incidence of complications and the infrequent use of LA.

Bakker et al. described a significantly higher cardiac event rate at thirty days comparing general and locoregional anesthesia (OR 3.8, 95\% Cl 1.1-12.9). ${ }^{23}$ Despite a larger group of patients, we found no significant difference in cardiac event rates between general and locoregional anesthesia (OR 1.09, 95\% Cl $0.45-2.67$ ).

The success of EVAR is highly dependent on patients' AAA anatomy. Short and angulated infrarenal aortic necks increase the risk of type 1 endoleaks. ${ }^{24}$ Complex AAA anatomy may also extend the duration of surgery, resulting in more discomfort for patients treated with locoregional anesthesia. ${ }^{25}$ We found a shorter infrarenal neck length and a smaller iliac access diameter in the LA group. However, these differences were minimal and did not result in relevant differences in AAA complexity. LA may influence imaging quality because it is very dependent on patient movement and their ability of holding their breath during imaging. ${ }^{16}$ This could be an explanation why we found significantly more contrast use in the LA group. 
GA might be preferred for extremely complex cases when there is a possibility of immediate conversion to open surgery. However, we found a low conversion rate of $0.3 \%$ in our study population. Furthermore, with an appropriate anesthetic team standby, conversion to GA is always possible.

To our best knowledge, this is the first study on anesthesia type and the effect of quality of life after EVAR. LA scored best on EQ-5D compared to RA and GA. This may imply that patients recover quicker after LA.

This study has several limitations. Unfortunately, pre-operative clarification regarding the choice of anesthesia type is missing. Information regarding possible anesthesia type conversion was not documented. Therefore, we were unable to perform an intention-to-treat analysis and selection bias may have affected our results. The technique of femoral/iliac access was not documented. Percutaneous EVAR influence the amount of blood loss, operating time and post-operative stay, possibly confounding results. Also, one has to take into account that the ENGAGE registry was not designed nor powered for this specific retrospective analysis, restraining our findings.

\section{Conclusion}

The main findings of this study were that LA and RA had advantages compared with GA regarding duration of procedure, post-operative stay. No effects of type of anesthesia on procedural success rates and perioperative mortality and morbidity were reported. Patients seem to recover quicker after LA. Based on our results, we advise a strategy based on preferential use of locoregional anesthesia for EVAR restricting GA only to those with predefined contraindications. 


\section{References}

1. Parodi JC, Palmaz JC, Barone HD: Transfemoral intraluminal graft implantation for abdominal aortic aneurysms. Ann Vasc Surg 1991; 5: 491-9

2. Endovascular aneurysm repair versus open repair in patients with abdominal aortic aneurysm (EVAR trial 1): randomised controlled trial. Lancet 2005; 365: 2179-86

3. Lederle FA, Freischlag JA, Kyriakides TC, et al.: Outcomes following endovascular vs open repair of abdominal aortic aneurysm: a randomized trial. JAMA 2009; 302: 1535-42

4. Prinssen $M$, Verhoeven EL, Buth J, et al.: A randomized trial comparing conventional and endovascular repair of abdominal aortic aneurysms. N Engl J Med 2004; 351: 1607-18

5. Henretta JP, Hodgson KJ, Mattos MA, et al.: Feasibility of endovascular repair of abdominal aortic aneurysms with local anesthesia with intravenous sedation. J Vasc Surg 1999; 29: 793-8

6. Moll FL, Powell JT, Fraedrich G, et al.: Management of abdominal aortic aneurysms clinical practice guidelines of the European society for vascular surgery. Eur J Vasc Endovasc Surg 2011; 41 Suppl 1: S1-S58

7. Chaikof EL, Brewster DC, Dalman RL, et al.: The care of patients with an abdominal aortic aneurysm: the Society for Vascular Surgery practice guidelines. J Vasc Surg 2009; 50: S2-49

8. Stokmans RA, Teijink JA, Forbes TL, et al.: Early results from the ENGAGE registry: real-world performance of the Endurant Stent Graft for endovascular AAA repair in 1262 patients. Eur J Vasc Endovasc Surg 2012; 44: 369-75

9. Bockler D, Fitridge $\mathrm{R}$, Wolf $\mathrm{Y}$, et al.: Rationale and design of the Endurant Stent Graft Natural Selection Global Postmarket Registry (ENGAGE): interim analysis at 30 days of the first 180 patients enrolled. J Cardiovasc Surg (Torino) 2010; 51: 481-91

10. Chaikof EL, Blankensteijn JD, Harris PL, et al.: Reporting standards for endovascular aortic aneurysm repair. J Vasc Surg 2002; 35: 1048-60

11. Cavrini G, Broccoli S, Puccini A, et al.: EQ-5D as a predictor of mortality and hospitalization in elderly people. Qual Life Res 2012; 21: 269-80

12. De Virgilio C, Romero L, Donayre C, et al.: Endovascular abdominal aortic aneurysm repair with general versus local anesthesia: a comparison of cardiopulmonary morbidity and mortality rates. J Vasc Surg 2002; 36: 988-91

13. Parra JR, Crabtree T, McLafferty RB, et al.: Anesthesia technique and outcomes of endovascular aneurysm repair. Ann Vasc Surg 2005; 19: 123-9

14. Ruppert V, Leurs LJ, Steckmeier B, et al.: Influence of anesthesia type on outcome after endovascular aortic aneurysm repair: an analysis based on EUROSTAR data. J Vasc Surg 2006; 44: 16-21; discussion 21

15. Edwards MS, Andrews JS, Edwards AF, et al.: Results of endovascular aortic aneurysm repair with general, regional, and local/monitored anesthesia care in the American College of Surgeons National Surgical Quality Improvement Program database. J Vasc Surg 2011; 54: 1273-82 
16. Geisbusch P, Katzen BT, Machado R, et al.: Local anaesthesia for endovascular repair of infrarenal aortic aneurysms. Eur J Vasc Endovasc Surg 2011; 42: 467-73

17. Lachat ML, Pecoraro F, Mayer D, et al.: Outpatient endovascular aortic aneurysm repair: experience in 100 consecutive patients. Ann Surg 2013; 258: 754-8; discussion 758-9

18. Bettex DA, Lachat M, Pfammatter T, et al.: To compare general, epidural and local anaesthesia for endovascular aneurysm repair (EVAR). Eur J Vasc Endovasc Surg 2001; 21: 179-84

19. Verhoeven EL, Cina CS, Tielliu IF, et al.: Local anesthesia for endovascular abdominal aortic aneurysm repair. J Vasc Surg 2005; 42: 402-9

20. Ruppert V, Leurs LJ, Rieger J, et al.: Risk-adapted outcome after endovascular aortic aneurysm repair: analysis of anesthesia types based on EUROSTAR data. J Endovasc Ther 2007; 14: 12-22

21. Asakura Y, Ishibashi H, Ishiguchi T, et al.: General versus locoregional anesthesia for endovascular aortic aneurysm repair: influences of the type of anesthesia on its outcome. J Anesth 2009; 23: 158-61

22. Karthikesalingam A, Thrumurthy SG, Young EL, et al.: Locoregional anesthesia for endovascular aneurysm repair. J Vasc Surg 2012; 56: 510-9

23. Bakker EJ, van de Luijtgaarden KM, van Lier F, et al.: General anaesthesia is associated with adverse cardiac outcome after endovascular aneurysm repair. Eur J Vasc Endovasc Surg 2012; 44: 121-5

24. Stather PW, Wild JB, Sayers RD, et al.: Endovascular aortic aneurysm repair in patients with hostile neck anatomy. J Endovasc Ther 2013; 20: 623-37

25. Georgiadis GS, Trellopoulos G, Antoniou GA, et al.: Early results of the Endurant endograft system in patients with friendly and hostile infrarenal abdominal aortic aneurysm anatomy. J Vasc Surg 2011; 54: 616-27 


Chapter 5

\title{
A ruptured abdominal aortic
} aneurysm requiring preoperative cardiopulmonary resuscitation is not necessarily lethal

\author{
P.P.H.L. Broos \\ Y.W. 't Mannetje \\ M.J.A. Loos \\ M.R. Scheltinga \\ L.H. Bouwman \\ Ph.W.M. Cuypers \\ M.R.H.M. van Sambeek \\ J.A.W. Teijink
}




\section{Abstract}

Objective: A ruptured abdominal aortic aneurysm (RAAA) is associated with a high mortality rate. If cardiopulmonary resuscitation (CPR) is required prior to operative repair, mortality rates are said to approach $100 \%$. Aim of this multicenter, retrospective study was to study outcome in RAAA patients who required CPR prior to a surgical (endovascular or open) repair (CPR group). RAAA patients who did not need CPR served as controls (non-CPR group).

Methods: Over a five-year time period, demographics, clinical characteristics and specifics of preoperative CPR if necessary were studied in all patients who were treated for a RAAA in three large, non-academic hospitals.

Results: A total of 199 consecutive RAAA patients were available for analysis, 176 patients were surgically treated. Thirteen of these 176 patients $(7.4 \%)$ needed CPR, whereas 163 (92.6\%) did not. A 38.5\% (5/13) survival rate was observed in the CPR group. Thirty-day mortality was almost three times higher in the CPR group compared to the non-CPR group (resp. $61.5 \%$ vs. $22.7 \%, p=.005$ ). Both CPR patients receiving EVAR survived. In contrast, survival in $11 \mathrm{CPR}$ patients undergoing open RAAA repair was $27 \%(3 / 11, p=.128)$. A trend for higher Hardman index scores was found in CPR compared to non-CPR $(p=.052)$. The 30-day mortality in patients with a $0,1,2$ or 3 Hardman index was $16.1 \%, 31.0 \%, 37.9 \%$ and $33.3 \%$, respectively $(p=.093)$.

Conclusion: A RAAA requiring preoperative CPR is not necessarily a lethal combination. Patient selection must be tailored before surgery is denied. 


\section{Introduction}

Although healthcare has demonstrated substantial improvements over the past decades, mortality rates in populations with a ruptured abdominal aortic aneurysm (RAAA) remain invariably high. For instance, the estimated total mortality rate of

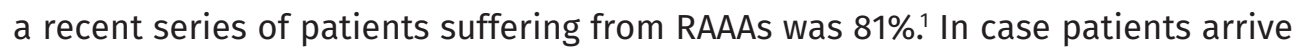
alive in the hospital and undergo emergent surgery, up to half will subsequently die in the perioperative period. ${ }^{2-4}$

Surgical outcome of RAAA may possibly improve if selection criteria for intervention are optimized. Scoring systems combining clinical findings and biochemical results were introduced for RAAA patients as a means to predict survival. One of these tools is the Hardman index that uses a set of five parameters. Although easily applicable, additional factors may also determine outcome. ${ }^{2}$ To date, not a single scoring system allows for a proper preoperative selection of candidates who might optimally benefit from vascular surgery for RAAA.

The necessity of preoperative cardiopulmonary resuscitation (CPR) reflects the dismal condition of a RAAA prior to an invasive procedure. Therefore, it is highly questionable whether RAAA patients requiring preoperative CPR should be offered surgical treatment at all. Previous publications on the matter show that after cardiac arrest there is a possibility of survival. ${ }^{5,6}$ However, a slim body of lowlevel literature are adamant that these patients are unlikely to survive. ${ }^{7-9}$ Senior authors of the present study have experienced that some patients may survive following the unfortunate combination of CPR prior to RAAA treatment.

Aim of the study was to evaluate clinical outcome in RAAA patients who received CPR prior to surgery (CPR). RAAA patients who did not need CPR served as controls (non-CPR). We also studied whether the Hardman index was of prognostic value in these resuscitated RAAA patients. 


\section{Methods}

\section{Patient population}

Consecutive patients registered with a RAAA (Dutch administrative code: DBC 406) between February 2009 and January 2014 were identified from hospital records of three large, non-academic teaching hospitals in the Netherlands. Inclusion criteria were RAAA and treatment using either endovascular aortic repair (EVAR) or open repair (OR). A RAAA was defined as a typical event of sudden severe abdominal pain in a patient having an aneurysm of the abdominal aorta and the presence of blood outside the adventitia of an aneurysmal abdominal aortic wall as determined using ultrasound (US). A contrast enhanced computed tomography angiography (CTA) was performed, if possible, to confirm the diagnosis and to allow for a precise treatment plan. Patients were excluded / not eligible if evidence of a rupture was lacking during OR. This retrospective study was conducted according to the Declaration of Helsinki and approved by local medical ethics committees. Patient informed consent was not required because this retrospective study did not involve medical treatment. Patient data were stored anonymously.

Patient data were collected through hospital, emergency department, and operation records. All patients were treated by or under the supervision of a consultant vascular surgeon. Type of operation (OR or EVAR) was left to the discretion of the surgeon. If the prognosis due to comorbidity was deemed exceedingly poor or if treatment options were limited, patients were managed conservatively following consultation in the presence of the patient and family.

\section{Definitions and outcomes}

Two patient populations were compared, a CPR and a non-CPR group. Cardiopulmonary resuscitation was defined as the combination of artificial respiration and heart massage by the exertion of pressure on the chest for at least a five-minutes period prior to the decision to institute invasive vascular surgery in a RAAA patient. A five-minute minimum was used to preclude the chance that an inadequate bystander reaction on loss of consciousness was registered as CPR. Whether the indication to initiate CPR was correct (type of cardiac arrest, e.g. ventricular fibrillation) was not the aim of our study, since we studied outcome 
after CPR (bystander, paramedic, in-hospital). We strived to answer the question whether CPR in itself was conditional for a surgeon to abstain from further action. The primary end-point was 30-day or in hospital mortality.

The Hardman Index was chosen for risk assessment. This tool was selected because it is easy to use in an emergency room setting as opposed to other scoring systems. It converts the presence/absence of 5 factors including age (>76 years), serum creatinine ( $>190 \mu \mathrm{mol} / \mathrm{L})$, hemoglobin $(<5.6 \mathrm{mmol} / \mathrm{L})$, loss of consciousness after arrival at the emergency department (ED) and electrocardiographic (ECG) signs of ischemia into a 0 to 5 point score. 2 We calculated the Hardman Index only in treated RAAA patients with available information regarding all five factors to avoid underscoring.

\section{Statistical analysis}

Statistical analyses were performed using SPSS version 21 for MAC (IBM Corporation, Armonk, NY, USA). Categorical variables are presented as frequencies with percentages. Continuous variables are presented as mean \pm standard deviation or as median and interquartile range (IQR) in case of skewed data. The $X^{2}$ or Fisher's exact test were used for categorical variables according to sample size. Incidence rates with $95 \%$ confidence intervals were determined. A P-value < 0.05 was considered statistically significant.

\section{Results}

A total of 199 consecutive RAAA patients were identified during the five-year period of interest. No surgical treatment was offered to 23 patients (11.6\%). Seven of these received prolonged CPR (>30 minutes) during transportation and/or during their stay in the ED. However, these efforts were in vain and they did not regain cardiac output. Sixteen additional patients received palliation, a vascular intervention, as considered by the attending vascular surgeon, was no option. Subjective reasons to deny invasive treatment in these patients were severe comorbidity and unfavorable vascular anatomy in patients who were physically not suitable to undergo OR. 
Table 1. Baseline characteristics, Hardman index score, 30-day mortality.

\begin{tabular}{|c|c|c|c|}
\hline \multirow{2}{*}{ Variables } & $\mathrm{CPR} \mathrm{N}=13$ & Non-CPR N=163 & \multirow{2}{*}{$p$-value } \\
\hline & $\%(n / N)^{a}$ & $\%(n / N)^{a}$ & \\
\hline Age (years) (Mean \pm SD) & $75.3 \pm 8.0$ & $74.2 \pm 8.0$ & .623 \\
\hline Male & $84.6 \%(11 / 13)$ & $85.3 \%(139 / 163)$ & $1.000^{b}$ \\
\hline Hemoglobin $(\mathrm{mmol} / \mathrm{L})$ & $7.0 \pm 1.4$ & $7.5 \pm 1.3$ & .199 \\
\hline Creatinine $(\mu \mathrm{mol} / \mathrm{L})$ & 102 [95 - 153] & $107[90-133]$ & .604 \\
\hline Hardman index score & & & $.052^{b}$ \\
\hline 0 & $0 \%(0 / 9)$ & $30.4 \%(31 / 102)$ & \\
\hline 1 & $33.3 \%(3 / 9)$ & $38.2 \%(39 / 102)$ & \\
\hline 2 & $44.4 \%(4 / 9)$ & $24.5 \%(25 / 102)$ & \\
\hline 3 & $22.2 \%(2 / 9)$ & $6.9 \%(7 / 102)$ & \\
\hline Treatment & & & .047 \\
\hline Open aneurysm repair & $84.6 \%(11 / 13)$ & $57.1 \%(92 / 163)$ & \\
\hline Endovascular aneurysm repair & $15.4 \%(2 / 13)$ & $42.9 \%(71 / 163)$ & \\
\hline 30-day mortality & $61.5 \%(8 / 13)$ & $22.7 \%(37 / 163)$ & $.005^{b}$ \\
\hline
\end{tabular}

a Values are reported as mean \pm standard deviation, median [Inter Quartile Range], or as frequencies $(\%)(n / N)$. Denominator differs when there are missing values.

${ }^{b}$ Fisher's exact test

In the remaining 176 patients (88.4\%), a treatment strategy consisting of controlled hypotension, medication and intravenous fluids followed by surgery was initiated. Temporary CPR prior to surgery was required in 13 patients (CPR group, 7.4\%) whereas 163 patients did not (non-CPR group, 92.6\%). There were no significant age and gender differences between these two groups (Table 1). One hundred and three open procedures (58.5\%) and 73 endovascular procedures (41.5\%) were performed (Table 2). 
Table 2. Outcome based on type of treatment.

\begin{tabular}{lccc}
\hline Variables & $\begin{array}{c}\text { OR N=103 } \\
\%(\mathrm{n} / \mathrm{N})\end{array}$ & $\begin{array}{c}\text { EVAR N=73 } \\
\%(\mathrm{n} / \mathrm{N})\end{array}$ & p-value \\
\hline Age (years) (Mean $\pm \mathrm{SD})$ & $73.9 \pm 8.0$ & $74.9 \pm 8.0$ & .430 \\
Gender & $85.4 \%(88 / 103)$ & $84.9 \%(62 / 73)$ & .926 \\
Cardiopulmonary resuscitation & $10.7 \%(11 / 103)$ & $4.1 \%(2 / 73)$ & .047 \\
Hardman index & & & $.503^{a}$ \\
0 & $26.6 \%(17 / 64)$ & $29.8 \%(14 / 47)$ & \\
1 & $35.9 \%(23 / 64)$ & $40.4 \%(19 / 47)$ & \\
2 & $31.3 \%(20 / 64)$ & $19.1 \%(9 / 47)$ & \\
3 & $6.3 \%(4 / 64)$ & $10.6 \%(5 / 47)$ & \\
30 -day mortality & $32.0 \%(33 / 103)$ & $16.4 \%(12 / 73)$ & .019 \\
\hline
\end{tabular}

OR, open aneurysm repair; EVAR, endovascular aneurysm repair a Fisher's exact test

There were more open procedures in the CPR group (11/13, 84.6\%) compared to the non-CPR group $(92 / 163,56.4 \%, p=.047)$. Table 3 depicts patient demographics and CPR characteristics including duration and adrenaline and atropine administration. The majority of patients were resuscitated in the hospital (10/13, 76.9\%). Median CPR duration was 20 (IQR 12.5 - 30) minutes. Table 3 also shows the lowest $\mathrm{pH}$, highest lactate levels and intraoperative required blood products. 
Table 3. Overview of patient characteristics, pre-operative status and follow-up of patients in the CPR-group.

\begin{tabular}{|c|c|c|c|c|c|c|c|c|}
\hline ID & $\begin{array}{c}\text { Gen- } \\
\text { der }\end{array}$ & $\begin{array}{c}\text { Age } \\
\text { (years) }\end{array}$ & $\begin{array}{c}\text { CPR } \\
\text { location }\end{array}$ & $\begin{array}{c}\text { CPR } \\
\text { duration }\end{array}$ & $\begin{array}{l}\text { Adrena- } \\
\text { line }\end{array}$ & Atropine & $\begin{array}{l}\text { Defibri } \\
\text { llation }\end{array}$ & $\begin{array}{c}\text { Performed } \\
\text { by }\end{array}$ \\
\hline 1 & $\mathrm{~F}$ & 76 & $\mathrm{ED} / \mathrm{OT}$ & 30 & NR & NR & NR & Doctor \\
\hline 2 & M & 66 & Ward/OT & $20 \mathrm{~min}$ & $1 \mathrm{mg}$ & None & NR & Doctor \\
\hline 3 & M & 69 & ED/OT & $5+25 \min$ & $13 \mathrm{mg}$ & None & $2 x$ & Doctor \\
\hline 4 & M & 79 & Home & 5 & None & None & NR & Bystander \\
\hline 5 & M & 78 & Ward & $5 \mathrm{~min}$ & None & None & NR & Nurse \\
\hline 6 & M & 85 & $\begin{array}{c}\text { Ambulanc } \\
\mathrm{e}\end{array}$ & NR & None & None & $1 \mathrm{x}$ & Paramedic \\
\hline 7 & M & 76 & ED & $5 \mathrm{~min}$ & NR & NR & NR & NR \\
\hline 8 & M & 78 & ED/OT & $\begin{array}{c}20+10 \\
\min \end{array}$ & $3 \mathrm{mg}$ & None & NR & Doctor \\
\hline 9 & M & 83 & ED & $30 \mathrm{~min}$ & NR & NR & NR & Doctor \\
\hline 10 & M & 82 & $\begin{array}{c}\text { Home/Am } \\
\text { bulance }\end{array}$ & 15 & None & None & NR & Bystander \\
\hline 11 & $F$ & 84 & Home/OT & $5+15 \min$ & NR & NR & NR & Paramedic \\
\hline 12 & M & 61 & ED & $30 \mathrm{~min}$ & $5 \mathrm{mg}$ & NR & NR & Doctor \\
\hline 13 & M & 63 & ED & $20 \mathrm{~min}$ & $5 \mathrm{mg}$ & NR & $3 x$ & Doctor \\
\hline
\end{tabular}

$N R$, not reported; F, female, $M$, male; ED, emergency department; OT, operating theatre; DNR, do not resuscitate.

\section{Hardman Index}

A full set of five variables was obtained and analyzed in 111 of 176 operated patients (63.1\%). Values of serum creatinine, loss of consciousness and ECG were missing in three $(1.7 \%)$, seven $(4.0 \%)$ and $63(35.8 \%)$ of the patients, respectively. No risk factor was present in 31 patients whereas 42 patients had one, 29 patients had two, nine patients had three; no patient possessed more than three risk factors. Hardman Index values were comparable between EVAR and OR patients ( $p=.503$ ). As expected, the CPR-group demonstrated a trend towards a higher Hardman index compared to non-CPR patients $(p=.052)$. 


\begin{tabular}{|c|c|c|c|c|}
\hline ID & Narrative & $\begin{array}{l}\text { Sur- } \\
\text { gery }\end{array}$ & $\begin{array}{c}\text { Survival } \\
\text { (days) }\end{array}$ & Status \\
\hline 1 & Regained blood pressure during aortic clamping. & OR & 20 & Dead \\
\hline 2 & CPR from ward to OT. & OR & 2092 & Alive \\
\hline 3 & $\begin{array}{l}\text { Regained output in ED after } 5 \text { minutes. In OT again arrhythmia. CPR } \\
\text { ceased after } 25 \text { minutes. }\end{array}$ & OR & 0 & Dead \\
\hline 4 & Regained output when ambulance arrived with RR 50/30. & OR & 1939 & Alive \\
\hline 5 & CPR started by nurse. & OR & 1 & Dead \\
\hline 6 & $\begin{array}{l}\text { Ventricular tachycardia for which defibrillation. Regained output } \\
\text { with RR } 70 / 60 \text { and } P 128 \text {. }\end{array}$ & EVAR & 1631 & Alive \\
\hline 7 & $\begin{array}{l}\text { Regained output, remained perioperative haemodynamically } \\
\text { unstable. }\end{array}$ & OR & 21 & Dead \\
\hline 8 & $\begin{array}{l}20 \text { minutes CPR in ED. In OT after aortic clamping } 10 \text { min CPR, } \\
\text { unsuccessful. }\end{array}$ & OR & 0 & Dead \\
\hline 9 & Cardiac arrest after CTA. & OR & 9 & Dead \\
\hline 10 & $\begin{array}{l}\text { Rib fractures with tension pneumothorax. Regained output in } \\
\text { ambulance. }\end{array}$ & OR & 1038 & Alive \\
\hline 11 & $\begin{array}{l}\text { Regained consciousness in ambulance. In OT } 15 \text { min CPR, however } \\
\text { ceased because of a DNR code. }\end{array}$ & OR & 0 & Dead \\
\hline 12 & After CTA cardiac arrest. & OR & 0 & Dead \\
\hline 13 & CPR in $\mathrm{CT}$ room, patient regained consciousness in OT. & EVAR & 432 & Alive \\
\hline
\end{tabular}

\section{Mortality}

CPR patients had an almost three times higher 30-day mortality rate compared to non-CPR patients (CPR 8/13, 61.5\% vs. non-CPR 37/163, 22.7\%, p = .005). The five surviving CPR patients were still alive, and lived independently, at the time of writing of this paper (March 2015) median 1631 days (IQR 735-2015, Table 3). Notably, thirty-day mortality was significantly lower for EVAR compared to OR across the entire population (EVAR $16.4 \%$ vs. OR $32.0 \%, p=.019$ ). Thirty-day mortality in the CPR group was zero in patients receiving EVAR $(n=2)$ compared to $73 \%$ in OR $(8 / 11$, $\mathrm{p}=.128)$. The overall mortality rates in groups with a 0, 1, 2 or 3 Hardman score were $16.1 \%, 31.0 \%, 37.9 \%$ and $33.3 \%$, respectively (Table 4 ). There was a tendency ( $p$ $=.093$ ) towards the presence of a higher Hardman index and mortality. 


\section{Discussion}

The ominous effect of cardiopulmonary resuscitation on survival in RAAA patients is hardly studied. Two studies reporting a $100 \%$ mortality rate in preoperatively resuscitated patients advocate that invasive treatment should be denied. ${ }^{7}, 9$ In contrast, a $67 \%$ and $72.8 \%$ 30-day mortality rates have been observed in patients with a RAAA requiring CPR. ${ }^{6,10}$ To our knowledge, this is the first multicenter-study describing survivors after resuscitation prior to RAAA surgery. As expected, the present study shows a substantially higher mortality rate in resuscitated RAAA patients (CPR $61.5 \%$ vs. non-CPR $22.7 \%, p=.005$ ). Conversely, the $38.5 \%$ survival rate in our CPR patients is not far removed from the $33 \%$ survival rate as reported by Crawford.10

The identification of people requiring out-of-hospital CPR is difficult if not impossible. As a consequence, timing and duration of CPR may not always be optimal.11 Although CPR might possibly be deemed unnecessary in retrospect by experts, a CPR notion prior to ED presentation may lead to a less objective and a less aggressive patient assessment, based on the premise that the combination CPR/ RAAA is always lethal. A recent report on palliated RAAA patients created a subgroup based on CPR indicating this as the main reason for palliation. ${ }^{2}$ In contrast, the current study demonstrates that $38.5 \%$ RAAA patient survived a period of CPR prior to surgery and should therefore be given a fair assessment.

Several explanations for increased survival rates following preoperative CPR in an RAAA population may be forwarded. Overall, improvements in preoperative management have reduced RAAA mortality rates in the last two decades.' A previous adage of aggressive fluid administration in a RAAA patient is replaced by the concept of permissive hypotension. In 1991, Crawford suggested that extensive volume resuscitation in RAAA promoted loss of whole blood and coagulation factors. In contrast, 'permissive' hypotension would reduce these losses thus increasing survival possibilities..$^{10}$ This concept is widely accepted and integrated in contemporary guidelines. ${ }^{13}$ Systolic blood pressures between 50 and $100 \mathrm{mmHg}$ are considered optimal if tolerated..$^{13}$ Survival is in part also determined by the experience of dedicated professionals. In the Netherlands, 
well-trained paramedics provide pre-hospital care. The application of permissive hypotension by Dutch ambulance staff in a retrospective study demonstrated an $81 \%$ adherence rate..$^{14}$ These modifications in preoperative patient management possibly have led to a better outcome.

The second major paradigm shift influencing outcome in RAAA is related to the vascular technique. Most modern vascular surgeons would contend that EVAR is the treatment of choice in elective AAA surgery..$^{15}$ With increased endovascular possibilities, experienced vascular centers have also adopted an 'EVAR first approach' for the treatment of RAAAs. In our study, not all three centers used an EVAR first approach at any time. However, an increase of endovascular repair over time was observed. Large efforts such as the IMPROVE and AJAX trial comparing EVAR to OR failed to demonstrate a beneficial effect of either technique on mortality rates. ${ }^{3,4}$ However, centers that introduced an EVAR first approach for RAAA did report improved overall mortality rates. ${ }^{16,17}$ The reduction in mortality is presumably related to reduced blood loss and less procedural time.4, 18 Moreover, emergency EVAR can be safely performed under local anesthesia in cooperative patients avoiding systemic cardiovascular depression associated with general anesthesia. ${ }^{19,20}$ In our total population the 30-day mortality based on treatment alone was significantly lower for EVAR compared to OR, respectively $16.4 \%$ vs. $32.0 \%$ $(p=.019)$. Of the treated patients, EVAR was performed in two patients requiring CPR (14.5\%) and in 71 (42.9\%) patients who did not. It is noteworthy that both CPR patients that underwent EVAR survived even though their parameters such as $\mathrm{pH}$, lactate and lowest blood pressure were poor (table 3). Therefore, endovascular repair is a feasible therapy, also in highly unstable patients. A recent study supports the contention that hemodynamically unstable RAAA patients possibly benefit from EVAR compared to OR as reflected by 30-day mortality rates. ${ }^{21}$

There are roughly two options in the management of hemodynamic unstable RAAA patients. Patients can be directly transported to the operating theatre to initiate OR, or they can undergo a CT scan allowing for a decision on EVAR or OR. When considering that aneurysm morphology is a predictor of mortality in EVAR and OR, a CTA is of the utmost importance in treatment selection. ${ }^{22}$ In specialized vascular centers, there is sufficient time to perform imaging and to assess EVAR 
suitability. ${ }^{23}$

Despite all of these considerations, RAAA mortality rates are exceedingly high. It is therefore important to study tools that allow for an improved selection of patients, preventing fruitless attempts and high costs. In the present study, 23 RAAA patients (11.6\%) did not receive invasive treatment (CPR $n=7$, non-CPR $n=16$ ). These patients were deemed inoperable or were deceased before surgery could be initiated. A turn down rate of $11.6 \%$ is low in comparison to previously reported rates of up to $40 \% .{ }^{24}$ Comparisons in RAAA care between the US and UK shows a very different palliation rate although treatment mortality rates are comparable. ${ }^{24}$ Although there is no obvious explanation for this difference, the results do underline the difficulty in selecting patients who benefit from surgical repair.

Various scoring systems to objectively identify high risk patients have been forwarded including the Glasgow Aneurysm Score (GAS), the VascularPhysiological and Operative Severity Score for enUmeration of Mortality and Morbidity (V-POSSUM), Vancouver scorings system and the Hardman Index.2, 25-27 The Hardman Index is a five-parameter tool that does not require calculations or knowledge of the patient's medical history and is therefore highly suitable in an emergency setting. It was previously found that mortality rates were $16 \%, 37 \%$, $72 \%$ and $100 \%$ in populations with a score of $0,1,2$ or 3 , respectively. ${ }^{2}$ Because the Hardman index is reasonably blunt, it is less capable of identifying individual high-risk patient. ${ }^{28,}{ }^{29}$ In the present study, the Hardman index was not a priori determined as a tool to preoperatively identify high-risk patients. After selection by the attending surgeon, the 30-day mortality rates of the entire population were $16.1 \%, 31.0 \%, 37.9 \%$ and $33.3 \%$ for a Hardman Index of respectively $0,1,2$ and 3 . These percentages indicate that experienced vascular surgeons are capable of selecting patients, even from a group regarded as high-risk patients. Therefore, a surgeon's experience and judgment should always outweigh a tool like the Hardman Index. In addition, an article by Cho et. al showed that CPR is not associated with an increased mortality rate. ${ }^{5}$ This underlines that tools like the Hardman Index and the notion of CPR should not be referred to as a reason for palliation, individual assessment is vital. 


\section{Study limitations}

The present study is a retrospective analysis with a limited sample size and therefore has its shortcomings. An unknown number of RAAA patients may have died before being correctly diagnosed so registration is possibly incomplete. Due to the urgent nature of a RAAA, documentation is sometimes limited. As a consequence, a substantial percentage of Hardman parameters are missing (36.9\%). The conclusions should be interpreted with caution due to the limited sample size. Nevertheless, these limitations do not affect the finding of the present study that a group of patients survived the combination of CPR and treatment for a RAAA as opposed to previous beliefs.

\section{Conclusion}

Patients with RAAAs who respond to CPR prior to emergency repair do have a chance of survival. Although CPR and a high Hardman Index are associated with a poor outcome, both parameters should not be used as an absolute criterion to deny surgical intervention in a patient with a RAAA. 


\section{References}

1. Reimerink JJ, van der Laan MJ, Koelemay MJ, Balm R, Legemate DA. Systematic review and metaanalysis of population-based mortality from ruptured abdominal aortic aneurysm. Br J Surg. 2013;100(11):1405-13.

2. Hardman DT, Fisher CM, Patel MI, Neale M, Chambers J, Lane R, et al. Ruptured abdominal aortic aneurysms: who should be offered surgery? J Vasc Surg. 1996;23(1):123-9.

3. Investigators IT, Powell JT, Sweeting MJ, Thompson MM, Ashleigh R, Bell R, et al. Endovascular or open repair strategy for ruptured abdominal aortic aneurysm: 30 day outcomes from IMPROVE randomised trial. BMJ. 2014;348:f7661.

4. Reimerink JJ, Hoornweg LL, Vahl AC, Wisselink W, van den Broek TA, Legemate DA, et al. Endovascular repair versus open repair of ruptured abdominal aortic aneurysms: a multicenter randomized controlled trial. Ann Surg. 2013;258(2):248-56.

5. Cho JS, Kim JY, Rhee RY, Gupta N, Marone LK, Dillavou ED, et al. Contemporary results of open repair of ruptured abdominal aortoiliac aneurysms: effect of surgeon volume on mortality. J Vasc Surg. 2008;48(1):10-7; discussion 7-8.

6. Gloviczki P, Pairolero PC, Mucha P, Jr., Farnell MB, Hallett JW, Jr., Ilstrup DM, et al. Ruptured abdominal aortic aneurysms: repair should not be denied. J Vasc Surg. 1992;15(5):851-7; discussion 7-9.

7. Greeven AP, Bouwman LH, Smeets HJ, van Baalen JM, Hamming JF. Outcome of patients with ruptured abdominal aortic aneurysm after cardiopulmonary resuscitation. Acta Chir Belg. 2011;111(2):78-82.

8. Urwin SC, Ridley SA. Prognostic indicators following emergency aortic aneurysm repair. Anaesthesia. 1999;54(8):739-44.

9. Johansen K, Kohler TR, Nicholls SC, Zierler RE, Clowes AW, Kazmers A. Ruptured abdominal aortic aneurysm: the Harborview experience. J Vasc Surg. 1991;13(2):240-5; discussion 5-7.

10. Crawford ES. Ruptured abdominal aortic aneurysm. J Vasc Surg. 1991;13(2):348-50.

11. White L, Rogers J, Bloomingdale M, Fahrenbruch C, Culley L, Subido C, et al. Dispatcher-assisted cardiopulmonary resuscitation: risks for patients not in cardiac arrest. Circulation. 2010;121(1):917.

12. van Beek SC, Vahl AC, Wisselink W, Balm R, Amsterdam Acute Aneurysm Trial C. Fate of patients unwilling or unsuitable to undergo surgical intervention for a ruptured abdominal aortic aneurysm. Eur J Vasc Endovasc Surg. 2015;49(2):163-5.

13. Moll FL, Powell JT, Fraedrich G, Verzini F, Haulon S, Waltham M, et al. Management of abdominal aortic aneurysms clinical practice guidelines of the European society for vascular surgery. Eur J Vasc Endovasc Surg. 2011;41 Suppl 1:S1-S58.

14. Reimerink JJ, Hoornweg LL, Vahl AC, Wisselink W, Balm R. Controlled hypotension in patients suspected of a ruptured abdominal aortic aneurysm: feasibility during transport by ambulance services and possible harm. Eur J Vasc Endovasc Surg. 2010;40(1):54-9. 
15. Paravastu SC, Jayarajasingam R, Cottam R, Palfreyman SJ, Michaels JA, Thomas SM. Endovascular repair of abdominal aortic aneurysm. Cochrane Database Syst Rev. 2014;1:CD004178.

16. Moore R, Nutley M, Cina CS, Motamedi M, Faris P, Abuznadah W. Improved survival after introduction of an emergency endovascular therapy protocol for ruptured abdominal aortic aneurysms. J Vasc Surg. 2007;45(3):443-50.

17. Arya N, Makar RR, Lau LL, Loan W, Lee B, Hannon RJ, et al. An intention-to-treat by endovascular repair policy may reduce overall mortality in ruptured abdominal aortic aneurysm. J Vasc Surg. 2006;44(3):467-71.

18. Peppelenbosch N, Geelkerken RH, Soong C, Cao P, Steinmetz OK, Teijink JA, et al. Endograft treatment of ruptured abdominal aortic aneurysms using the Talent aortouniiliac system: an international multicenter study. J Vasc Surg. 2006;43(6):1111-23; discussion 23.

19. Lachat ML, Pfammatter T, Witzke HJ, Bettex D, Kunzli A, Wolfensberger U, et al. Reprinted article "Endovascular repair with bifurcated stent-grafts under local anaesthesia to improve outcome of ruptured aortoiliac aneurysms”. Eur J Vasc Endovasc Surg. 2011;42 Suppl 1:S86-93.

20. Ellard L, Djaiani G. Anaesthesia for vascular emergencies. Anaesthesia. 2013;68 Suppl 1:72-83.

21. Gupta PK, Ramanan B, Engelbert TL, Tefera G, Hoch JR, Kent KC. A comparison of open surgery versus endovascular repair of unstable ruptured abdominal aortic aneurysms. J Vasc Surg. 2014;60(6):1439-45.

22. Investigators IT. The effect of aortic morphology on peri-operative mortality of ruptured abdominal aortic aneurysm. Eur Heart J. 2015.

23. Boyle JR, Gibbs PJ, Kruger A, Shearman CP, Raptis S, Phillips MJ. Existing delays following the presentation of ruptured abdominal aortic aneurysm allow sufficient time to assess patients for endovascular repair. Eur J Vasc Endovasc Surg. 2005;29(5):505-9.

24. Karthikesalingam A, Holt PJ, Vidal-Diez A, Ozdemir BA, Poloniecki JD, Hinchliffe RJ, et al. Mortality from ruptured abdominal aortic aneurysms: clinical lessons from a comparison of outcomes in England and the USA. Lancet. 2014;383(9921):963-9.

25. Samy AK, Murray G, MacBain G. Glasgow aneurysm score. Cardiovasc Surg. 1994;2(1):41-4.

26. Prytherch DR, Ridler BM, Beard JD, Earnshaw JJ, Audit, Research Committee TVSSoGB, et al. A model for national outcome audit in vascular surgery. Eur J Vasc Endovasc Surg. 2001;21(6):477-83.

27. Chen JC, Hildebrand HD, Salvian AJ, Taylor DC, Strandberg S, Myckatyn TM, et al. Predictors of death in nonruptured and ruptured abdominal aortic aneurysms. J Vasc Surg. 1996;24(4):614-20; discussion 21-3.

28. Tambyraja AL, Murie JA, Chalmers RT. Prediction of outcome after abdominal aortic aneurysm rupture. J Vasc Surg. 2008;47(1):222-30.

29. Acosta S, Ogren M, Bergqvist D, Lindblad B, Dencker M, Zdanowski Z. The Hardman index in patients operated on for ruptured abdominal aortic aneurysm: A systematic review. J Vasc Surg. 2006;44(5):949-54. 



\section{Abstract}

Objectives: To compare the midterm results of endovascular aortic aneurysm repair (EVAR) for ruptured abdominal aortic aneurysms (RAAAs) in patients with favourable aortic neck anatomy (FNA) and hostile aortic neck anatomy (HNA).

Methods: Patients treated for a RAAA in a high-volume endovascular centre in the Netherlands between February 2009 and January 2014 were retrospectively identified and divided into two groups based on aortic neck anatomy, FNA and HNA. HNA was defined as RAAA with a proximal neck of $<10 \mathrm{~mm}$, or a proximal neck of $10-15 \mathrm{~mm}$ with a suprarenal angulation $(\alpha)>45^{\circ}$ and/or an infrarenal angulation $(\beta)>60^{\circ}$, or a proximal neck of $>15 \mathrm{~mm}$ combined with $\alpha>60^{\circ}$ and/or $\beta>75^{\circ}$. Patient demographics, procedure details, 30-day and one-year outcomes were recorded.

Results: Of 39 included patients, 17 (44\%) had HNA. Technical success was $100 \%$ for FNA and $88 \%$ for HNA ( $p=.184)$. There were no type IA endoleaks at completion angiography in either group, however more adjunctive procedures were necessary for intraoperative type IA endoleaks in the HNA group ( $24 \%$ vs. $0 \%, p=.029$ ). Thirtyday mortality rates were comparable, FNA $14 \%$ vs. HNA $12 \%, p=1.000$. There were no statistically significant differences at one-year follow up in type I endoleaks, secondary endovascular procedures, and all-cause mortality.

Conclusions: In our experience, emergency EVAR provided excellent results for the treatment of RAAA patients with both FNA and HNA. EVAR in RAAAs with HNA is technically feasible and safe in experienced endovascular centres. anatomy is technically feasible and safe in experienced hands. 


\section{What this paper adds}

Patients with a ruptured AAA are often excluded for EVAR based on aortic morphology. This paper evaluates technical and clinical outcome of emergency EVAR in patients with hostile infrarenal aortic neck anatomy and reports excellent results, suggesting that emergency EVAR in ruptured AAA with hostile aortic neck anatomy is technically feasible and safe in experienced hands.

\section{Introduction}

A ruptured abdominal aortic aneurysm (RAAA) is fatal without emergency surgical intervention. The first report of a successful endovascular treatment of RAAA was published in 1994. ${ }^{1}$ With doctors becoming more experienced in endovascular techniques and due to the improved availability of off-the-shelf endografts, an increasing number of RAAA patients undergo endovascular treatment. Endovascular aneurysm repair (EVAR) might improve short-term survival rates of RAAA patients compared to traditional open surgical repair (OR). ${ }^{2}$ The implementation of an EVAR-first strategy for RAAAs in experienced centres shows an improved clinical outcome. ${ }^{3}$ However, according to the best available data, the IMPROVE trial, the AJAX trial and a recent meta-analysis, there is no significant difference in shortterm survival rates between EVAR and OR.4-6

The choice between OR and EVAR is based on operator preference, patient characteristics and anatomic suitability. Anatomic suitability is defined in the instructions for use (IFU) of each endograft. With the evolution of endografts, the anatomic suitability for EVAR increased from $20 \%$ to approximately $46-64 \%$ with current devices. ${ }^{4,5,7}$ Unfavourable anatomy of the aneurysm and adverse anatomic characteristics of the aortic neck could be predictors of poorer short-term outcomes.8 However, in experienced endovascular centres, an increasing number of patients with an abdominal aortic aneurysm (AAA) are treated outside the IFU. In our experience, this certainly includes RAAAs.

This study aimed to compare the 1-year results of EVAR for RAAA patients with favourable aortic neck anatomy (FNA) and hostile aortic neck anatomy (HNA). 


\section{Methods}

\section{Patient selection}

Patients with a proven RAAA were retrospectively identified based on the Dutch administrative code for RAAA (406) in the hospital records of a large, tertiary referral centre for cardiovascular disease in the Netherlands. Patients were included for this analysis if the RAAA had been treated by means of EVAR between February 2009 and January 2014. A RAAA was defined as bleeding outside the adventitia of a dilated aortic wall. The diagnosis of a ruptured AAA was based on clinical findings, an ultrasound (US) in the emergency department, followed by a contrast-enhanced computed tomography angiography (CTA) to confirm the diagnosis and allow for precise treatment planning. Patients were excluded if there was no evidence of a rupture. Patients who underwent previous EVAR or OR were also excluded.

Patients' clinical status, medical history, treatment and follow-up data were collected through hospital, emergency department and operation records.

\section{Patient management}

All patients were treated by (or under the supervision of) an experienced endovascular surgeon. The type of treatment (OR or EVAR) was left to the discretion of the surgeon, though under an EVAR-first strategy. All patients scheduled for endovascular treatment underwent preoperative CTA to determine baseline aortic and aneurysmal dimensions. Both bifurcated and aorto-uni-iliac (AUI) devices were used, including Endurant (Medtronic Vascular, Santa Rosa, CA, USA) and Excluder (W.L. Gore and Associates, Flagstaff, Ariz, USA). All endografts were implanted through the common femoral artery via a transverse surgical cutdown.

If the prognosis due to comorbidity was exceedingly poor or if treatment options were limited, patients were palliated. Standard follow-up of treated RAAA patients was performed at one month with a CTA scan, and yearly thereafter with CTA or duplex ultrasound. 


\section{Anatomic evaluation}

Two trained researchers independently and blinded for treatment outcome, reviewed all available preoperative CTAs. Measurements were made using dedicated three-dimensional (3D) sizing software (3mensio; 3mensio Vascular; Bilthoven, The Netherlands). Central lumen line (CLL) was generated manually. Measurements were taken perpendicular to the CLL, and suprarenal and infrarenal angulations were determined according to the method described by Van Keulen et al..9 In case of a discrepancy of more than two millimetres neck length or five degrees angulation, consensus was obtained by consultation of one of the endovascular surgeons. A common iliac artery (CIA) with a diameter $\geq 17 \mathrm{~mm}$ in males or $\geq 15 \mathrm{~mm}$ in females was considered aneurysmal.10

\section{Definitions and outcomes}

For this study we divided our cohort of patients into two groups based on infrarenal aortic neck anatomy. FNA was defined as RAAAs with a proximal neck of $\geq 15 \mathrm{~mm}$ combined with a suprarenal angulation $(\alpha) \leq 60^{\circ}$ and an infrarenal angulation $(\beta)$ $\leq 75^{\circ}$ or defined as a proximal neck of $\geq 10 \mathrm{~mm}$ combined with $\alpha \leq 45^{\circ}$ and $\beta \leq 60^{\circ}$. HNA was defined as RAAAs with a proximal neck of $<10 \mathrm{~mm}$, or a proximal neck of $10-15 \mathrm{~mm}$ with $\alpha>45^{\circ}$ and $/$ or $\beta>60^{\circ}$, or a proximal neck of $>15 \mathrm{~mm}$ combined with $\alpha>60^{\circ}$ and $/$ or $\beta>75^{\circ}$. The limits correspond with the instructions for use (IFU) for the Endurant stent graft.

Technical success was defined as successful delivery and deployment of the endograft, without unintentional coverage of renal or visceral arteries, followed by successful removal of the delivery system, and the absence of either a type I or III endoleak. Completion angiography was performed to document any possible endoleaks and other endograft-related complications. The duration of procedure was defined as the time between arterial cut down and closure. Thirty-day and one-year outcomes included endograft-related complications, mortality rates, and need for secondary interventions. Significant migration was defined as a displacement of the endograft of $\geq 10 \mathrm{~mm}$. There was no loss to follow-up at oneyear. 


\section{Statistical analysis}

Statistical analyses were performed using SPSS version 21 for MAC (IBM Corporation, Armonk, NY, USA). Categorical variables are presented as frequencies with percentages. The $\chi^{2}$ or Fisher's exact test were used for categorical variables depending on sample size. Continuous variables are presented as mean \pm standard deviation (SD) or as median and interquartile range (IQR) in case of skewed data. Mean differences were assessed using independent group t-tests and median differences were assessed using Mann-Whitney $U$ tests. A p-value $<.05$ was considered statistically significant. A per protocol analysis was performed for the technical endograft-related observations. All other variables were evaluated on an intention-to-treat basis. Missing values were excluded for analysis. Followup data were analysed by Kaplan-Meier life-table analysis and the log-rank test.

\section{Results}

\section{Patients}

A total of 69 patients presented with a RAAA at our emergency department between February 2009 and January 2014. Six patients were rejected for surgery based on extensive co-morbidities and 4 did not regain cardiac output after cardiopulmonary resuscitation. Of the 59 patients that underwent an intervention, 12 patients (20\%) underwent OR. Primary reason for OR was the presence of a juxtarenal aneurysm. The remaining 47 patients (80\%) underwent EVAR; 8 of these patients were excluded because they had a secondary rupture after previous AAA repair (5 OR and 3 EVAR). The remaining 39 patients were included in the present study. The FNA group consisted of 22 patients (56\%), and the remaining 17 patients (44\%) were assigned to the HNA group. 
Table 1. Patient demographics and risk factors by neck anatomy.

\begin{tabular}{lccc}
\hline Variables & FNA $(\mathrm{N}=22)^{\mathrm{a}}$ & HNA $(\mathrm{N}=17)^{\mathrm{a}}$ & $p$-value \\
\hline Age, years & $72.6 \pm 8.2$ & $75.6 \pm 6.5$ & $.230^{b}$ \\
Female & $18 \%(4 / 22)$ & $18 \%(3 / 17)$ & $1.000^{c}$ \\
Admission data & & & \\
$\quad$ Pulse (beats per minute) & $85 \pm 21$ & $79 \pm 13$ & $.378^{b}$ \\
Blood pressure (mmHg) & & & \\
$\quad$ Systolic & $112 \pm 29$ & $114 \pm 37$ & $.920^{b}$ \\
$\quad$ Diastolic & $69 \pm 19$ & $67 \pm 21$ & $.843^{b}$ \\
Haemoglobin (mmol/L) & $7.3 \pm 1.2$ & $7.0 \pm 1.4$ & $.589^{b}$ \\
Creatinine ( $\mu$ mol/L) & $115(82-130)$ & $110(98-38)$ & $.573^{d}$ \\
Risk factors & & & $.477^{c}$ \\
Tobacco use & $22 \%(4 / 18)$ & $35 \%(6 / 17)$ & $.706^{c}$ \\
Hypertension & $79 \%(15 / 19)$ & $71 \%(12 / 17)$ & $.637^{e}$ \\
Hypercholesterolemia & $67 \%(12 / 18)$ & $59 \%(10 / 17)$ & $1.000^{c}$ \\
Diabetes & $11 \%(2 / 18)$ & $6 \%(1 / 17)$ & $.603^{c}$ \\
Cancer & $17 \%(3 / 18)$ & $6 \%(1 / 17)$ & $.890^{e}$ \\
Cardiac disease & $39 \%(7 / 18)$ & $41 \%(7 / 17)$ & $.443^{c}$ \\
Pulmonary disease & $17 \%(3 / 18)$ & $29 \%(5 / 17)$ & $1.000^{c}$ \\
Renal insufficiency & $6 \%(1 / 18)$ & $6 \%(1 / 17)$ & \\
\hline
\end{tabular}

a Values are reported as mean \pm standard deviation, median and interquartile range (IQR) or as frequencies $(\%)(n / N)$.

${ }^{b}$ T-test

'Fisher's Exact test

d Kruskal-Wallis test

e Pearson Chi-Square

Denominator differs when there are missing values.

\section{Preoperative clinical and anatomic features}

Demographic data, haemodynamic status, serum creatinine, haemoglobin, and baseline risk factors of the study groups are outlined in Table 1. There were no significant differences in age, gender, haemodynamic stability and risk factors. Mean preoperative AAA measurements are listed in Table 2. The HNA group tended to have a larger maximum AAA diameter (HNA $86 \pm 15 \mathrm{~mm}$ vs. FNA $70 \pm 18 \mathrm{~mm}, \mathrm{p}=$ .004). The shortest proximal neck was $4 \mathrm{~mm}$ and the largest $\alpha$ and $\beta$ were $85^{\circ}$ and $90^{\circ}$, respectively. In the HNA group, seven (41\%) patients had a proximal aortic neck length $<10 \mathrm{~mm}$, seven (41\%) patients had a suprarenal angulation $>60^{\circ}$, and $11(65 \%)$ patients had an infrarenal angulation $>75^{\circ}$. 
Table 2. Baseline aneurysm characteristics by neck anatomy.

\begin{tabular}{lccc}
\hline Variable & FNA $(\mathrm{N}=22)^{\mathrm{a}}$ & HNA $(\mathrm{N}=17)^{\mathrm{a}}$ & $\mathrm{p}$-value \\
\hline Suprarenal angulation $(\alpha)$, degrees & $27 \pm 17$ & $47 \pm 19$ & $.002^{c}$ \\
Infrarenal angulation $(\beta)$, degrees & $50 \pm 15$ & $73 \pm 16$ & $<.001^{c}$ \\
Neck length, mm & $35 \pm 14$ & $22 \pm 16$ & $.016^{c}$ \\
Neck diameter, mm & $23 \pm 4$ & $22 \pm 4$ & $.595^{c}$ \\
Maximum AAA diameter, mm & $70 \pm 17$ & $86 \pm 15$ & $.004^{c}$ \\
Right iliac diameter, mm & $22 \pm 18$ & $16 \pm 5$ & $.184^{c}$ \\
Left iliac diameter, mm & $19 \pm 9$ & $17 \pm 8$ & $.639^{c}$ \\
Right femoral diameter, mm & $10 \pm 4$ & $9 \pm 2$ & $.144^{c}$ \\
Left femoral diameter, mm & $10 \pm 2$ & $9 \pm 2$ & $.356^{c}$ \\
Iliac aneurysm & $55 \%(12 / 22)$ & $35 \%(6 / 17)$ & $.232^{d}$ \\
\hline
\end{tabular}

a Values are reported as mean \pm standard deviation or as frequencies $(\%)(n / N)$.

${ }^{b}$ Abdominal aortic aneurysm

c T-test

d Pearson Chi-Square

\section{Intraoperative results}

Operation time was significantly longer for HNA (HNA 122 (IQR 88-179) mins vs. FNA 87 (IQR 65-104) mins $p=.021$ ). There was trend of implanting more AUI devices in HNA patients however not significantly different (Table 3). No endograft was implanted in one HNA patient because of iliac access difficulties. Due to severe co-morbidities, this patient was not converted to open surgery and died within 24 hours. Intraoperative type IA endoleaks were more frequent in the HNA group. However, all endoleaks were addressed and resolved during the initial procedure. All intraoperative endoleaks required the use of a balloon-expandable stent and in one patient an extension cuff was added. Unintentional overstenting of both renal arteries occurred in one HNA patient. A hepatorenal bypass was performed to preserve blood flow to one kidney. Technical success was $100 \%(22 / 22)$ for FNA and $88 \%(15 / 17)$ for HNA $(p=.184)$. Two FNA patients $(9 \%)$ and two HNA patients (12\%) died within 24 hours after surgery. 
Table 3. Initial procedural data and evaluation by neck anatomy.

\begin{tabular}{lccc}
\hline Variable & FNA (N =22) & HNA (N =17) & $p$-value \\
\hline Duration of procedure (mins) & $87(65-104)$ & $122(88-179)$ & $.021^{\mathrm{a}}$ \\
Anaesthesia used & & & $.584^{d}$ \\
$\quad$ General & $50 \%(11 / 22)$ & $59 \%(10 / 17)$ & \\
$\quad$ Local or Regional & $50 \%(11 / 22)$ & $41 \%(7 / 17)$ & $.147^{e}$ \\
Configuration endograft & & & \\
$\quad$ Bifurcated & $95 \%(21 / 22)$ & $76 \%(13 / 17)$ & \\
AUI & $5 \%(1 / 22)$ & $24 \%(4 / 17)$ & $1.000^{e}$ \\
Device name & & & \\
Endurant & $95 \%(21 / 22)$ & $100 \%(17 / 17)$ & \\
$\quad$ Excluder & $5 \%(1 / 22)$ & $0 \%(0 / 17)$ & $.029^{e}$ \\
Adjunctive procedures & & & $.436^{e}$ \\
$\quad$ Resolve endoleak type IA & $0 \%(0 / 22)$ & $24 \%(4 / 17)$ & - \\
$\quad$ Resolve endoleak type III & $0 \%(0 / 22)$ & $6 \%(1 / 17)$ & - \\
Completion angiography & & & \\
$\quad$ Endoleak type IA & $0 \%(0 / 22)$ & $0 \%(0 / 17)$ & $.436^{e}$ \\
Endoleak type III & $0 \%(0 / 22)$ & $0 \%(0 / 17)$ & \\
Unintentional overstenting of renal artery & $0 \%(0 / 22)$ & $6 \%(1 / 17)$ & $.184^{e}$ \\
Basic outcome & & & $.436^{e}$ \\
$\quad$ Technical success & $100 \%(22 / 22)$ & $88 \%(15 / 17)$ & - \\
$\quad$ No implant & $0 \%(0 / 22)$ & $6 \%(1 / 17)$ & $1.000^{e}$ \\
Conversion to open surgery & $0 \%(0 / 22)$ & $0 \%(0 / 17)$ & \\
Dead within 24 hours & $9 \%(2 / 22)$ & $12 \%(2 / 17)$ & \\
\hline
\end{tabular}

a Values are reported as median and interquartile range (IQR) or as frequencies (\%) $(\mathrm{n} / \mathrm{N})$.

${ }^{\mathrm{b}}$ Aorto-uni-iliac

c Kruskal-Wallis test

d Pearson Chi-square

e Fisher's Exact test

\section{Thirty-day outcome}

Within 30 days after implant, 3 FNA patients (13\%) died, versus 2 HNA patients $(12 \%, p=1.000)$, including the direct postoperative deaths. One-month imaging was performed in 33 implanted patients (85\%), one patient was diagnosed with metastasised cancer therefore no follow-up was planned. Table 4 presents the 30-day clinical and technical outcomes. One FNA patient developed a type IA endoleak on postoperative day one, which required open surgical correction. Unfortunately, the patient died during this procedure. One HNA patient was converted to open repair due to an AAA re-rupture based on a type IA endoleak on postoperative day three. One type IB endoleak was reported in an HNA patient, requiring an extension cuff just to the level of the hypogastric artery. An endograft limb occlusion was observed in an FNA patient, which was corrected by converting the bifurcated graft to an AUI graft in combination with a femoro-femoral bypass. 
A total of four HNA patients (24\%) versus zero FNA patients developed an abdominal compartment syndrome, which required decompression laparotomy $(p=.029)$.

Table 4. Patient outcome within 30-days by neck anatomy.

\begin{tabular}{lccc}
\hline Variable & FNA (N = 22) & HNA (N = 17) & p-value \\
\hline Technical outcome $^{\mathrm{b}}$ & & & \\
Endoleak type IA & $5 \%(1 / 19)$ & $7 \%(1 / 14)$ & 1.000 \\
Endoleak type IB & $0 \%(0 / 19)$ & $7 \%(1 / 14)$ & .424 \\
Endoleak type III & $0 \%(0 / 19)$ & $0 \%(0 / 14)$ & - \\
Endograft occlusion & $5 \%(1 / 19)$ & $0 \%(0 / 14)$ & 1.000 \\
Endograft migration & $0 \%(0 / 19)$ & $0 \%(0 / 14)$ & - \\
Clinical outcome & & & \\
Secondary surgical procedures & & & \\
$\quad$ Endovascular procedure & $5 \%(1 / 22)$ & $6 \%(1 / 17)$ & 1.000 \\
$\quad$ Laparotomy for ACS & & $24 \%(4 / 17)$ & .029 \\
Conversion to open surgery & $0 \%(0 / 22)$ & $6 \%(1 / 17)$ & 1.000 \\
Aneurysm rupture & $5 \%(1 / 22)$ & $6 \%(1 / 17)$ & .421 \\
All-cause mortality & $0 \%(0 / 22)$ & $12 \%(2 / 17)$ & 1.000 \\
\hline
\end{tabular}

a Values are reported as frequencies $(\%)(n / N)$.

b Per protocol analysis. Only patients with 30-day imaging were included in the analysis.

c Intention-to-treat analysis. All patients were included in the analysis.

d Abdominal compartment syndrome

e Fisher's Exact test

\section{One-year outcome}

One-year imaging was available for 28 (72\%) patients. No new type I endoleaks were reported in either group. One FNA patient developed a type III endoleak, which was endovascularly corrected with an interposition graft. Freedom from device-related secondary interventions at 1 year was comparable between groups (FNA 85\% vs. HNA 87\%, $p=.962$, Figure 1). In addition, there were no significant differences in estimated freedom from all-cause mortality (FNA 77\% vs. HNA $65 \%, p=.413$, Figure 2). Within 1-year four HNA patients died (urosepsis, sepsis of unknown origin, cardiac, incarcerated femoral hernia). In the FNA group two patients died (metastasised cancer, pulmonary insufficiency). In all patients there were no stent graft related complications. 
Table 5. Patient outcome at 1-year by neck anatomy

\begin{tabular}{lllc}
\hline Variable & FNA (N = 22) & HNA $(\mathrm{N}=17)^{\mathrm{a}}$ & -value $^{\mathrm{c}}$ \\
\hline Endograft related complications $^{\mathrm{b}}$ & & & \\
$\quad$ Endoleak type IA & $0 \%(0 / 16)$ & $0 \%(0 / 12)$ & - \\
Endoleak type IB & $0 \%(0 / 16)$ & $0 \%(0 / 12)$ & - \\
Endoleak type III & $6 \%(1 / 16)$ & $0 \%(0 / 12)$ & 1.000 \\
Endograft occlusion & $0 \%(0 / 16)$ & $0 \%(0 / 12)$ & - \\
Endograft migration & $0 \%(0 / 16)$ & $0 \%(0 / 12)$ & - \\
\hline
\end{tabular}

a Values are reported as frequencies $(\%)(n / N)$.

b Per protocol analysis. Only patients with 1-year imaging were included in the analysis.

c Fisher's Exact test

Figure 1. Kaplan-Meier curves representing the 1-year freedom from device-related secondary interventions. Log-rank, p = .962.

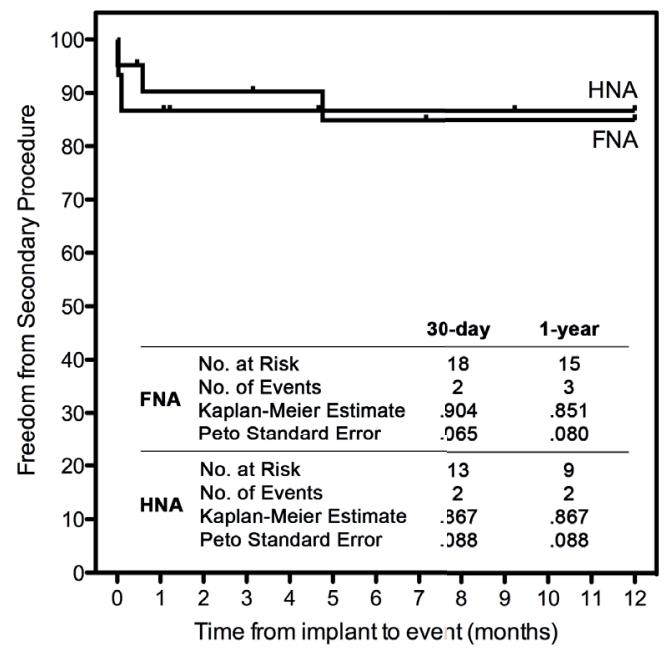


Figure 2. Kaplan-Meier curves representing the 1-year freedom from all-cause mortality. Log-rank, $p=.413$.

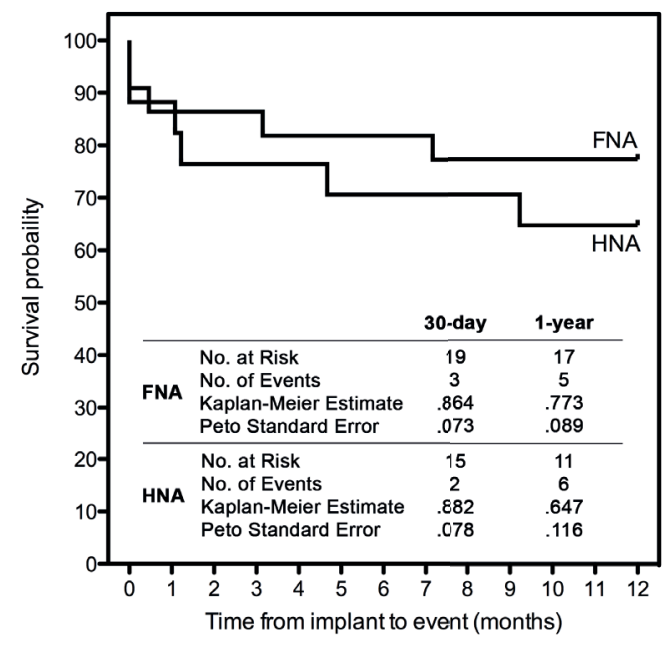

\section{Discussion}

To the best of our knowledge, this is the first report that evaluates the outcomes of EVAR in RAAAs with hostile aortic neck anatomy. We report encouraging results with no differences in clinical and technical outcomes between FNA and HNA patients.

Mortality is of the utmost importance in the discussion whether patients with hostile anatomical features should be treated with EVAR. In our study, following an EVAR-first strategy, the overall 30-day or in-hospital mortality was $13 \%$. This is in line with reports showing an improvement in 30-day mortality in various centres that changed from an OR-first to an EVAR-first approach. ${ }^{11}$ When taking aneurysm morphology into account it has been shown that especially short infrarenal neck length influences mortality, as it does in OR.12 in OR this is most likely caused by the need for high cross-clamping, impairing circulation of the visceral arteries. In our study the mortality rates were not influenced by the suitability for EVAR (FNA $14 \%$ vs. HNA $12 \% p=1.000$ ). This supports our view that patients should not be denied endovascular surgery based on hostile anatomical features alone. Especially when considering that data on emergency EVAR in HNA are limited and 
OR in this population shows no survival benefit. ${ }^{12}$

In our study, 44\% of patients undergoing EVAR had HNA. This is in contrast with reports estimating that $17 \%$ to $30 \%$ of elective patients are treated outside IFU. ${ }^{13}$, ${ }^{14}$ Anatomic unsuitability for EVAR remains one of the main reasons to treat AAAs via open surgery, and there have been reports stating that up to $80 \%$ of RAAAs are regarded as not suitable for EVAR. ${ }^{7}$ However, unsuitability is based on preclinically obtained test data and defined by the manufacturer. With increasing experience, off-label use of several stent grafts has become widely accepted in elective surgery.

The discrepancy between our results and previous reports on suitability can partly be explained by the fact that juxtarenal AAAs underwent OR and were not included in this analysis. However, this does not account for the difference between elective and emergency EVAR. One reason for the high number of patients treated with HNA can be the diameter of the AAA. In this study, the mean AAA diameter was significantly larger for HNA patients. Besides increasing the risk of a rupture, a large AAA diameter may also negatively influence infrarenal neck length or shape, or both, which can result in a higher percentage of RAAAs regarded as unsuitable for EVAR.7 Although our study shows no difference at 1-year between HNA and FNA, the larger AAA diameter could attribute to a higher reintervention rate at longterm follow-up as has been previously described..$^{15}$

Our results did show a significantly higher rate of adjunctive procedures for intraoperative type IA endoleaks in HNA patients. Comparable results can be found in studies reporting the outcome of EVAR in elective AAA patients with hostile infrarenal necks. A recent meta-analysis of these studies also concluded that patients with hostile neck anatomy required significantly more adjunctive procedures to resolve intraoperative type IA endoleaks (FNA 9\% vs. HNA 22\%, $p<$ .001).${ }^{16}$ Remarkably, however, our study reported a comparable rate of adjunctive procedures of $24 \%$ in HNA patients, even though there was notably less time for procedure planning compared to elective surgery. This indicates that emergency planning by an experienced vascular surgeon was adequate, and did not lead to an increased need for adjunctive procedures. 
Although EVAR requires a lifelong follow-up and has an increased secondary intervention rate compared to OR, we found no differences in the need for secondary interventions between HNA and FNA within one-year. This finding is in line with previous reports on AAAs with challenging aortic necks treated with comparable devices in an elective setting. ${ }^{17-19}$ This implies that the need for secondary interventions within one year of follow-up was not influenced by the emergency setting and the higher number of adjunctive procedures in our study.

A marked advantage of EVAR is that its physiological impact is notably reduced compared to OR, due to the possibility of local anaesthesia and the avoidance of aortic cross clamping. A recent study by Gupta et al. supports this theory with an improved mortality in unstable patients who received EVAR. ${ }^{20}$ On the other hand, the AJAX-trial and IMPROVE-trial did not show any significant differences in 30day mortality between EVAR and OR. ${ }^{4,5}$ However, it should be noted that these two randomised trials reported only on a selected group of patients with RAAA and are not necessarily generalizable to the general population. Moreover, the nature of these trials did not permit surgeons to perform the procedure they personally prefer.

While our study suggests that a hostile infrarenal neck is not necessarily a reason for OR, there are limitations to the use of a 'regular' endograft, depending on the extent of neck hostility. Several techniques have been developed to increase EVAR suitability, one of which is the chimney technique introduced by Greenberg et al.. ${ }^{21}$ This is a cheap and readily available procedure and therefore ideal for RAAAs. However, evidence is scarce and consists of small studies, case reports without long-term follow-up. ${ }^{22}$

Even without advanced techniques, we reported a low percentage (14\%) of RAAA patients rejected for intervention. This finding may inform the debate on rejection for repair, which is considered to be subject to many influencing factors. In current literature, rejection rates vary greatly between centres and countries, ranging from $20 \%$ to up to $42 \% .{ }^{23}$ These differences arise because a large variation of criteria is used to decide whether or not to operate on a patient. Some of the patients are rejected for any form of surgery because anatomy does not allow EVAR and co- 
morbidity precludes OR.

In our hospital, treatment decisions are based on a multitude of anatomical and patient characteristics. Therefore, our patient sample ranges from small haemodynamically stable retroperitoneal haemorrhaging to large free intraperitoneal ruptures. While open surgery is probably lethal in the latter patients, they may potentially survive EVAR in combination with optimized inhospital logistics (availability of preoperative $\mathrm{CT}$, an experienced endovascular team and immediate availability of a variety of endografts) and the use of permissive hypotension. ${ }^{3}$

In clinical practice, a CT scan is essential, even in an emergency setting, to determine the best surgical care and to make a substantiated decision to perform open or endovascular surgery. A previous study suggests that, in a majority of RAAA patients, there is enough time to obtain CT imaging, assess AAA morphology and EVAR suitability, and transfer the patient to the operating theatre. ${ }^{24}$

\section{Study limitations}

This study is limited by the small sample size and the single-centre design. Due to the low rate of complications, modern stent grafts require a larger patient sample to detect significant differences. We described the results of emergency EVAR in a hospital with three vascular surgeons performing over 100 EVARs annually. Our results may not be generalizable to centres with less experience in EVAR. Further prospective studies, with a larger group of patients, and longer follow-up are necessary to evaluate the safety and durability of EVAR in patients with RAAAs and hostile infrarenal aortic neck anatomy.

\section{Conclusion}

EVAR in RAAAs with hostile infrarenal aortic necks appears technically feasible and safe in experienced hands. Endograft-related complication rates and secondary intervention rates were not significantly higher in RAAA patients with HNA at 1-year. 


\section{References}

1. Yusuf SW, Whitaker SC, Chuter TA, Wenham PW, Hopkinson BR. Emergency endovascular repair of leaking aortic aneurysm. Lancet. 1994;344(8937):1645.

2. Antoniou GA, Georgiadis GS, Antoniou SA, Pavlidis P, Maras D, Sfyroeras GS, et al. Endovascular repair for ruptured abdominal aortic aneurysm confers an early survival benefit over open repair. J Vasc Surg. 2013;58(4):1091-105.

3. Mehta M, Taggert J, Darling RC, III, Chang BB, Kreienberg PB, Paty PSK, et al. Establishing a protocol for endovascular treatment of ruptured abdominal aortic aneurysms: Outcomes of a prospective analysis. J Vasc Surg. 2006;44(1):1-8.

4. Investigators IT, Powell JT, Sweeting MJ, Thompson MM, Ashleigh R, Bell R, et al. Endovascular or open repair strategy for ruptured abdominal aortic aneurysm: 30 day outcomes from IMPROVE randomised trial. BMJ. 2014;348:f7661.

5. Reimerink JJ, Hoornweg LL, Vahl AC, Wisselink W, van den Broek TA, Legemate DA, et al. Endovascular repair versus open repair of ruptured abdominal aortic aneurysms: a multicenter randomized controlled trial. Ann Surg. 2013;258(2):248-56.

6. van Beek SC, Conijn AP, Koelemay MJ, Balm R. Editor's Choice - Endovascular aneurysm repair versus open repair for patients with a ruptured abdominal aortic aneurysm: a systematic review and meta-analysis of short-term survival. Eur J Vasc Endovasc Surg. 2014;47(6):593-602.

7. Rose DF, Davidson IR, Hinchliffe RJ, Whitaker SC, Gregson RH, MacSweeney ST, et al. Anatomical suitability of ruptured abdominal aortic aneurysms for endovascular repair. J Endovasc Ther. 2003;10(3):453-7.

8. Stather PW, Wild JB, Sayers RD, Bown MJ, Choke E. Endovascular aortic aneurysm repair in patients with hostile neck anatomy. J Endovasc Ther. 2013;20(5):623-37.

9. van Keulen JW, Moll FL, Tolenaar JL, Verhagen HJ, van Herwaarden JA. Validation of a new standardized method to measure proximal aneurysm neck angulation. J Vasc Surg. 2010;51(4):8218.

10. Johnston KW, Rutherford RB, Tilson MD, Shah DM, Hollier L, Stanley JC. Suggested standards for reporting on arterial aneurysms. Subcommittee on Reporting Standards for Arterial Aneurysms, Ad Hoc Committee on Reporting Standards, Society for Vascular Surgery and North American Chapter, International Society for Cardiovascular Surgery. J Vasc Surg. 1991;13(3):452-8.

11. Moore R, Nutley M, Cina CS, Motamedi M, Faris P, Abuznadah W. Improved survival after introduction of an emergency endovascular therapy protocol for ruptured abdominal aortic aneurysms. J Vasc Surg. 2007;45(3):443-50.

12. Investigators IT. The effect of aortic morphology on peri-operative mortality of ruptured abdominal aortic aneurysm. Eur Heart J. 2015;[Epud ahead of print]. 
13. Schanzer A, Greenberg RK, Hevelone N, Robinson WP, Eslami MH, Goldberg RJ, et al. Predictors of abdominal aortic aneurysm sac enlargement after endovascular repair. Circulation. 2011;123(24):2848-55.

14. Stokmans RA, Teijink JA, Forbes TL, Bockler D, Peeters PJ, Riambau V, et al. Early results from the ENGAGE registry: real-world performance of the Endurant Stent Graft for endovascular AAA repair in 1262 patients. Eur J Vasc Endovasc Surg. 2012;44(4):369-75.

15. Karthikesalingam A, Holt PJ, Vidal-Diez A, Choke EC, Patterson BO, Thompson LJ, et al. Predicting aortic complications after endovascular aneurysm repair. Br J Surg. 2013;100(10):1302-11.

16. Antoniou GA, Georgiadis GS, Antoniou SA, Kuhan G, Murray D. A meta-analysis of outcomes of endovascular abdominal aortic aneurysm repair in patients with hostile and friendly neck anatomy. J Vasc Surg. 2013;57(2):527-38.

17. Georgiadis GS, Trellopoulos G, Antoniou GA, Gallis K, Nikolopoulos ES, Kapoulas KC, et al. Early results of the Endurant endograft system in patients with friendly and hostile infrarenal abdominal aortic aneurysm anatomy. J Vasc Surg. 2011;54(3):616-27.

18. Torsello G, Troisi N, Donas KP, Austermann M. Evaluation of the Endurant stent graft under instructions for use vs off-label conditions for endovascular aortic aneurysm repair. J Vasc Surg. 2011;54(2):300-6.

19. Setacci F, Sirignano P, de Donato G, Galzerano G, Messina G, Guerrini S, et al. Two-year-results of Endurant stent-graft in challenging aortic neck morphologies versus standard anatomies. J Cardiovasc Surg (Torino). 2014;55(1):85-92.

20. Gupta PK, Ramanan B, Engelbert TL, Tefera G, Hoch JR, Kent KC. A comparison of open surgery versus endovascular repair of unstable ruptured abdominal aortic aneurysms. J Vasc Surg. 2014;60(6):1439-45.

21. Greenberg RK, Clair D, Srivastava S, Bhandari G, Turc A, Hampton J, et al. Should patients with challenging anatomy be offered endovascular aneurysm repair? J Vasc Surg. 2003;38(5):990-6.

22. Tolenaar JL, van Keulen JW, Trimarchi S, Muhs BE, Moll FL, van Herwaarden JA. The chimney graft, a systematic review. Ann Vasc Surg. 2012;26(7):1030-8.

23. Karthikesalingam A, Holt PJ, Vidal-Diez A, Ozdemir BA, Poloniecki JD, Hinchliffe RJ, et al. Mortality from ruptured abdominal aortic aneurysms: clinical lessons from a comparison of outcomes in England and the USA. Lancet. 2014;383(9921):963-9.

24. Lloyd GM, Bown MJ, Norwood MG, Deb R, Fishwick G, Bell PR, et al. Feasibility of preoperative computer tomography in patients with ruptured abdominal aortic aneurysm: a time-to-death study in patients without operation. J Vasc Surg. 2004;39(4):788-91. 

Chapter 7

\title{
Performance of the endurant stent graft in challenging anatomy: 30-day and 1-year analyses
}

\author{
P.P.H.L. Broos \\ R.A. Stokmans \\ S.M. van Sterkenburg \\ G. Torsello \\ F. Vermassen \\ Ph.W.M. Cuypers \\ M.R.H.M. van Sambeek \\ J.A.W. Teijink
}

Journal of Vascular Surgery 2015;62(2):312-8 


\section{Abstract}

Objective: This study aimed to compare perioperative and postoperative outcomes after endovascular repair of abdominal aortic aneurysms (AAA) in patients with various neck morphologies.

Methods: Data from the ENGAGE Registry were used for the analyses. Patients were categorized into three different groups according to proximal aortic neck anatomy: regular (REG), intermediate (INT), and challenging (CHA). REG was defined as AAAs with a proximal neck $\geq 15 \mathrm{~mm}$ combined with a suprarenal angulation $(\alpha) \leq 45^{\circ}$ and an infrarenal neck angulation $(B) \leq 60^{\circ}$. INT was defined as AAAs with a proximal neck of 10-15 mm combined with $\alpha \leq 45^{\circ}$ and $\beta \leq 60^{\circ}$ or with a proximal neck of > $15 \mathrm{~mm}$ combined with $\alpha \leq 60^{\circ}$ and $\beta=60^{\circ}-75^{\circ}$ or $\alpha=45^{\circ}-60^{\circ}$ and $\beta \leq 75^{\circ}$. CHA was defined as infrarenal necks that exceed at least one of the three defining factors.

Results: Overall, 925 patients (75.9\%) had REG anatomy, 189 patients (15.5\%) had INT anatomy, and 104 patients (8.5\%) had CHA anatomy. Patient demographics and risk factors were similar. There was a significant difference in AAA diameter between the REG and CHA group ( $59.4 \mathrm{~mm}$ vs. $65.2 \mathrm{~mm}, \mathrm{P}<.001)$. Technical success was similar among groups (REG $99.1 \%$ vs. INT $99.5 \%$ vs. CHA $97.1 \%$ ). There were no differences in mortality or the need for secondary procedures within 30 days or at 1 year. A significantly higher rate of type-I endoleaks within 30 days was seen in CHA compared with REG and INT (adjusted OR $0.15,95 \% \mathrm{Cl} 0.05-0.46$ and adjusted OR $0.08,95 \% \mathrm{Cl} 0.01-0.70$, respectively), but there was no difference at the 1-year follow-up.

Conclusions: This real world, global experience shows promising results and indicates that endovascular AAA repair with the Endurant Stent Graft is safe and effective in patients with challenging aortic neck anatomy. However, long-term follow-up of patients is required to confirm results. 


\section{Introduction}

There have been substantial changes in the treatment of abdominal aortic aneurysms (AAAs) since the introduction of endovascular aortic aneurysm repair (EVAR) in 1991.' The success of an EVAR procedure, in terms of exclusion of the aneurysm and absence of perioperative and postoperative complications, is closely dependent on the AAA's morphology and dimensions. ${ }^{2}$ For this reason, each commercially available endograft comes with its own instructions for use (IFU) with clear recommendations on AAA morphology and aortic dimensions. Short infrarenal aortic necks and/or severe infrarenal aortic neck angulation are likely to cause more intraoperative and postoperative complications such as graft migration and type I endoleaks. ${ }^{3-5}$

A substantial proportion of AAA patients is not eligible for EVAR, due to presence of anatomy outside the endograft inclusion criteria. ${ }^{6}$ Unfortunately, these patients are often also considered to be less attractive for open surgery. ${ }^{7}$ However, as practitioners become more experienced with endovascular therapy and with improved stent graft technology, increasing numbers of patients with challenging AAA morphology are treated with EVAR.

The main objective of this study was to compare the outcomes of EVAR with a latest-generation stent graft system in different infrarenal aortic neck anatomies within the context of contemporary, real-world practice. Retrospective analysis was performed on data from the Endurant Stent Graft Natural Selections Global Postmarket Registry (ENGAGE).

\section{Methods}

\section{Study design}

ENGAGE is a multi-center, non-randomized, prospective observational study of patients treated with the Endurant Stent Graft System (Medtronic Vascular, Santa Rosa, CA, USA). This endograft is specifically designed to broaden the EVAR eligibility range. To reflect real-world clinical practice, the eligibility criteria for ENGAGE were 
minimal and enrollment of patients outside Endurant's IFU was accepted. Patients needed to be at least 18 years old and have an indications for elective AAA repair. The only exclusion criteria were the probability of non-adherence to followup requirements and the concurrent participation in another trial that might confound results. Centers were selected based on a minimal annual case volume of 20 AAA stent graft procedures in combination with a history of minimal three successful Endurant stent graft procedures. To avoid selection bias, participating sites were requested to enroll patients consecutively. Ruptured AAAs were not considered for enrollment into ENGAGE. The trial was conducted according to the Declaration of Helsinki and the International Conference on Harmonization (ICH) Good Clinical Practice (GCP) guidelines, and approved by local medical ethics committees. The study is registered on clinicaltrials.gov (NCT00870051). Technical specifications of the Endurant Stent Graft System and further methodological details of the ENGAGE Registry have been published previously. ${ }^{8,9}$

\section{Definitions and study endpoints}

For this retrospective analysis, the study population was partitioned based on the IFU criteria of the Endurant. We created three groups divided according to anatomical complexity of the infrarenal neck: regular (REG), intermediate (INT) and challenging ( $\mathrm{CHA}$ ) (Table 1). Suprarenal angulation ( $\alpha$ ) was defined as the angle between the flow axis of the suprarenal aorta and the infrarenal neck. Infrarenal angulation ( $($ ) was defined as the angle between the flow axis of the infrarenal neck and the body of the aneurysm. REG was defined to include AAAs with a proximal neck of $>15 \mathrm{~mm}$ combined with $\alpha \leq 45^{\circ}$ and $B \leq 60^{\circ}$. INT was defined to include AAAs with a proximal neck of $10-15 \mathrm{~mm}$ combined with $\alpha \leq 45^{\circ}$ and $\beta \leq 60^{\circ}$ or with a proximal neck of $>15 \mathrm{~mm}$ combined with $\alpha \leq 60^{\circ}$ and $\beta=60^{\circ}-75^{\circ}$ or $\alpha=$ $45^{\circ}-60^{\circ}$ and $\beta \leq 75^{\circ}$. CHA was defined to include infrarenal necks that exceed at least one of the three defining factors (i.e., neck length $<10 \mathrm{~mm}$, or a neck length of $10-15 \mathrm{~mm}$ with $\alpha>45^{\circ}$ and $/$ or $\beta>60^{\circ}$, or a neck length $>15 \mathrm{~mm}$ combined with $\alpha$ $>60^{\circ}$ and $/$ or $\beta>75^{\circ}$ ). All patients underwent computed tomography angiography (CTA) preoperatively to determine baseline aortic and aneurysmal dimensions. CTA measurements were performed by the participating centers and not reviewed by a central CORE-lab. Pre-existing medical comorbidity information was collected 
immediately after patient enrollment. It was recommended to have annual followup imaging after the index procedure. The first choice of imaging modality was a CTA.

Table 1. Classification of patients based on anatomy of the proximal nonaneurysmal infrarenal neck.

\begin{tabular}{|c|c|c|c|c|}
\hline & \multirow{2}{*}{ Anatomic Criteria } & \multicolumn{3}{|c|}{ Proximal Neck Length } \\
\hline & & $>15 \mathrm{~mm}$ & $10-15 \mathrm{~mm}$ & $<10 \mathrm{~mm}$ \\
\hline \multirow{3}{*}{ 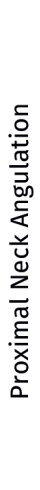 } & $\begin{array}{c}\text { Suprarenal } \leq 45^{\circ} \\
\text { AND } \\
\text { Infrarenal } \leq 60^{\circ}\end{array}$ & $\begin{array}{l}\text { Regular } \\
(\mathrm{N}=925)\end{array}$ & $\begin{array}{l}\text { Intermediate } \\
\qquad(N=107)\end{array}$ & $\begin{array}{l}\text { Challenging } \\
\qquad(\mathrm{N}=23)\end{array}$ \\
\hline & $\begin{array}{c}\text { Suprarenal } \leq 60^{\circ} \\
\text { AND Infrarenal } 60^{\circ}- \\
75^{\circ} \\
\text { OR } \\
\text { Suprarenal } 45^{\circ}-60^{\circ} \\
\text { AND infrarenal } \leq 75^{\circ}\end{array}$ & $\begin{array}{l}\text { Intermediate } \\
\qquad(\mathbf{N}=\mathbf{8 2})\end{array}$ & $\begin{array}{l}\text { Challenging } \\
\qquad(\mathrm{N}=9)\end{array}$ & $\begin{array}{l}\text { Challenging } \\
\qquad(\mathrm{N}=2)\end{array}$ \\
\hline & $\begin{array}{c}\text { Suprarenal > } 60^{\circ} \\
\text { AND } / O R \\
\text { Infrarenal }>75^{\circ}\end{array}$ & $\begin{array}{l}\text { Challenging } \\
\qquad(\mathrm{N}=63)\end{array}$ & $\begin{array}{l}\text { Challenging } \\
\qquad(\mathrm{N}=6)\end{array}$ & $\begin{array}{l}\text { Challenging } \\
\qquad(N=1)\end{array}$ \\
\hline
\end{tabular}

Regular anatomy: $\mathrm{N}=925$, Intermediate anatomy: $\mathrm{N}=189$, Challenging anatomy: $\mathrm{N}=$ 104

Technical success was defined as successful delivery and deployment of the Endurant endograft, without unintentional coverage of renal arteries, internal iliac arteries or visceral branches, with absence of either a type I or III endoleak, followed by successful removal of the delivery system. ${ }^{10} \mathrm{~A}$ completion angiogram was performed to document the status of endograft implantation. The necessity of proximal extension cuff placement to correct peroperative type $1 \mathrm{~A}$ endoleaks was documented. Duration of implant procedure was defined as the time between cutdown or puncture and removal of the last guide wire. Fluoroscopic time, volume of contrast, post-operative stay and possible intensive care unit (ICU) admission were documented. Thirty-day and 1-year outcomes included endograft-related complications, mortality rates, and need for secondary interventions. Technical complications included; occlusion (100\% stent graft obstruction); stenosis (partial 
stent graft obstruction); kinking (stent graft obstruction in the horizontal plane); and migration (stent graft movement $>10 \mathrm{~mm}$ ). All patients completed 1-year follow-up.

\section{Data collection and statistical analysis}

The clinical investigators recorded data on a web-based electronic case report form to ensure reliable data collection, data management, secure authentication, and traceability. All entered data were reviewed and more than $40 \%$ of patients' source documentation was monitored randomly. Each center's institutional review committee approved the Registry and informed consent was obtained from all patients.

Categorical variables are presented as frequencies (percentages). Continuous variables are presented as mean \pm standard deviation or as median and interquartile range in the case of skewed data. Differences in baseline characteristics among the three study groups were analysed using the $x^{2}$ test for discrete variables and the ANOVA or the Kruskal-Wallis test for continuous variables. Differences among study groups were tested using the Bonferroni multiple-comparison test. Multivariate logistic and linear regression analyses were used to adjust for possible confounding factors. Multicollinearity was checked using the variance inflation factor and the tolerance. A P-value $<.05$ was considered statistically significant. All statistical analyses were performed using SPSS ${ }^{\circledR}$ version 21 for MAC (IBM Corporation, Armonk, NY, USA).

\section{Results}

Between March 2009 and April 2011, 1263 AAA patients treated with an Endurant were enrolled from 79 sites in 30 countries worldwide. We excluded 45 patients with insufficient baseline data on aortic morphology. Data for the remaining 1218 patients comprise the basis of this report. REG anatomy was present in 925 patients (75.9\%), INT anatomy in 189 patients (15.5\%), and CHA anatomy in 104 patients (8.5\%). 


\section{Baseline characteristics}

Demographic data and baseline risk factors of the study groups are outlined in Table 2. There was a significant difference in the distribution of sexes, with the most females in the CHA group $(P=.001)$. There were no differences in age or American Society of Anaesthesiologists (ASA) classification among the groups. The prevalence of cancer and gastro-intestinal complications were significantly different among the groups $(P=.009$ and $P=.036$, respectively).

Table 2. Demographics and risk factors in patients grouped by neck anatomy.

\begin{tabular}{lcccc}
\hline Variable & REG & INT & CHA & $\begin{array}{c}p^{-} \\
\text {value }\end{array}$ \\
\hline Age (years) & $\mathrm{N}=925^{\mathrm{a}}$ & $\mathrm{N}=189^{\mathrm{a}}$ & $\mathrm{N}=104^{\mathrm{a}}$ & .41 \\
Gender & $73.0 \pm 8.0$ & $72.7 \pm 8.8$ & $74.0 \pm 7.7$ & .01 \\
$\quad$ & & & & \\
$\quad$ Male & $90.9 \%(841 / 925)$ & $86.8 \%(164 / 189)$ & $79.8 \%(83 / 104)$ & \\
$\quad$ Female & $9.1 \%(84 / 925)$ & $13.2 \%(25 / 189)$ & $20.2 \%(21 / 104)$ & \\
ASA Classification & & & & .63 \\
Class I & $5.9 \%(55 / 925)$ & $5.3 \%(10 / 189)$ & $9.6 \%(10 / 104)$ & \\
Class II & $44.1 \%(408 / 925)$ & $34.4 \%(65 / 189)$ & $40.4 \%(42 / 104)$ & \\
Class III & $38.3 \%(354 / 925)$ & $50.8 \%(96 / 189)$ & $46.2 \%(48 / 104)$ & \\
Class IV & $11.7 \%(108 / 925)$ & $9.5 \%(18 / 189)$ & $3.8 \%(4 / 104)$ & \\
Symptoms & & & & .20 \\
Asymptomatic AAA & $84.3 \%(780 / 925)$ & $86.7 \%(164 / 189)$ & $78.8 \%(82 / 104)$ & \\
Symptomatic AAA & $15.7 \%(145 / 925)$ & $13.2 \%(25 / 189)$ & $21.2 \%(22 / 104)$ & \\
Risk factors & & & & \\
Tobacco use & $49.8 \%(450 / 903)$ & $53.0 \%(97 / 183)$ & $43.3 \%(45 / 104)$ & .28 \\
Hypertension & $76.4 \%(696 / 911)$ & $73.4 \%(138 / 188)$ & $70.9 \%(73 / 103)$ & .36 \\
Hyperlipidaemia & $62.0 \%(541 / 873)$ & $58.0 \%(102 / 176)$ & $52.6 \%(51 / 97)$ & .15 \\
Diabetes & $19.8 \%(180 / 911)$ & $17.1 \%(32 / 187)$ & $17.5 \%(18 / 103)$ & .64 \\
Cancer & $19.7 \%(179 / 908)$ & $27.8 \%(52 / 187)$ & $13.6 \%(14 / 103)$ & .01 \\
Cardiac disease & $53.3 \%(493 / 925)$ & $55.0 \%(104 / 189)$ & $51.0 \%(53 / 104)$ & .80 \\
Pulmonary disease & $24.1 \%(220 / 911)$ & $27.2 \%(50 / 184)$ & $28.8 \%(30 / 104)$ & .44 \\
Renal insufficiency & $14.8 \%(136 / 917)$ & $17.1 \%(32 / 187)$ & $15.4 \%(16 / 104)$ & .73 \\
Cerebrovascular disease & $12.9 \%(119 / 925)$ & $11.1 \%(21 / 189)$ & $13.5 \%(14 / 104)$ & .78 \\
Peripheral vascular disease & $18.4 \%(168 / 911)$ & $16.6 \%(31 / 187)$ & $20.4 \%(21 / 103)$ & .71 \\
Gastro-intestinal & $21.3 \%(197 / 925)$ & $15.9 \%(30 / 189)$ & $12.5 \%(13 / 104)$ & .04 \\
$\quad$ complications & & & & \\
\hline
\end{tabular}

REG, Regular anatomy; INT, Intermediate anatomy; CHA, Challenging anatomy; ASA, American Society of Anaesthesiologists; AAA, abdominal aortic aneurysm.

a Values are reported as mean \pm standard deviation or frequencies $(\%)(n / N)$.

Denominator differs when there are missing values. 
Baseline aneurysm characteristics are shown in Table 3. The CHA group had larger maximum AAA diameters on average compared with the REG group $(P<.001)$. There was no significant difference in proximal non-aneurysmal neck length between INT and CHA (P = .162). Suprarenal and infrarenal neck angles were significantly different among all groups (all $\mathrm{P}<.001$ ). Proximal neck diameter and bilateral iliac fixation site diameters were comparable among groups.

Table 3. Baseline aneurysm characteristics by neck anatomy.

\begin{tabular}{|c|c|c|c|c|c|c|}
\hline Variable & $\begin{array}{c}\text { REG } \\
\mathrm{N}=925^{\mathrm{a}}\end{array}$ & $\begin{array}{c}\text { INT } \\
\mathrm{N}=189^{\mathrm{a}}\end{array}$ & $\begin{array}{c}\text { CHA } \\
\mathrm{N}=104^{\mathrm{a}}\end{array}$ & $\begin{array}{c}\text { REG vs. } \\
\text { INT }\end{array}$ & $\begin{array}{c}\text { REG vs. } \\
\text { CHA }\end{array}$ & $\begin{array}{c}\text { INT vs. } \\
\text { CHA }\end{array}$ \\
\hline Maximum AAA diameter $(\mathrm{mm})$ & $58(53-64)$ & $58(53-67)$ & $61(55-73)$ & .11 & $<.01$ & .05 \\
\hline Proximal non-aneurysmal neck length ( $\mathrm{mm}$ ) & $29 \pm 11$ & $20 \pm 12$ & $22 \pm 15$ & $<.01$ & $<.01$ & .16 \\
\hline Suprarenal neck angle $\left({ }^{\circ}\right)$ & $15 \pm 14$ & $25 \pm 19$ & $45 \pm 29$ & $<.01$ & $<.01$ & $<.01$ \\
\hline Infrarenal neck angle $\left(^{\circ}\right)$ & $24 \pm 18$ & $40 \pm 24$ & $68 \pm 29$ & $<.01$ & $<.01$ & $<.01$ \\
\hline Proximal neck diameter $(\mathrm{mm})$ & $24 \pm 4$ & $24 \pm 4$ & $24 \pm 4$ & 1.00 & 1.00 & 1.00 \\
\hline \multicolumn{7}{|l|}{ Distal iliac fixation site diameter ( $\mathrm{mm}$ ) } \\
\hline Right & $14 \pm 4$ & $14 \pm 4$ & $14 \pm 4$ & 1.00 & 1.00 & 1.00 \\
\hline Left & $14 \pm 3$ & $14 \pm 4$ & $14 \pm 4$ & 1.00 & .85 & .80 \\
\hline
\end{tabular}

REG, Regular anatomy; INT, Intermediate anatomy; CHA, Challenging anatomy; AAA, Abdominal aortic aneurysm.

a Values are reported as mean \pm standard deviation or as median and interquartile range in case of skewed data.

\section{Intra-operative outcome}

Initial procedural data and evaluations are detailed in Table 4. Operation time was significantly longer in the CHA group compared with the REG and INT groups (adjusted $\mathrm{P}<.001$ and adjusted $\mathrm{P}=.001$, respectively). Significantly more contrast was used in CHA compared with REG (127.0 cc vs. $152.7 \mathrm{cc}$, adjusted $\mathrm{P}=.001$ ). Fluoroscopic time was significantly longer in INT and CHA compared with REG (adjusted $\mathrm{P}=.033$ and adjusted $\mathrm{P}<.001$, respectively). No differences in postoperative stay or ICU admission rate were noted among groups. 
Table 4. Initial procedural data and evaluations.

\begin{tabular}{|c|c|c|c|c|c|c|}
\hline \multirow{2}{*}{ Variables } & \multirow{2}{*}{$\begin{array}{l}\text { Regular } \\
\mathrm{N}=925^{\mathrm{a}}\end{array}$} & \multirow{2}{*}{$\begin{array}{c}\text { Intermediate } \\
\mathrm{N}=189^{\mathrm{a}}\end{array}$} & \multirow{2}{*}{$\begin{array}{c}\text { Challenging } \\
\mathrm{N}=104^{\mathrm{a}}\end{array}$} & \multicolumn{3}{|c|}{ Adjusted $P$-value ${ }^{b}$} \\
\hline & & & & REG vS. INT & REG vs. CHA & INT vs. CHA \\
\hline Duration of procedure (min) & $97.4 \pm 43.2$ & $100.2 \pm 42.3$ & $119.2 \pm 58.0$ & .48 & $<.01^{c}$ & $.01^{c}$ \\
\hline Volume of contrast (cc) & $127.0 \pm 69.9$ & $137.1 \pm 71.4$ & $152.7 \pm 74.3$ & .08 & $.01^{c}$ & .11 \\
\hline Total fluoroscopic time (min) & $19.7 \pm 12.3$ & $22.1 \pm 11.8$ & $24.8 \pm 12.6$ & $.03^{c}$ & $<.01^{c}$ & .11 \\
\hline \multirow[t]{3}{*}{ Post-operative stay (day) } & $4.8 \pm 5.2$ & $4.9 \pm 4.3$ & $5.2 \pm 5.6$ & .99 & .75 & .80 \\
\hline & & & & \multicolumn{3}{|c|}{ Adjusted OR $^{\mathrm{b}}(95 \% \mathrm{Cl})$} \\
\hline & & & & REG vS. INT & REG vs. CHA & INT vs. CHA \\
\hline Admission to ICU & $\begin{array}{c}33.6 \% \\
(309 / 921)\end{array}$ & $\begin{array}{c}31 \% \\
(59 / 188)\end{array}$ & $\begin{array}{c}34 \\
(35 / 103)\end{array}$ & $\begin{array}{c}1.16 \\
(.82-1.64)\end{array}$ & $\begin{array}{c}1.04 \\
(.67-1.62)\end{array}$ & $\begin{array}{c}.90 \\
(.53-1.51)\end{array}$ \\
\hline $\begin{array}{l}\text { Extension cuff to correct } \\
\text { peroperative type } 1 \mathrm{~A} \text { endoleak }\end{array}$ & $\begin{array}{c}1.3 \% \\
(12 / 925)\end{array}$ & $\begin{array}{c}2 \% \\
(4 / 189)\end{array}$ & $\begin{array}{c}7 \% \\
(7 / 104)\end{array}$ & $\begin{array}{c}.67 \\
(.21-2.16)\end{array}$ & $\begin{array}{c}.25^{c} \\
(.09-.71)\end{array}$ & $\begin{array}{c}.37 \\
(.10-1.37)\end{array}$ \\
\hline $\begin{array}{l}\text { Endoleak type } 1 \text { at final } \\
\text { angiogram }\end{array}$ & $1.2 \%(11 / 925)$ & $1 \%(1 / 189)$ & $1 \%(1 / 104)$ & $\begin{array}{c}2.71 \\
(.32-22.78)\end{array}$ & $\begin{array}{c}1.68 \\
(.20-14.05)\end{array}$ & $\begin{array}{c}.62 \\
(.04-10.20)\end{array}$ \\
\hline $\begin{array}{l}\text { Endoleak type } 3 \text { at final } \\
\text { angingram }\end{array}$ & $0.2 \%(2 / 925)$ & $1 \%(2 / 189)$ & $0 \%(0)$ & $\begin{array}{c}.20 \\
(.03-1.48)\end{array}$ & - & - \\
\hline \multicolumn{7}{|l|}{ Evaluation } \\
\hline Intra-operative mortality & $0 \%(0)$ & $0 \%(0)$ & $0 \%(0)$ & - & - & - \\
\hline Conversion to open surgery & $0.3 \%(3 / 925)$ & $0 \%(0)$ & $1 \%(1 / 104)$ & - & $\begin{array}{c}.46 \\
(.04-5.20)\end{array}$ & - \\
\hline Technical success & $\begin{array}{c}99.1 \% \\
(917 / 925)\end{array}$ & $\begin{array}{c}99 \% \\
(188 / 189)\end{array}$ & $\begin{array}{c}97 \% \\
(101 / 104)\end{array}$ & $\begin{array}{c}.44 \\
(.05-3.69)\end{array}$ & $\begin{array}{c}2.45 \\
(.59-10.13)\end{array}$ & $\begin{array}{c}5.56 \\
(.55-55.72)\end{array}$ \\
\hline
\end{tabular}

REG, Regular anatomy; INT, Intermediate anatomy; CHA, Challenging anatomy; OR, Odds ratio; ICU, Intensive care unit.

a Values are reported as mean \pm standard deviation or frequencies $(\%)(n / N)$.

Denominator differs when there are missing values.

${ }^{\text {b }}$ Adjusted for Gender, Cancer, Gastro-intestinal complications, Maximum AAA diameter.

' Significantly different

Four patients required immediate conversion to open surgery, of whom three were in the REG group and one in the CHA group. Among the REG patients, two required open surgery because of difficulties passing the iliac arteries and one because of unintentional coverage of both renal arteries. The CHA patient was converted to open surgery because the surgeon was unable to remove the delivery device when a suprarenal strut became entrapped in the delivery system. Incidences of type I and type III endoleaks were distributed equally among the groups. However, significantly more proximal extension cuffs placements were necessary to correct peroperative type $1 \mathrm{~A}$ endoleaks in the CHA group compared to the REG group. There were no significant differences in technical success among the groups. No patients died during the procedure. 


\section{Thirty-day outcome}

Thirty-day outcomes are summarized in Table 5. Twelve REG patients (1.3\%), one INT patient $(0.5 \%)$, and three CHA patients (2.9\%) died within 30 days of implant. Only one ruptured AAA was reported (in a REG patient), which did not result in a significant difference among groups. Two REG patients and one CHA patient were converted to open surgery (adjusted OR $0.33,95 \% \mathrm{Cl} 0.02-4.46$ ). We observed no significant differences in secondary interventions.

Table 5. Patient outcomes within 30-days.

\begin{tabular}{|c|c|c|c|c|c|c|}
\hline \multirow{2}{*}{ Variables } & \multirow{2}{*}{$\begin{array}{l}\text { Regular } \\
\mathrm{N}=925^{\mathrm{a}}\end{array}$} & \multirow{2}{*}{$\begin{array}{c}\text { Intermediate } \\
\mathrm{N}=189^{\mathrm{a}}\end{array}$} & \multirow{2}{*}{$\begin{array}{c}\text { Challenging } \\
\mathrm{N}=104^{\mathrm{a}}\end{array}$} & \multicolumn{3}{|c|}{ Adjusted $\mathrm{OR}^{\mathrm{b}}(95 \% \mathrm{Cl})$} \\
\hline & & & & $\overline{\text { REG vs. INT }}$ & REG vs. CHA & INT vs. CHA \\
\hline All-cause mortality & $1.3 \%(12 / 925)$ & $1 \%(1 / 189)$ & $3 \%(3 / 104)$ & $\begin{array}{c}2.35 \\
(.29-18.82)\end{array}$ & $\begin{array}{c}.37 \\
(.10-1.45)\end{array}$ & $\begin{array}{c}.16 \\
(.02-1.57)\end{array}$ \\
\hline AAA rupture & $0.1 \%(1 / 925)$ & $0 \%(0 / 189)$ & $0 \%(0 / 104)$ & - & - & - \\
\hline Endoleak type I & $0.8 \%(7 / 854)$ & $1 \%(1 / 176)$ & $7 \%(7 / 95)$ & $\begin{array}{c}1.82 \\
(.22-15.36)\end{array}$ & $\begin{array}{c}.15^{c} \\
(.05-.46)\end{array}$ & $\begin{array}{c}.08^{\mathrm{c}} \\
(.01-.70)\end{array}$ \\
\hline Endoleak type 3 & $0.2 \%(2 / 854)$ & $0 \%(0 / 176)$ & $0 \%(0 / 95)$ & - & - & - \\
\hline Stent Graft occlusion & $1.8 \%(15 / 854)$ & $2 \%(4 / 176)$ & $3 \%(3 / 95)$ & $\begin{array}{c}.76 \\
(.25-2.34)\end{array}$ & $\begin{array}{c}.48 \\
(.13-1.74)\end{array}$ & $\begin{array}{c}.63 \\
(.13-2.91)\end{array}$ \\
\hline Stent Graft stenosis & $1.3 \%(11 / 854)$ & $2 \%(3 / 176)$ & $2 \%(2 / 95)$ & $\begin{array}{c}.63 \\
(.17-2.30)\end{array}$ & $\begin{array}{c}.44 \\
(.09-2.10)\end{array}$ & $\begin{array}{c}.70 \\
(.11-4.38)\end{array}$ \\
\hline Stent Graft kinking & $1.4 \%(12 / 854)$ & $2 \%(4 / 176)$ & $4 \%(4 / 95)$ & $\begin{array}{c}.62 \\
(.20-1.98)\end{array}$ & $\begin{array}{c}.29^{c} \\
(.09-.95)\end{array}$ & $\begin{array}{c}.47 \\
(.11-1.95)\end{array}$ \\
\hline Stent Graft migration & $0 \%(0 / 854)$ & $0 \%(0 / 176)$ & $0.0 \%(0 / 95)$ & - & - & - \\
\hline Conversion & $0.2 \%(2 / 925)$ & $0 \%(0 / 189)$ & $1 \%(1 / 104)$ & - & $\begin{array}{c}.33 \\
(0.02-4.46)\end{array}$ & - \\
\hline Secondary procedure & $1.6 \%(15 / 925)$ & $1 \%(1 / 189)$ & $2 \%(2 / 104)$ & $\begin{array}{c}3.21 \\
(.42-24.64)\end{array}$ & $\begin{array}{c}.69 \\
(.15-3.16)\end{array}$ & $\begin{array}{c}.21 \\
(.02-2.43)\end{array}$ \\
\hline
\end{tabular}

REG, Regular anatomy; INT, Intermediate anatomy; CHA, Challenging anatomy; OR, Odds ratio.

${ }^{a}$ Values are reported as mean \pm standard deviation or frequencies $(\%)(n / N)$.

Denominator differs when there are missing values.

${ }^{\mathrm{b}}$ Adjusted for Gender, Cancer, Gastro-intestinal complications, Maximum AAA diameter.

c Significantly different 
Type I endoleaks occurred in seven REG patients (0.8\%), one INT patient ( $0.6 \%)$, and seven CHA patients (7.4\%). The incidence of type I endoleaks was significantly higher in the CHA group (REG vs. CHA: adjusted OR $0.15,95 \% \mathrm{Cl} 0.05-0.46$ and INT vs. CHA: adjusted OR $0.08,95 \% \mathrm{Cl} 0.01-0.70)$. No differences were noted in rates of type III endoleak, stent graft occlusion, stent graft stenosis, or stent graft migration. Stent graft kinking was significantly more prevalent in CHA compared with REG (adjusted OR 0.29, 95\% Cl 0.09-0.95). Notably, only two patients (one INT and one $\mathrm{CHA}$ ) suffered stent graft kinking in the proximal aortic neck.

\section{One-year outcome}

There were no significant differences regarding all-cause and AAA-related mortality among groups within 1 year of endograft implantation (Table 6). Furthermore, there was no significant difference in secondary procedure rates. Conversion to open surgery was comparable among groups and was necessary in four REG patients (0.4\%), two INT patients (1.1\%), and one CHA patient (1.0\%).

At one year, endoleak type I and III rates were not significantly different among groups. Stent graft stenosis was significantly more prevalent in CHA versus REG (adjusted $\mathrm{OR}=0.22,95 \% \mathrm{Cl}=0.05-0.92$ ). No statistical differences were found among groups with respect to stent graft occlusion, kinking, or migration. 
Table 6. Patient outcomes at 1-year.

\begin{tabular}{|c|c|c|c|c|c|c|}
\hline \multirow{2}{*}{ Variables } & \multirow{2}{*}{$\begin{array}{l}\text { Regular } \\
\mathrm{N}=925^{\mathrm{a}}\end{array}$} & \multirow{2}{*}{$\begin{array}{c}\text { Intermediate } \\
\mathrm{N}=189^{\mathrm{a}}\end{array}$} & \multirow{2}{*}{$\begin{array}{l}\text { Challenging } \\
\mathrm{N}=104^{\mathrm{a}}\end{array}$} & \multicolumn{3}{|c|}{ Adjusted $\mathrm{OR}^{\mathrm{b}}(95 \% \mathrm{Cl})$} \\
\hline & & & & $\overline{\text { REG VS. INT }}$ & REG vs. CHA & INT vs. CHA \\
\hline All-cause mortality & $6.7 \%(62 / 925)$ & $10 \%(18 / 189)$ & $10 \%(10 / 104)$ & $\begin{array}{c}.85 \\
(.48-1.52)\end{array}$ & $\begin{array}{c}.71 \\
(.34-1.49)\end{array}$ & $\begin{array}{c}.83 \\
(.36-1.94)\end{array}$ \\
\hline AAA-related mortality & $1.4 \%(13 / 925)$ & $1 \%(2 / 189)$ & $3 \%(3 / 104)$ & $\begin{array}{c}1.18 \\
(.25-5.46)\end{array}$ & $\begin{array}{c}.39 \\
(.10-1.48)\end{array}$ & $\begin{array}{c}.33 \\
(.05-2.05)\end{array}$ \\
\hline AAA rupture & $0.0 \%(0 / 925)$ & $1 \%(2 / 189)$ & $0 \%(0 / 104)$ & - & - & - \\
\hline Endoleak type I & $0.4 \%(3 / 793)$ & $0 \%(0 / 153)$ & $1 \%(1 / 88)$ & - & $\begin{array}{c}.92 \\
(.08-10.38)\end{array}$ & - \\
\hline Endoleak type 3 & $0 \%(0 / 793)$ & $1 \%(1 / 153)$ & $1 \%(1 / 88)$ & - & - & $\begin{array}{c}.78 \\
(.04-14.20)\end{array}$ \\
\hline Stent Graft occlusion & $2.4 \%(19 / 793)$ & $1 \%(2 / 153)$ & $1 \%(1 / 88)$ & $\begin{array}{c}1.71 \\
(.39-7.49)\end{array}$ & $\begin{array}{c}2.08 \\
(.27-16.24)\end{array}$ & $\begin{array}{c}1.22 \\
(.11-13.90)\end{array}$ \\
\hline Stent Graft stenosis & $1.3 \%(10 / 793)$ & $1 \%(1 / 153)$ & $3 \%(3 / 88)$ & $\begin{array}{c}1.63 \\
(.20-13.19)\end{array}$ & $\begin{array}{c}.22^{c} \\
(.05-.92)\end{array}$ & $\begin{array}{c}.14 \\
(.01-1.39)\end{array}$ \\
\hline Stent Graft kinking & $0.3 \%(2 / 793)$ & $0 \%(0 / 153)$ & $1 \%(1 / 88)$ & - & $\begin{array}{c}.32 \\
(.02-4.62)\end{array}$ & - \\
\hline Stent Graft migration & $0 \%(0 / 793)$ & $0 \%(0 / 153)$ & $0 \%(0 / 88)$ & - & - & - \\
\hline Conversion & $0.4 \%(4 / 925)$ & $1 \%(2 / 189)$ & $1 \%(1 / 104)$ & $\begin{array}{c}.47 \\
(.08-2.83)\end{array}$ & $\begin{array}{c}.52 \\
(.05-5.06)\end{array}$ & $\begin{array}{c}1.10 \\
(.10-12.68)\end{array}$ \\
\hline Secondary procedure & $5.4 \%(50 / 925)$ & $5 \%(9 / 189)$ & $9 \%(9 / 104)$ & $\begin{array}{c}1.14 \\
(.55-2.38)\end{array}$ & $\begin{array}{c}.59 \\
(.28-1.27)\end{array}$ & $\begin{array}{c}.52 \\
(.20-1.37)\end{array}$ \\
\hline
\end{tabular}

REG, Regular anatomy; INT, Intermediate anatomy; CHA, Challenging anatomy; OR, Odds ratio.

a Values are reported as mean \pm standard deviation or frequencies $(\%)(n / N)$.

Denominator differs when there are missing values.

b Corrected for Gender, Cancer, Gastro-intestinal complications, Maximum AAA

diameter.

c Significantly different

\section{Discussion}

We created three anatomic groups to gain better insight into the influence of aortic neck length and angulation on EVAR outcomes. The REG criteria are within the IFU criteria for the Talent Abdominal Stent Graft (Medtronic Vascular, Santa Rosa, CA, USA), whereas the INT criteria include the Talent indication as well as the broader indications specified in the Endurant IFU. The CHA patients had aortic neck characteristics outside both the Talent and Endurant IFUs.

Advances in technology, imaging, and operator experience have led to an extension of the use of EVAR beyond initial manufacturers' guidelines. Nowadays, an increasing number of patients with more challenging anatomies of the proximal 
infrarenal neck are treated with conventional EVAR. The performance of the Endurant Stent Graft in challenging anatomy was evaluated in previous reports, and showed no differences in operative success rate and early outcome.1-14 However, these studies consisted of small, retrospective patient groups with possible selection bias. The results of this study are in line with previous findings, showing comparable perioperative results among anatomic groups.

We report more type I endoleaks within 30 days for CHA patients. However, these were not seen at final angiogram or at 1-year follow-up. Type I endoleaks result in direct blood flow in the aneurysm sac, causing further dilatation and, eventually, rupture of the aneurysm sac. Despite this possible danger, a conservative approach to small intraoperative type I endoleaks may be justified in selected patients. ${ }^{15}$ In this study, 13 type I endoleaks were seen at final angiogram, of which 10 type I endoleaks (76.9\%) resolved spontaneously within 30 days of the procedure. Two type I endoleaks were successfully corrected after secondary intervention. One patient died within 30 days due to cardiac arrest.

According the European guidelines, all delayed type I endoleaks should be treated. ${ }^{16}$ At 1-month follow-up, 15 type I endoleaks were seen, of which 11 were corrected with a secondary intervention and 1 with open surgery. Three type I endoleaks remained uncorrected, of which 2 resolved spontaneously. One patient died, but this was unrelated to the uncorrected type I endoleak. At the 1-year follow-up, there were 4 new type I endoleaks, which were all corrected after secondary procedure.

Despite more stent graft-related complications in the CHA group at 30 days, the need for secondary procedures was equally distributed among groups. This is in line with previous reports on the use of the Endurant Stent Graft System outside the IFU..$^{12-14}$

One could expect that technical success would be lower in challenging AAA anatomies. However, we found no significant difference in technical success rates among groups. We reported more contrast use and longer operation time for CHA patients. This may imply that the procedures were more complicated. In addition, 
there was a more frequent use of proximal extension cuffs to correct peroperative type $1 \mathrm{~A}$ endoleaks in the CHA group. A previous study on the ENGAGE database reported neck length as an independent risk factor for intra-operative neck related adverse events. ${ }^{17}$ In patients with challenging neck anatomy, preoperative planning with adequate sizing is of utmost importance. High image quality and optimal alignment of the C-arm in the cranial-caudal position is crucial to obtain maximum sealing in short necks.

Patients in the CHA group had larger maximum AAA diameters compared with the REG group. Aneurysm size is a predictor of survival after EVAR.18 Torsello et al. also reported larger AAA diameters in patients with complex anatomies..$^{14}$ Additionally, they found that patients with proximal aortic neck anatomy outside the IFU also presented with higher mean angulations of the iliac axis..$^{13}$ Although we did not have information regarding iliac angulations for this analysis, this could explain the increased iliac stent graft kinking observed in the CHA group. Therefore, challenging anatomy of the infrarenal neck involves aneurysm size and probably the iliac axis.

Previous studies conclude that females have an increased risk for postoperative complications. ${ }^{19,20}$ In addition, females have more often challenging aortoiliac anatomy than males. ${ }^{21}$ We also reported a higher percentage of female gender in the CHA group. In contrast however, the effect of gender on outcomes as studied previously in the ENGAGE Registry showed no differences in major adverse events and technical outcomes within one year. ${ }^{22}$ This can be explained by the use of the Endurant stent graft that may be better suited to overcome challenging aortoiliac anatomy in females compared to previous devices.

A recent meta-analysis by Stather et al. reported increased 30-day mortality in patients with hostile infrarenal aortic necks. ${ }^{23}$ In contrast, we did not observe significant differences in survival among groups. The differences in outcomes could possibly be secondary to the application of other anatomic criteria for the classification of challenging infrarenal aortic necks in the studies included in the meta-analysis. The significant difference in 30-day mortality was mainly reported following an analysis of the EUROpean Collaborators on Stent-graft Techniques 
for aortic Aneurysm Repair (EUROSTAR) data, which only evaluated the influence of infrarenal aortic neck length. ${ }^{24}$

Neck length and angulation have been reported as risk factors for device migration. ${ }^{5} 25$ These findings were based on experience with first-generation endografts without active suprarenal fixation. The Endurant Stent Graft System includes anchoring pins to ensure active proximal fixation and prevent endograft migration. The present study reports no stent graft migration at 1-year follow-up in any of the anatomic groups.

A limitation of the present study is the fact that we could not evaluate the effect of neck thrombus and calcification due to registry constraints. In addition, longer follow-up is necessary to evaluate the durability of the endograft in challenging anatomies. Also, our results could be influenced by low statistical power. An adequate number of patients with challenging anatomy needs to be added to this study to produce firm results and conclusions. The Endurant for Challenging Anatomy: Global Experience (EAGLE) Registry is currently enrolling patients with challenging anatomy to critically assess whether the current guidelines for anatomic eligibility for EVAR with the Endurant stent graft system are still applicable. $^{26}$

\section{Conclusion}

Patients with neck anatomy that is challenging in terms of severe angulation and short neck length can be treated successfully with the Endurant Stent Graft System. Technical success and mortality rates were comparable among groups. Despite an increased risk of type I endoleaks within 30 days, we did not observe an increase in secondary interventions. Extensive surveillance with annual imaging is recommended to detect and treat stent graft-related complications, especially in patients with challenging anatomy. Further prospective studies, with a larger group of patients and longer follow-up, are necessary to evaluate the safety and durability of the Endurant Stent Graft System in patients with challenging AAA anatomies. 


\section{References}

1. Parodi JC, Palmaz JC, Barone HD. Transfemoral intraluminal graft implantation for abdominal aortic aneurysms. Annals of vascular surgery. 1991;5(6):491-9.

2. Ouriel K, Tanquilut E, Greenberg RK, Walker E. Aortoiliac morphologic correlations in aneurysms undergoing endovascular repair. Journal of vascular surgery. 2003;38(2):323-8.

3. Sternbergh WC, 3rd, Carter G, York JW, Yoselevitz M, Money SR. Aortic neck angulation predicts adverse outcome with endovascular abdominal aortic aneurysm repair. Journal of vascular surgery. 2002;35(3):482-6.

4. Sampaio SM, Panneton JM, Mozes GI, Andrews JC, Bower TC, Karla M, et al. Proximal type I endoleak after endovascular abdominal aortic aneurysm repair: predictive factors. Annals of vascular surgery. 2004;18(6):621-8.

5. Hobo R, Kievit J, Leurs LJ, Buth J, Collaborators E. Influence of severe infrarenal aortic neck angulation on complications at the proximal neck following endovascular AAA repair: a EUROSTAR study. Journal of endovascular therapy : an official journal of the International Society of Endovascular Specialists. 2007;14(1):1-11.

6. Schanzer A, Greenberg RK, Hevelone N, Robinson WP, Eslami MH, Goldberg RJ, et al. Predictors of abdominal aortic aneurysm sac enlargement after endovascular repair. Circulation. 2011;123(24):2848-55.

7. Carpenter JP, Baum RA, Barker CF, Golden MA, Mitchell ME, Velazquez OC, et al. Impact of exclusion criteria on patient selection for endovascular abdominal aortic aneurysm repair. Journal of vascular surgery. 2001;34(6):1050-4.

8. Rouwet EV, Torsello G, de Vries JP, Cuypers P, van Herwaarden JA, Eckstein HH, et al. Final results of the prospective European trial of the Endurant stent graft for endovascular abdominal aortic aneurysm repair. European journal of vascular and endovascular surgery : the official journal of the European Society for Vascular Surgery. 2011;42(4):489-97.

9. Stokmans RA, Teijink JA, Forbes TL, Bockler D, Peeters PJ, Riambau V, et al. Early results from the ENGAGE registry: real-world performance of the Endurant Stent Graft for endovascular AAA repair in 1262 patients. European journal of vascular and endovascular surgery : the official journal of the European Society for Vascular Surgery. 2012;44(4):369-75.

10. Chaikof EL, Blankensteijn JD, Harris PL, White GH, Zarins CK, Bernhard VM, et al. Reporting standards for endovascular aortic aneurysm repair. Journal of vascular surgery. 2002;35(5):1048-60.

11. Hyhlik-Durr A, Weber TF, Kotelis D, Rengier F, Gahlen J, Bock S, et al. The Endurant Stent Graft System: 15-month follow-up report in patients with challenging abdominal aortic anatomies. Langenbeck's archives of surgery / Deutsche Gesellschaft fur Chirurgie. 2011;396(6):801-10.

12. Georgiadis GS, Trellopoulos G, Antoniou GA, Gallis K, Nikolopoulos ES, Kapoulas KC, et al. Early results of the Endurant endograft system in patients with friendly and hostile infrarenal abdominal aortic aneurysm anatomy. Journal of vascular surgery. 2011;54(3):616-27. 
13. Torsello G, Troisi N, Donas KP, Austermann M. Evaluation of the Endurant stent graft under instructions for use vs off-label conditions for endovascular aortic aneurysm repair. Journal of vascular surgery. 2011;54(2):300-6.

14. Setacci F, Sirignano P, de Donato G, Galzerano G, Messina G, Guerrini S, et al. Two-year-results of Endurant stent-graft in challenging aortic neck morphologies versus standard anatomies. The Journal of cardiovascular surgery. 2014;55(1):85-92.

15. Bastos Goncalves F, Verhagen HJ, Vasanthananthan K, Zandvoort HJ, Moll FL, van Herwaarden JA. Spontaneous delayed sealing in selected patients with a primary type-ia endoleak after endovascular aneurysm repair. European journal of vascular and endovascular surgery : the official journal of the European Society for Vascular Surgery. 2014;48(1):53-9.

16. Moll FL, Powell JT, Fraedrich G, Verzini F, Haulon S, Waltham M, et al. Management of abdominal aortic aneurysms clinical practice guidelines of the European society for vascular surgery. European journal of vascular and endovascular surgery : the official journal of the European Society for Vascular Surgery. 2011;41 Suppl 1:S1-S58.

17. Bastos Goncalves F, Hoeks SE, Teijink JA, Moll FL, Castro JA, Stolker RJ, et al. Risk factors for proximal neck complications after endovascular aneurysm repair using the endurant stentgraft. European journal of vascular and endovascular surgery : the official journal of the European Society for Vascular Surgery. 2015;49(2):156-62.

18. Boult M, Maddern G, Barnes M, Fitridge R. Factors affecting survival after endovascular aneurysm repair: results from a population based audit. European journal of vascular and endovascular surgery : the official journal of the European Society for Vascular Surgery. 2007;34(2):156-62.

19. Miller M, Byington R, Hunninghake D, Pitt B, Furberg CD. Sex bias and underutilization of lipidlowering therapy in patients with coronary artery disease at academic medical centers in the United States and Canada. Prospective Randomized Evaluation of the Vascular Effects of Norvasc Trial (PREVENT) Investigators. Archives of internal medicine. 2000;160(3):343-7.

20. Mehta M, Byrne WJ, Robinson H, Roddy SP, Paty PS, Kreienberg PB, et al. Women derive less benefit from elective endovascular aneurysm repair than men. Journal of vascular surgery. 2012;55(4):90613.

21. Chung C, Tadros R, Torres M, Malik R, Ellozy S, Faries P, et al. Evolution of gender-related differences in outcomes from two decades of endovascular aneurysm repair. Journal of vascular surgery. 2015.

22. Dubois L, Novick TV, Harris JR, Derose G, Forbes TL. Outcomes after endovascular abdominal aortic aneurysm repair are equivalent between genders despite anatomic differences in women. Journal of vascular surgery. 2013;57(2):382-9 e1.

23. Stather PW, Wild JB, Sayers RD, Bown MJ, Choke E. Endovascular aortic aneurysm repair in patients with hostile neck anatomy. Journal of endovascular therapy : an official journal of the International Society of Endovascular Specialists. 2013;20(5):623-37.

24. Leurs LJ, Kievit J, Dagnelie PC, Nelemans PJ, Buth J, Collaborators E. Influence of infrarenal neck length on outcome of endovascular abdominal aortic aneurysm repair. Journal of endovascular therapy : an official journal of the International Society of Endovascular Specialists. 2006;13(5):6408. 
25. 25. Fulton JJ, Farber MA, Sanchez LA, Godshall CJ, Marston WA, Mendes R, et al. Effect of challenging neck anatomy on mid-term migration rates in AneuRx endografts. Journal of vascular surgery. 2006;44(5):932-7; discussion 7.

26. 26. Stokmans RA, Broos P, Cuypers PW, Forbes TL, Vahl AC, Swartbol P, et al. Rationale and design of the EAGLE Registry: EVAR with the Endurant in challenging anatomy. The Journal of cardiovascular surgery. 2014. 
Performance of the endurant stent graft in challenging anatomy 

Chapter 8

\title{
Rationale and design of the eagle registry: EVAR with the endurant in challening anatomy
}

\author{
P.P.H.L. Broos \\ R.A. Stokmans \\ Ph.W.M. Cuypers \\ T.L. Forbes \\ A.C. Vahl \\ P. Swartbol \\ M.R.H.M. van Sambeek \\ J.A.W. Teijink
}




\section{Abstract}

Aim: The aim of this study is to collect clinical information on the performance of the Endurant (II) Stent Graft System for endovascular repair in anatomically challenging infrarenal aneurysms, and to critically assess whether the current instructions for anatomic eligibility for endovascular treatment with this system are still applicable.

Methods: Initiated by doctors, EAGLE is a prospective, non-interventional study, aiming to enrol 250 patients in 20 experienced centres across several countries worldwide. EAGLE focuses on patients with challenging angulation or neck length. To minimize the risk of selection bias and enhance data quality, EAGLE eligibility will be determined by an independent core-lab and efforts will be made to secure consecutive enrolment of challenging cases. The EAGLE database is designed to merge with the on-going ENGAGE database, which enables comparative analysis of cases and results. The primary endpoint is treatment success at 30 days, 12 months and yearly up to 5 years post-implant.

Discussion: Separate studies on the performance of EVAR in challenging anatomy are necessary to demonstrate safety and effectiveness of the latest generation stent grafts, which is essential in making a balanced judgment about the optimal management of AAAs. 


\section{Introduction}

Over the past twenty years, endovascular aneurysm repair (EVAR) has been very successful in terms of the exclusion of aneurysms and the absence of perioperative and postoperative complications. Following to the instructions for use (IFU), the applicability of endografts to abdominal aortic aneurysms (AAAs) is restricted by AAA morphology and aortic dimensions. However, the management of AAAs has changed dramatically since Parodi et al. ${ }^{1}$ and Volodos et al. ${ }^{2}$ independently introduced EVAR in 1991.

According to several studies, the success of EVAR is closely dependent on an AAA's morphology and dimensions. ${ }^{3,4}$ For this reason, the IFU for all commercially available endografts present clear recommendations on AAA morphology and aortic dimensions. If the device-specific IFU are strictly followed, a substantial proportion (40\%) of patients must be rejected for having an anatomy that is unsuitable for EVAR, and more woman are rejected for EVAR than men. ${ }^{5}$

Despite these stringent IFU, it is clear that patients with an anatomy outside the recommend limits are also being treated by means of EVAR. When reviewing anatomic measurement data at our centre, we found that numerous patients with shorter and more angulated infrarenal necks, outside the IFU, had been treated with an EVAR device. In the United States, a retrospective study of CT-scans of 10,228 AAA-patients showed that $30 \%$ did not met the most liberal IFU criteria. ${ }^{4}$ In the ENGAGE registry approximately $10 \%$ of the treated patients had angulated or short necks, outside the IFU criteria, despite the fact that Endurant's IFU are liberal compared to other devices. ${ }^{4,7}$

Success rates and complication rates in these types of patients tend to be similar to those of patients who do meet the IFU criteria. These outcomes may be explained by the fact that the anatomic requirements defined in the IFU are based on research performed on first-generation endovascular stent grafts. Due to increased experience and improved devices, these criteria may therefore have become out-dated and may not be applicable to new-generation stet grafts, including the Endurant (II) System. 
Based on the encouraging initial results from the ENGAGE and our own centre's experience, it is possible that with current devices even more challenging cases could be treated endovascularly. So far, however, no large prospective study on these outcomes has been performed. Evidence on this topic may create an opportunity for a broader group of AAA patients to be treated with this minimally invasive technique.

Therefore we designed the EAGLE (Endurant for Challenging Anatomy: Global Experience) Registry. The aim of this study is to prospectively collect global 'real world' data on the performance of the Endurant Stent Graft System for endovascular repair in anatomically challenging infrarenal AAAs and to critically assess whether the current recommendations for anatomic eligibility for endovascular treatment with this system are still applicable.

\section{Methods}

EAGLE is a multi-centre, post-market, non-interventional, non-randomized, singlearm, prospective observational study, initiated by the Department of Vascular Surgery at Catharina Hospital Eindhoven, The Netherlands. The study has a singlearm without controls, as it is descriptive in nature. With an anticipated percentage of success of $94 \%$, sample size was calculated based on a hypothesis of noninferiority with a maximum of $10 \%$ difference. It will recruit approximately 250 anatomically challenging subjects from 20 high-volume sites from 10 countries worldwide from September 2012 until December 2015. Study enrolment is open to consecutively enrolled subjects who in the opinion of the investigators are candidates for endovascular AAA repair with the Endurant Stent Graft System despite having challenging anatomic measurements. With the approval of the ENGAGE executive committee all patients within the ENGAGE dataset exceeding anatomic requirements (approximately 100 subjects) will also be included in the EAGLE comparative analysis.

EAGLE does not interfere with the physician's decision whether or not to choose EVAR with an Endurant Stent Graft. Follow-up imaging studies are requested at 1 month, 12 months, and yearly thereafter, as minimally required by the reporting 
standards for endovascular aortic aneurysm repair.8 Beyond this, sites can schedule a subject's follow-up visits as usual in their clinical practice, as this study does not interfere with or influence the follow-up regimen. For data completion it is, however, possible that a telephone contact with subjects will be requested.

\section{Participating centres}

Clinical sites with an annual case volume of more than 50 EVAR procedures and at least 25 successful prior Endurant implants are eligible to participate in the EAGLE Registry. Local ethical committees must approve participation in EAGLE. The initiating centre, Catharina Hospital, Eindhoven, the Netherlands, will also participate as one of the enrolling sites in the EAGLE Registry.

\section{Device description}

The Endurant Stent Graft is designed to treat infrarenal abdominal aortic or aorto-iliac aneurysms using an endovascular approach. When placed within the aneurysm, the Endurant Stent Graft provides a permanent, alternative conduit for blood flow within the subject's vasculature by excluding the aneurysm sac from blood flow and pressurization.

Certain key features are present in the Endurant Stent Graft System, such as a design optimized to treat difficult anatomies with $\leq 75^{\circ}$ infrarenal neck angulation, a lower diameter profile to access and track small iliac vessels and a hydrophiliccoated delivery system for improved handling. The Endurant Stent Graft also includes suprarenal anchoring pins for improved proximal fixation.

The Endurant II Stent Graft System differs from its predecessor in three ways: 28 mm-diameter bifurcated segment to fit inside an 18 French OD catheter (down from 20 French), addition of two new contralateral limb lengths (156 mm and 199 $\mathrm{mm}$ ), and improved radiopacity of the distal end of the bifurcated segment's contralateral gate.

The Endurant (II) Stent Graft System is indicated for the endovascular treatment of infrarenal abdominal aortic or aorto-iliac aneurysms in patients with the characteristics according the IFU (Table 1). 
Table 1. Endurant ${ }^{\circledR}$ and Endurant ${ }^{\circledR}$ II instructions for use.

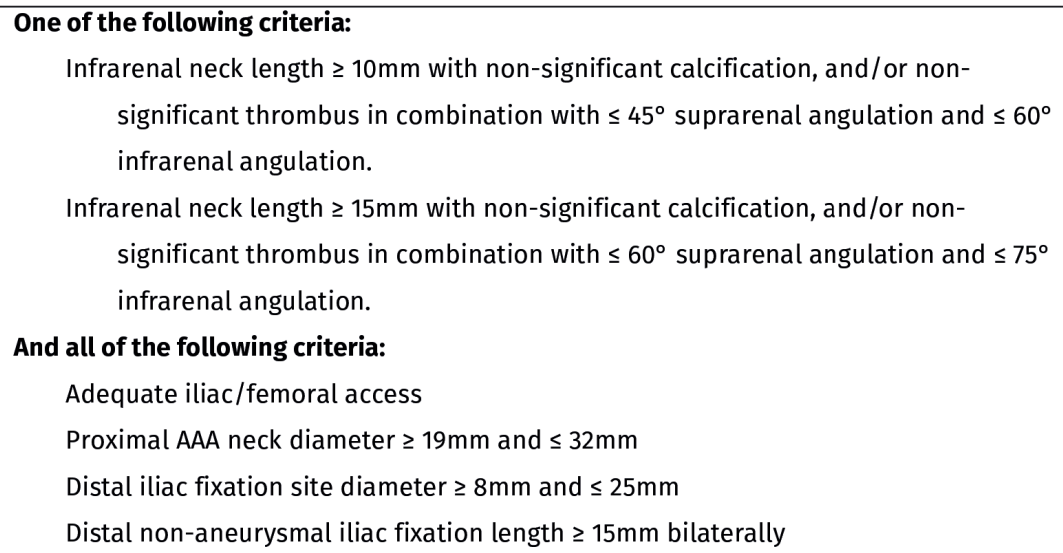

\section{Enrollment criteria}

Participation in the EAGLE registry is intended for all subjects diagnosed with an infrarenal AAA whom their own physicians consider candidates for endovascular repair and who meet the inclusion criteria. EAGLE focuses on patients with challenging angulation or challenging neck length. To prevent selection bias, sites are requested to provide a minimal set of morphologic data of all patients scheduled for EVAR treatment with the Endurant Stent Graft from the moment a site participates in the EAGLE registry. To be included in the trial, patients need to be 18 years old and have an indication for elective EVAR with the Endurant (II) stent graft. AAA anatomy must be challenging as defined in the measurements described in table 2.

Exclusion criteria are high probability of non-adherence to physician's follow-up requirements or participation in a concurrent trial, because this may confound study results. Patients will also be excluded if adjuvant procedures at the proximal aortic neck are planned, such as chimney technique, branched device, fenestrated device or endostaplers. 
Subjects who meet all of the study eligibility criteria will be eligible for enrolment in the EAGLE study. An independent core-lab will crosscheck these considered patients' appropriate imaging studies (Computed tomography angiography (CTA) with a minimal slice thickness of $3 \mathrm{~mm}$ ) for EAGLE inclusion eligibility. The core-lab will be blinded for patient identity and for responsible physician. Subjects will be included if morphologic inclusion criteria are verified by the core-lab.

Table 2. Inclusion and exclusion criteria EAGLE Registry

\section{INCLUSION}

- Age $\geq 18$ years or minimum age as required by local regulations

- Indication for elective EVAR

- AAA diameter of $>5.5 \mathrm{~cm}$, or

- AAA diameter of $4.5-5.5 \mathrm{~cm}$ with $>0.5 \mathrm{~cm}$ growth in 6 months, or

- AAA diameter of >1.5 times reference infrarenal aortic diameter

- Challenging AAA anatomy defined by having one of the following measurements:

- Proximal necks $5-10 \mathrm{~mm}$

in combination with $\leq 60^{\circ}$ infrarenal $A N D \leq 45^{\circ}$ suprarenal angulation

- Proximal necks $10-15 \mathrm{~mm}$

in combination with $60^{\circ}-75^{\circ}$ infrarenal $A N D \leq 60^{\circ}$ suprarenal angulation

$O R$ in combination with $\leq 75^{\circ}$ infrarenal AND $45^{\circ}-60^{\circ}$ suprarenal angulation

- Proximal necks $\geq 15 \mathrm{~mm}$

in combination with $75^{\circ}-90^{\circ}$ infrarenal $A N D \leq 75^{\circ}$ suprarenal angulation

$O R$ in combination with $\leq 90^{\circ}$ infrarenal AND $60^{\circ}-75^{\circ}$ suprarenal angulation

- Intention to electively implant the Endurant or Endurant II Stent Graft System ${ }^{\circ}$

- $\quad$ Signed informed consent form

\section{EXCLUSION}

- High probability of non-adherence to physician's follow-up requirements

- Current participation in a concurrent trial which may confound study results

- Planned for following adjuvant procedures at the proximal aortic neck: chimney technique, branched device or endostaplers 


\section{Implantation and follow-up}

The implant procedure shall be performed according to usual practice at the site and in line with the IFU. During the endovascular procedure it is at the investigator's discretion to employ anesthesia, to administer antibiotics and systemic heparin, and to obtain and close access to the arterial site. All the devices should be deployed following all the steps in the IFU.

Use of an angiographic catheter with calibrated radiopaque marking is preferred. The investigator will verify dimensions and characterizations of each subject's anatomy in relation to the Endurant Stent Graft System.

Each subject will continue to be followed according to the follow-up regimen that is standard clinical practice at each site. To be compliant to the protocol and current standard care in EVAR therapy, the subjects are requested to return to the sites for 1-year follow-up visits and annually thereafter until the 5-year visit at the end of the study. The 30-day visit will be considered the first visit after the initial implantation procedure and the timing of this visit may vary according to local follow-up regimes.

\section{Study endpoints}

The primary endpoint of the EAGLE registry is treatment success at the time of the index procedure, at 30 days, 12 months and yearly up to 5 years post-implant. Treatment success is defined by technical success and clinical success. Technical success is defined as successful delivery and deployment of the Endurant Stent Graft in planned position without unintentional coverage of one or both internal iliac arteries or renal or visceral aortic branches and with successful removal of the delivery system. Clinical success is defined as freedom from aneurysm expansion of $>5 \mathrm{~mm}$, freedom from Type I and III endoleaks, freedom from aneurysm rupture, freedom from conversion to open surgery, and freedom from stent graft migration (>10mm) and occlusion.

The secondary endpoints comprise technical observation, adverse events, major adverse events and quality of life. Technical observations include: presence of an endoleak, stent graft kinking, stent graft wire form fracture, suprarenal bare stent 
fracture or detachment from fabric, stent graft occlusion or stent graft stenosis. Major adverse events include all-cause mortality, bowel ischemia, myocardial infarction, paraplegia, procedural blood loss $\geq 1000 \mathrm{cc}$, renal failure, respiratory failure and stroke. All deaths within 30 days after procedure are defined as aneurysm-related. Quality of life will be assessed before admission, after discharge, at 30 days, at 12 months and annually thereafter. Health outcome will be measured by the EuroQol 5-Dimensions (EQ-5D) questionnaire, which includes a visual analogue scale and a descriptive system. ${ }^{9}$ The EQ-5D questionnaire forms are designed for self-completion by subjects and will be provided in local language.

\section{Adverse event monitoring}

Study-specific Adverse Events (AE) information will be collected throughout the study, documented in the subject's medical record and reported to the coordinating centre on an Adverse Event e-CRF. For the purpose of the clinical report, we will classify each study-specific AE according to EN ISO 14155-1. Serious AEs will be reported to investigators, ECs and Regulatory Authorities according to national regulations and requirements.

\section{Data collection and monitoring}

Clinical data collection will only start after the subject has given voluntary, documented informed consent. Data collected will be recorded on appropriate web-based or paper format case report forms (CRFs). Instructions for proper completion of the CRFs may be printed at the sites to use as a working copy. The CRFs will be completed, reviewed, signed and dated by the clinical investigators. Data will be collected at baseline, during the implant procedure, throughout the hospital stay, and in the 5-year post-operative follow-up phase.

All participating centres are monitored by a research team of the Department of Vascular Surgery, Catharina Hospital, Eindhoven to confirm adherence to the clinical investigational plan, to assess the accuracy and completeness of submitted clinical data, and to verify that records and documents are being properly maintained for the duration of the study. The Statistics \& Data Analysis team at the Department of Vascular Surgery, Catharina Hospital, Eindhoven will 
check the data entered on the CRFs for consistency and completeness on a regular basis, both manually as well as by means of statistical monitoring of the clinical database. Sites will be contacted for data inconsistencies in order to recover incomplete, inconsistent, or missing data. In case of multiple futile attempts at data completeness and non-response from clinical sites, sites will be visited by monitors of the Department of Vascular Surgery, Catharina Hospital, Eindhoven. In such cases, they will collect data from source documents in a final attempt to complete the applicable CRFs. To enhance data quality, additional site visits will be conducted to crosschecks CRFs with patient files in approximately $20 \%$ of enrolled subjects.

\section{Statistical analysis}

Statistical analyses will take place after final subject's 30-day follow-up, 1 year follow-up and thereafter annually. Statistical analyses will be performed using Predicting Analytics Software (SPAW/SPSS) for Mac (version 20 or more recent) or other validated statistical software.

\section{Discussion}

Endovascular aneurysm repair (EVAR) is considered a safe and effective alternative to open repair for the treatment of selected cases of abdominal aortic aneurysm (AAA). The success of EVAR is, however, dependent upon patient-specific factors, including aortic dimensions and aneurysm morphology. Severely angulated or short infrarenal necks are associated with an increased risk of operative failure and late aneurysm rupture due to proximal Type-I endoleaks and graft migration. To limit these risks, IFU for commercially available stent grafts indicate use within a specific range of aortic anatomy. As a consequence, a substantial proportion of AAA patients are considered ineligible for EVAR as they fail to meet IFU criteria.

In the past two decades, many technological advances have been introduced to improve feasibility and durability of EVAR. Also, surgeons have become more proficient in applying endovascular techniques. These developments have led to an increasing interest and confidence to extend treatment to challenging anatomies. Currently, $>70 \%$ of elective AAA repairs are performed with EVAR, and 
approximately $30 \%$ of these patients are considered outside IFU criteria. 4 Multiple studies show comparable results in patients with conservative and challenging anatomy regarding mortality, proximal Type-1 endoleaks and reinterventions (Table 3). These studies indicate that EVAR with simple infrarenal stent graft placement can be used with caution in patients with unfavourable anatomy. ${ }^{10}$ However the quality of the evidence in challenging cases is still scarce, due to a lack of long-term results and consecutive series.

Therefore, the EAGLE (Endurant for Challenging Anatomy: Global Experience) Registry is designed to register the performance of the newest generation stent graft in challenging anatomy in a real-world setting, and to critically assess whether or not it is reasonable and safe to expand current guidelines of anatomic eligibility for endovascular treatment. To minimize the risks of selection bias and enhance data quality, EAGLE eligibility will be determined by an independent core-lab and efforts will be made to secure consecutive enrolment of challenging cases.

The EAGLE Registry is unique and revolutionary in its design, aiming at a high number of challenging cases with a long-term follow-up. It will create a consecutive case series of the performance of EVAR in challenging anatomy with the latest generation stent graft. Future results from the EAGLE registry may reveal how far boundaries can be safely stretched, and broaden the applicability rate of EVAR.

Table 3. Overview of results in studies presenting Challenging and Friendly anatomy

\begin{tabular}{|c|c|c|c|c|c|c|}
\hline \multirow[t]{2}{*}{ Study } & \multicolumn{2}{|c|}{ Population Size } & \multicolumn{2}{|c|}{$\begin{array}{c}\text { Mortality } \\
\text { at } 30 \text {-days (\%) }\end{array}$} & \multicolumn{2}{|c|}{$\begin{array}{l}\text { Type-I endoleaks } \\
\text { within } 30 \text { days (\%) }\end{array}$} \\
\hline & Challenging & Friendly & Challenging & Friendly & Challenging & Friendly \\
\hline$\overline{\text { Setacci (2012) }}{ }^{11}$ & 72 & 65 & $2(2.7)$ & $1(1.5)$ & $0(0)$ & $0(0)$ \\
\hline Stather $(2012)^{12}$ & 199 & 353 & $1(0.5)$ & $4(1.1)$ & $5(2.5)$ & $3(0.8)$ \\
\hline Torsello (2011) ${ }^{13}$ & 56 & 121 & $1(1.8)$ & $2(1.7)$ & $2(3.6)$ & $0(0)$ \\
\hline Goncalves (2011) ${ }^{14}$ & 45 & 65 & $1(2.2)$ & $2(3.1)$ & $0(0)$ & $0(0)$ \\
\hline Aburahma (2011) ${ }^{15}$ & 149 & 89 & - & - & $1(0.7)$ & $0(0)$ \\
\hline \multirow[t]{3}{*}{ Weighted MEAN } & 521 & 693 & $1.3 \%$ & $1.5 \%$ & $1.5 \%$ & $0.4 \%$ \\
\hline & \multicolumn{2}{|c|}{$\begin{array}{l}\text { Type-I endoleaks } \\
\text { at } 1 \text { year }(\%)\end{array}$} & \multicolumn{2}{|c|}{$\begin{array}{c}\text { Re-interventions within } 1 \\
\text { year }(\%)\end{array}$} & \multicolumn{2}{|c|}{$\begin{array}{c}\text { AAA-related mortality } \\
\text { at } 1 \text { year }(\%)\end{array}$} \\
\hline & Challenging & Friendly & Challenging & Friendly & Challenging & Friendly \\
\hline Setacci (2012) ${ }^{11}$ & - & - & - & - & - & - \\
\hline Stather $(2012)^{12}$ & - & - & - & - & - & - \\
\hline Torsello $(2011)^{13}$ & $4(7.1)$ & $0(0)$ & $5(8.9)$ & $6(5.0)$ & $1(1.8)$ & $0(0)$ \\
\hline Goncalves (2011) ${ }^{14}$ & - & - & - & - & - & - \\
\hline Aburahma (2011) ${ }^{15}$ & $16(10.7)$ & $3(3.4)$ & $7(4.7)$ & $5(5.6)$ & $1(0.7)$ & $0(0)$ \\
\hline Weighted MEAN & $9.8 \%$ & $1.4 \%$ & $5.9 \%$ & $5.2 \%$ & $1.0 \%$ & $0.0 \%$ \\
\hline
\end{tabular}




\section{References}

1. Parodi JC, Palmaz JC, Barone HD. Transfemoral intraluminal graft implantation for abdominal aortic aneurysms. Ann Vasc Surg 1991;5:491-9.

2. Volodos NL, Karpovich IP, Troyan VI, Kalashnikova Yu V, Shekhanin VE, Ternyuk NE, et al. Clinical experience of the use of self-fixing synthetic prostheses for remote endoprosthetics of the thoracic and the abdominal aorta and iliac arteries through the femoral artery and as intraoperative endoprosthesis for aorta reconstruction. Vasa Suppl 1991;33:93-5.

3. Ouriel K, Tanquilut E, Greenberg RK, Walker E. Aortoiliac morphologic correlations in aneurysms undergoing endovascular repair. J Vasc Surg 2003;38:323-8.

4. Schanzer A, Greenberg RK, Hevelone N, Robinson WP, Eslami MH, Goldberg RJ, et al. Predictors of abdominal aortic aneurysm sac enlargement after endovascular repair. Circulation 2011;123:284855.

5. Moise MA, Woo EY, Velazquez OC, Fairman RM, Golden MA, Mitchell ME, et al. Barriers to endovascular aortic aneurysm repair: past experience and implications for future device development. Vasc Endovascular Surg 2006;40:197-203.

6. Bockler D, Fitridge R, Wolf $\mathrm{Y}$, Hayes $\mathrm{P}$, Silveira PG, Numan F, et al. Rationale and design of the Endurant Stent Graft Natural Selection Global Postmarket Registry (ENGAGE): interim analysis at 30 days of the first 180 patients enrolled. J Cardiovasc Surg (Torino) 2010;51:481-91.

7. Stokmans RA, Teijink JA, Forbes TL, Bockler D, Peeters PJ, Riambau V, et al. Early Results from the ENGAGE Registry: Real-world Performance of the Endurant Stent Graft for Endovascular AAA Repair in 1262 Patients. Eur J Vasc Endovasc Surg 2012;44(4):379-75.

8. Chaikof EL, Brewster DC, Dalman RL, Makaroun MS, Illig KA, Sicard GA, et al. The care of patients with an abdominal aortic aneurysm: the Society for Vascular Surgery practice guidelines. J Vasc Surg 2009;50:S2-49.

9. Cavrini G, Broccoli S, Puccini A, Zoli M. EQ-5D as a predictor of mortality and hospitalization in elderly people. Qual Life Res 2012;21:269-80.

10. Antoniou GA, Georgiadis GS, Antoniou SA, Kuhan G, Murray D. A meta-analysis of outcomes of endovascular abdominal aortic aneurysm repair in patients with hostile and friendly neck anatomy. J Vasc Surg 2013;57:527-38.

11. Setacci F, Sirignano P, de Donato G, Chisci E, lacoponi F, Galzerano G, et al. AAA with a challenging neck: early outcomes using the Endurant stent-graft system. Eur J Vasc Endovasc Surg 2012;44:2749.

12. Stather PW, Sayers RD, Cheah A, Wild JB, Bown MJ, Choke E. Outcomes of endovascular aneurysm repair in patients with hostile neck anatomy. Eur J Vasc Endovasc Surg 2012;44:556-61.

13. Torsello G, Troisi N, Donas KP, Austermann M. Evaluation of the Endurant stent graft under instructions for use vs off-label conditions for endovascular aortic aneurysm repair. J Vasc Surg 2011;54:300-6. 
14. Bastos Goncalves F, de Vries JP, van Keulen JW, Dekker H, Moll FL, van Herwaarden JA, et al. Severe proximal aneurysm neck angulation: early results using the Endurant stentgraft system. Eur J Vasc Endovasc Surg 2011;41:193-200.

15. Aburahma AF, Campbell JE, Mousa AY, Hass SM, Stone PA, Jain A, et al. Clinical outcomes for hostile versus favorable aortic neck anatomy in endovascular aortic aneurysm repair using modular devices. J Vasc Surg 2011;54:13-21. 




\section{Summary and general discussion}

This thesis focuses on endovascular repair (EVAR) and outcome in patients with non-ruptured and ruptured abdominal aortic aneurysms (AAAs), evaluates new insights and possibilities for EVAR, and evaluates EVAR in challenging infrarenal aortic neck anatomy.

This chapter describes the main findings of this thesis and concludes with the limitations of this thesis and some suggestions for future research.

\section{PART ONE - Evolution and long-term follow-up in EVAR}

Since the introduction of elective EVAR in 1991 by Parodi and Volodos, followed by the introduction of emergency EVAR in 1994 by Yusuf, the endovascular approach of AAAs has been applied with increasing frequency. ${ }^{1-4}$ The endovascular approach of AAAs is less invasive than open surgical repair (OR) and demonstrates decreased early mortality and morbidity.,5 PART ONE focuses on the outcome of elective and emergency EVAR using a prospective single-centre database.

The occurrence of graft-related and aneurysm-related complications remains the Achilles' heel of the endovascular approach of abdominal aortic aneurysm treatment. Indicationsto perform secondary interventionsare endoleaks, stentgraft migration, stent fractures and stent graft occlusions. ${ }^{7,8}$ Current guidelines advise lifelong surveillance after EVAR in order to detect EVAR related complications. 9 However, there is limited data on long-term stent graft related complications to support this recommendation. This raises the question whether such an extended follow-up is really necessary. Chapter 2 evaluated 149 AAA patients treated with the Talent Abdominal Stent Graft (Medtronic Vascular, Santa Rosa, CA, USA) with a minimum of ten-year follow-up. Technical success, defined as a successful stent graft deployment and the absence of type I and III endoleaks, was achieved in $89.3 \%$ of the procedures. The primary outcome was clinical success, defined as the absence of aneurysm related death, graft stenosis, occlusion or infection, type I or III endoleak, aneurysm expansion, aneurysm rupture, or conversion to open repair. In our population, the 30-day, one-year, five-year and ten-year clinical success rates were $81.1 \%, 74.3 \%, 70.3 \%$ and $65.5 \%$, respectively. A total of $20.7 \%$ of 
patients required at least one secondary intervention, which is comparable with previous studies. In $70 \%$ of the secondary interventions, stent graft failure was detected at regular follow-up, as patients were asymptomatic. The outcome of this study demonstrated EVAR-related complications during the entire follow-up period and therefore justifies surveillance at least up to ten years.

The technical success of EVAR is highly dependent on accurate preoperative planning, including aortic aneurysm sizing and adequate stent graft selection. In emergency EVAR, planning has to be done in a restricted time frame with a limited availability of stent graft modules. This could hypothetically influence the technical outcome. Chapter 3 describes a 15-year single-centre experience of EVAR in 773 patients with a non-ruptured AAA and 90 patients with a ruptured AAA. This study demonstrates excellent intra-operative success rates of $95.0 \%$ in elective EVAR and $90.0 \%$ in emergency EVAR $(p=.052)$. We found a higher incidence of type I endoleaks at completion angiography after emergency EVAR (6.9\% vs. $2.8 \%$, p = .038). However, the majority of these type I endoleaks resolved spontaneously without secondary intervention. In addition, there were no significant differences in the need for endograft-related secondary interventions after five years of follow-up. As may be expected, the survival rates for all-cause mortality at 5-year follow-up were significantly lower after emergency EVAR ( $48.1 \%$ vs. $65.2 \%, p<.001)$. The outcome of this study indicates that EVAR is technically comparable in elective and emergency settings.

\section{PART TWO - Clinical experience and new insights regarding EVAR}

Despite more than two decades of experience with EVAR, opinions are still divided regarding some aspects of this technique. PART TWO of this thesis focuses on the use of different anaesthesia types and emergency EVAR in hemodynamically unstable patients.

EVAR can be performed under general, regional and local anaesthesia. There is still no consensus on which type of anaesthesia is most suitable. Being less invasive, the use of local anaesthesia is preferred according the guideline of the European Society of Vascular Surgery. ${ }^{9}$ However, EVAR is still mainly performed under general anaesthesia. ${ }^{10}$ Chapter $\mathbf{4}$ examined outcomes of EVAR using general anaesthesia 
(GA), regional anaesthesia (RA) and local anaesthesia (LA) in 1262 patients. The majority of patients were treated under general anaesthesia (GA 62.3\%, RA 26.2\%, LA 11.5\%). We reported advantages of local and regional anaesthesia regarding procedure time and post-operative stay. Type of anaesthesia used did not influence technical success rates. LA resulted in fewer short-term complications, however a significant advantage was not established (GA $5.6 \%$ vs. RA $4.8 \%$ vs. LA 2.8\%). Thirty-day mortality was comparable among groups (GA $1.4 \%$ vs. RA $0.9 \%$ vs. LA 1.4\%).

According to a recent meta-analysis, mortality rates in patients with a ruptured AAA are estimated at $81 \% .^{11} \mathrm{Up}$ to half of the patients who undergo surgical treatment will subsequently die in the perioperative period.12 Previous studies reported no survival probability in patients requiring preoperative cardiopulmonary resuscitation (CPR). 13,14 We evaluated 199 patients with an RAAA in three large nonacademic teaching hospitals, and the results are reported in Chapter 5. Twentythree RAAA patients (11.6\%) did not receive invasive treatment, because they were deemed inoperable or were deceased before surgery could be initiated. This turndown rate is relatively low in comparison to the literature with turn-down rates of up to $40 \% .^{15}$ We identified 13 (7.4\%) treated patients who needed preoperative CPR. The majority were resuscitated in the hospital (76.9\%). A total of 11 CPR patients were treated with open aortic surgery (OR), and two CPR patients underwent EVAR. Both EVAR patients survived, in contrast to $3 / 11$ of OR patients $(p=.128$ ). In contrast to the in literature reported $100 \%$ mortality in this patient group, we found a 30 -day survival rate of $38.5 \%(5 / 13))^{13,14}$ Although no firm conclusions can be drawn based on these low numbers, our results suggest that aneurysm treatment in hemodynamically unstable patients is still feasible and that EVAR may be preferred over open repair.

\section{PART THREE - Challenging anatomy in EVAR}

Anatomic suitability for EVAR is defined by the manufacturers' instructions for use (IFU) and remains one of the main reasons for treating an AAA via open surgery. However, contemporary stent grafts are used in challenging aortic neck situations exceeding the IFU limitations. PART THREE focuses on elective and emergency EVAR in challenging aortic neck anatomies. 
There have been reports that up to $80 \%$ of patients with an RAAA are regarded not suitable for EVAR. ${ }^{16}$ In Chapter 6, we compare the midterm results of EVAR for RAAAs in patients with favourable (FNA) and challenging neck anatomy (HNA) according the IFU. An EVAR-first strategy was followed for RAAA repair. A total of 39 patients were included who primarily underwent endovascular treatment. Challenging neck anatomy was present in $43.6 \%$. Technical success was comparable (FNA $100 \%$ vs. HNA $88.2 \%, p=.184$ ). There was no type I endoleak at completion angiography in any of the groups, but the HNA group required significantly more adjunctive procedures to resolve an intra-operative type IA endoleak ( $23.5 \%$ vs. $0 \%, p=.029$ ). There were no significant differences between groups at one-year follow up in type I endoleaks, secondary endovascular procedures and all-cause mortality. These excellent results indicate that EVAR applicability in RAAAs with challenging neck anatomy is technically feasible and safe in experienced endovascular centres.

Chapter 7 compares outcomes of EVAR in patients with various neck morphologies in an elective setting. Data from the ENGAGE Registry were used for the analyses. Patients were categorized into three groups, based on the complexity of the proximal aortic neck: regular (REG), intermediate (INT) and challenging (CHA). There were no significant differences in operative technical success. The 30day incidence of type I endoleaks was significantly higher in patients with $\mathrm{CHA}$ anatomy compared to INT and REG anatomy (REG vs. CHA: OR 0.15, 95\% Cl 0.050.46 and INT vs. CHA: OR 0.08, 95\% Cl 0.01-0.70). Surprisingly this difference did not result in more secondary interventions. Most type I endoleaks were small and resolved spontaneously. At 1-year follow-up, there were no differences in type I endoleaks, secondary interventions or mortality among groups. Based on these data, we can conclude that patients with severely angulated and short infrarenal necks can be treated successfully with the Endurant Stent Graft.

The performance of the Endurant Stent Graft in challenging anatomy is evaluated in many reports, showing no differences in operative success and early outcome.17-19 However, these studies consisted of (relatively) small, retrospectively collected patient groups with possible selection bias. Therefore, the Endurant for challenging Anatomy: GLobal Experience (EAGLE) Registry was initiated to prospectively collect global 'real-world' performance data on the Endurant Stent Graft in anatomically 
challenging aneurysms and to critically assess whether the current guidelines for anatomic eligibility for EVAR are still applicable if EVAR is performed with this system. The penultimate chapter of this thesis (Chapter $\mathbf{8}$ ) describes the rationale and design of the EAGLE Registry. Initiated by doctors, EAGLE is a prospective, noninterventional study, aiming to enrol 250 patients with a challenging anatomy in at least 20 experienced vascular centres worldwide. Ruptured AAAs will be excluded. To minimize the risk of selection bias, anatomic eligibility will be determined by an independent core laboratory, and efforts will be made to secure consecutive enrolment. The primary endpoint is technical success at 30 days, 1 year and yearly up to five years post-implant. EAGLE aims to complete enrolment in 2016.

\section{Study limitation and future perspectives}

\section{PART ONE - Evolution and long-term follow up in EVAR}

A quarter of a century has passed since Parodi and Volodos introduced the endovascular repair of AAA. The Achilles's heel of EVAR remains the high rate of secondary interventions. Lifelong follow-up requires a great investment of time and resources, while the majority of these patients do not require any further intervention. It would be desirable to identify patients with a significantly higher risk for complications and provide these patients with an extensive follow-up. Our data analysis could not identify predictors for graft-related complications or secondary interventions. The success of EVAR is closely dependent on AAA morphology and aortic dimensions. However, anatomical data was missing in our study. ${ }^{20}$

There is an ever need for improved stent grafts and endovascular techniques to increase the durability and safety of EVAR. In the past few years, the focus of improvements has been mainly on deliverability, placement accuracy and tight sealing to reduce graft-related complications and the need for secondary interventions. With continuous refinement of both the stent graft and its delivery system, and with the increasing experience of physicians, the outcome and applicability of EVAR will continue to improve in the future. ${ }^{21}$ 


\section{PART TWO Clinical experience and new insights regarding EVAR}

We described fewer systemic complications for the use of local anaesthesia, but no significant advantage of local anaesthesia was established. This could be explained by the low incidence of complications after EVAR. A much larger study population is necessary to demonstrate clinical differences between anaesthesia types. Local anaesthesia did result in shorter procedure time and shorter postoperative stay. The standard use of local anaesthesia during EVAR procedures could reduce treatment costs in the future.

We described survivors after CPR prior to RAAA surgery, which is in contrast to previous studies that described $100 \%$ mortality in this patient group. Of the survivors, two patients were treated with EVAR and three with open surgical repair. Due to these small numbers, we were unable to conclude if EVAR is better than open repair. However, one might expect that a minimally invasive treatment under local anaesthesia with a shorter operating time, less bloodloss en no need for aortic cross clamping will result in better outcome. Future research with more patients is necessary to investigate if a minimally invasive approach may be preferred in highly unstable patients.

\section{PART THREE - Challenging anatomy in EVAR}

We did not investigate whether EVAR or open surgical repair is better for patients with challenging aortic anatomies. The optimal study design for answering this question is a randomized controlled trial comparing open repair with EVAR. However, one must question if such an RCT design is feasible in view of the contemporary preference for EVAR. Moreover, RCT results may not reflect 'real world' outcome since patient inclusion is often subject to strict inclusion criteria. The ENGAGE registry will contain a great number of data regarding the real world performance of a latest generation stent graft system. Based on this database, on current literature and on our own experience, it seems that a great share of EVAR patients are actually treated outside of IFU criteria. Although a great number of surgeons do so, at least apparently, no evidence exists on the 'rightful' use of these devices outside IFU. Unfortunately, the number of challenging cases in ENGAGE has not enough power to perform a sub-analysis to test for non-inferiority of these challenging cases. With the EAGLE registry, which has a similar design as ENGAGE, we aim to expand the subgroup of challenging cases in an effective 
way so we can perform an adequate analysis. We aim to answer the question if the technical success rate and the successful treatment rate are comparable in anatomically challenging aneurysms. 


\section{References}

1. Parodi JC, Palmaz JC, Barone HD: Transfemoral intraluminal graft implantation for abdominal aortic aneurysms. Ann Vasc Surg 1991; 5: 491-9

2. Volodos NL, Karpovich IP, Shekhanin VE, et al.: [A case of distant transfemoral endoprosthesis of the thoracic artery using a self-fixing synthetic prosthesis in traumatic aneurysm]. Grudn Khir 1988: 84-6

3. Yusuf SW, Whitaker SC, Chuter TA, et al.: Emergency endovascular repair of leaking aortic aneurysm. Lancet 1994; 344: 1645

4. Park BD, Azefor $\mathrm{N}$, Huang $\mathrm{CC}$, et al.: Trends in treatment of ruptured abdominal aortic aneurysm: impact of endovascular repair and implications for future care. J Am Coll Surg 2013; 216: 745-54; discussion 754-5

5. participants Et: Endovascular aneurysm repair versus open repair in patients with abdominal aortic aneurysm (EVAR trial 1): randomised controlled trial. Lancet 2005; 365: 2179-86

6. Prinssen M, Verhoeven EL, Buth J, et al.: A randomized trial comparing conventional and endovascular repair of abdominal aortic aneurysms. N Engl J Med 2004; 351: 1607-18

7. Chaikof EL, Blankensteijn JD, Harris PL, et al.: Reporting standards for endovascular aortic aneurysm repair. J Vasc Surg 2002; 35: 1048-60

8. Torsello GB, Klenk E, Kasprzak B, et al.: Rupture of abdominal aortic aneurysm previously treated by endovascular stentgraft. J Vasc Surg 1998; 28: 184-7

9. Moll FL, Powell JT, Fraedrich G, et al.: Management of abdominal aortic aneurysms clinical practice guidelines of the European society for vascular surgery. Eur J Vasc Endovasc Surg 2011; 41 Suppl 1: S1-S58

10. Ruppert V, Leurs LJ, Steckmeier B, et al.: Influence of anesthesia type on outcome after endovascular aortic aneurysm repair: an analysis based on EUROSTAR data. J Vasc Surg 2006; 44: 16-21; discussion 21

11. Reimerink JJ, van der Laan MJ, Koelemay MJ, et al.: Systematic review and meta-analysis of population-based mortality from ruptured abdominal aortic aneurysm. Br J Surg 2013; 100: 140513

12. Investigators IT, Powell JT, Sweeting MJ, et al.: Endovascular or open repair strategy for ruptured abdominal aortic aneurysm: 30 day outcomes from IMPROVE randomised trial. BMJ 2014; 348: f7661

13. Greeven AP, Bouwman LH, Smeets HJ, et al.: Outcome of patients with ruptured abdominal aortic aneurysm after cardiopulmonary resuscitation. Acta Chir Belg 2011; 111: 78-82

14. Johansen K, Kohler TR, Nicholls SC, et al.: Ruptured abdominal aortic aneurysm: the Harborview experience. J Vasc Surg 1991; 13: 240-5; discussion 245-7 
15. Karthikesalingam A, Holt PJ, Vidal-Diez A, et al.: Mortality from ruptured abdominal aortic aneurysms: clinical lessons from a comparison of outcomes in England and the USA. Lancet 2014; 383: $963-9$

16. Rose DF, Davidson IR, Hinchliffe RJ, et al.: Anatomical suitability of ruptured abdominal aortic aneurysms for endovascular repair. J Endovasc Ther 2003; 10: 453-7

17. Hyhlik-Durr A, Weber TF, Kotelis D, et al.: The Endurant Stent Graft System: 15-month follow-up report in patients with challenging abdominal aortic anatomies. Langenbecks Arch Surg 2011; 396: $801-10$

18. Torsello G, Troisi N, Donas KP, et al.: Evaluation of the Endurant stent graft under instructions for use vs off-label conditions for endovascular aortic aneurysm repair. J Vasc Surg 2011; 54: 300-6

19. Georgiadis GS, Trellopoulos G, Antoniou GA, et al.: Early results of the Endurant endograft system in patients with friendly and hostile infrarenal abdominal aortic aneurysm anatomy. J Vasc Surg 2011; 54: 616-27

20. Ouriel K, Tanquilut E, Greenberg RK, et al.: Aortoiliac morphologic correlations in aneurysms undergoing endovascular repair. J Vasc Surg 2003; 38: 323-8

21. Tadros RO, Faries PL, Ellozy SH, et al.: The impact of stent graft evolution on the results of endovascular abdominal aortic aneurysm repair. J Vasc Surg 2014; 59: 1518-27 

Chapter 10 Nederlandse samenvatting

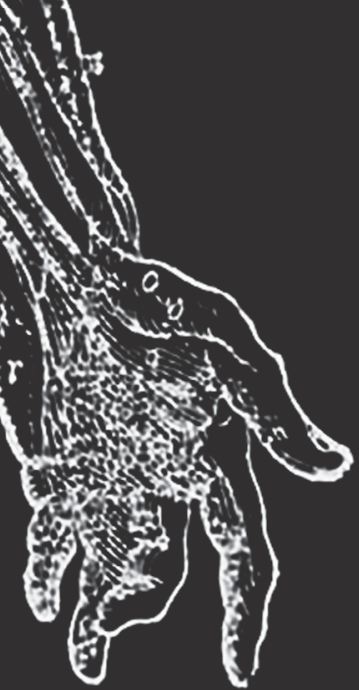





\section{Nederlandse samenvatting}

Dit proefschrift richtzich op de uitkomsten van de endovasculaire(via de binnenzijde van het bloedvat) reparatie (EVAR) van aneurysmata van de abdominale aorta (AAA). Dit proefschrift is onderverdeeld in drie delen. De resultaten van EVAR in patiënten met niet-geruptureerde en geruptureerde AAAs worden geanalyseerd in het eerste deel. Vervolgens worden nieuwe inzichten en mogelijkheden van EVAR geanalyseerd. In het laatste deel wordt de toepasbaarheid van EVAR in complexie aorta anatomie getoetst. Dit hoofdstuk beschrijft de belangrijkste bevindingen van dit proefschrift.

\section{DEEL ÉÉN - Evolutie en lange-termijn resultaten van EVAR}

De eerste EVAR procedure vond plaats in 1991 door Parodi in Argentinië en Volodos in Oekraïne.,2 In 1994 werd de eerste acute EVAR uitgevoerd bij een geruptureerd AAA door Yusuf. ${ }^{3}$ Over de afgelopen 25 jaar wordt EVAR in toenemende mate toegepast voor de behandeling van een AAA. De endovasculaire behandeling is minder invasief dan de 'open' chirurgische behandeling. Er wordt gebruik gemaakt van een speciaal implantaat, een zogenaamde endovasculaire stentgraft. Uit eerder onderzoek is gebleken dat EVAR resulteert in minder vroegtijdige sterfte en morbiditeit ten opzichte van de open chirurgische behandeling. ${ }^{4,5}$ Het eerste deel van dit proefschrift analyseert de uitkomst van electieve en acute EVAR procedures gebaseerd op een prospectieve, single center studie.

Ondanks uitstekende resultaten met betrekking tot vroegtijdige sterfte en morbiditeit van EVAR, kent deze techniek ook complicaties welke uniek zijn voor deze behandeling. Het optreden van stentgraft-gerelateerde complicaties, met vaak een secundaire behandeling (revisie) als gevolg, blijft het grootste nadeel van deze techniek. Complicaties die een secundaire behandeling behoeven zijn endoleaks, migratie en occlusie van de stentgraft. ${ }^{6,7}$ Een endoleak is een lekkage van bloed in de aneurysmazak, waardoor het aneurysma weer onder druk komt te staan met het daarmee geassocieerde risico van een ruptuur. De huidige richtlijnen adviseren levenslange controle omdat deze complicaties jaren na de endovasculaire procedure kunnen ontstaan. ${ }^{8} \mathrm{Er}$ is echter weinig beschreven over de lange termijn resultaten die deze aanbevelingen ondersteunen. De eventuele 
noodzaak voor een lange termijn controle wordt geanalyseerd in hoofdstuk 2. Dit hoofdstuk evalueert 149 patiënten met een AAA die behandeld zijn met de Talent $^{\mathrm{TM}}$ stentgraft (Medtronic Vascular, Santa Rosa, CA, USA) met een minimale opvolging van tien jaar. Technisch succes, gedefinieerd als succesvolle stentgraft plaatsing met de afwezigheid van een type 1 en/of 3 endoleak, werd bereikt in $89.3 \%$ van de patiënten. De primaire uitkomstmaat was klinisch succes, gedefinieerd als de afwezigheid van aneurysma-gerelateerde sterfte, stentgraft stenose, occlusie of infectie, type 1 en/of 3 endoleak, aneurysma groei, aneurysma ruptuur of de noodzaak tot conversie naar de open chirurgische behandeling. De klinische succes percentages na 30-dagen, één-jaar, vijf-jaar en tien jaar waren respectievelijk $81.1 \%, 74.3 \%, 70.3 \%$ en $65.5 \%$. Tijdens de totale opvolging werd in verband met stentgraft-gerelateerde complicaties bij $20.7 \%$ van de patiënten op zijn minst één secundaire procedure uitgevoerd, wat vergelijkbaar is met de resultaten in eerder gepubliceerde studies. In $70 \%$ van deze complicaties waren de patiënten asymptomatisch en werd de complicatie gezien op beeldvorming tijdens de reguliere opvolging. Uit deze studie kunnen we dan ook concluderen dat stentgraft-gerelateerde complicaties tijdens de eerste tien jaar na EVAR niet zeldzaam zijn en in de meeste gevallen bij regulier beeldvormend follow-up onderzoek worden gedetecteerd. Deze bevinding rechtvaardigt onze inspanningen bij de opvolging van EVAR patiënten voor tenminste de eerste tien jaar postoperatief.

Het technisch succesvol uitvoeren van een EVAR procedure is sterk afhankelijk van nauwkeurige preoperatieve planning. Dit omvat onder andere het opmeten van de aorta en het uitkiezen van de juiste maat stentgraft. In het geval van een geruptureerd AAA (acute EVAR) moet deze planning in een beperkte tijd plaatsvinden in verband met de instabiliteit van de patiënt op dat moment. Ook zal de juiste maat stentgraft gekozen moeten worden uit een (relatief) beperkt assortiment wat op dat moment in het ziekenhuis aanwezig is. Hypothetisch gezien kunnen deze factoren de technische uitkomst van een EVAR procedure negatief beïnvloeden. Hoofdstuk 3 evalueert de uitkomsten van EVAR procedures bij 773 patiënten met een niet-geruptureerd AAA (E-EVAR) en 90 patiënten met een geruptureerd AAA (R-EVAR). Deze studie laat uitstekende resultaten zien met een operatief succes percentage van $95 \%$ in de E-EVAR groep en $90.0 \%$ in 
de R-EVAR groep ( $p=0.052$ ). Er werden significant meer type I endoleaks op de completering angiografie gezien in de R-EVAR groep ten opzichte van de E-EVAR groep (6.9\% vs. $2.8 \%, p=0.038)$. Echter, de meerderheid van deze type I endoleaks verdween spontaan zonder de noodzaak van een secundaire interventie. Er waren geen significante verschillen tussen beide groepen in de hoeveelheid secundaire interventies na vijf jaar follow-up. Zoals men kon verwachten was de vijfjaarsoverleving lager in de R-EVAR groep (65.2\% vs. 48.1\%, p < 0.001). Deze studie laat zien dat de resultaten van EVAR procedures in een electieve en spoed setting technisch vergelijkbaar zijn.

\section{DEEL TWEE - Klinische ervaring en nieuwe inzichten ten aanzien van EVAR}

Meer dan twee decennia na de introductie van EVAR zijn de meningen nog steeds verdeeld over een aantal aspecten van deze techniek. Deel twee van dit proefschrift richt zich op het gebruik van verschillende anesthesie technieken en op EVAR bij hemodynamisch zeer instabiele, gereanimeerde patiënten.

Een EVAR procedure kan onder algehele, regionale (spinaal/epiduraal) en lokale anesthesie worden uitgevoerd. Er is geen consensus over welk type anesthesie het meest geschikt is voor EVAR. De richtlijn van de European Society of Vascular Surgery geeft de voorkeur aan de minder invasieve lokale anesthesie. ${ }^{8}$ Ondanks deze aanbeveling wordt EVAR voornamelijk onder algehele anesthesie verricht. ${ }^{9}$ Hoofdstuk 4 vergelijkt de resultaten van EVAR onder algehele anesthesie (GA), regionale anesthesie (RA) en lokale anesthesie (LA) in 1262 patiënten. De meeste patiënten werden behandeld onder algehele anesthesie (GA 62.3\%, RA 26.2\%, LA $11.5 \%)$. Lokale en regionale anesthesie resulteerden in een kortere operatie tijd en een korter postoperatief verblijf in het ziekenhuis ten opzichte van algehele anesthesie. Het type anesthesie had geen invloed op het technisch operatief succespercentage. Patiënten in de lokale anesthesie groep hadden minder korte termijn complicaties, echter niet significant verschillend ten opzichte van de andere twee groepen (GA 5.6 vs. RA 4.8\% vs. LA 2.8\%). De sterfte in de eerste 30 dagen na EVAR was vergelijkbaar tussen de groepen (GA $1.4 \%$ vs. RA $0.9 \%$ vs. LA $1.4 \%)$. 
Het sterftecijfer van patiënten met een geruptureerd AAA is ongeveer $81 \%$ volgens een recente meta-analyse. ${ }^{10}$ Tot ongeveer $50 \%$ van de patiënten met een ruptuur die behandeld worden overlijdt in de perioperatieve periode.11 Eerdere studies rapporteerden $100 \%$ sterfte bij patiënten die gereanimeerd zijn voordat ze geopereerd worden en concludeerden dat een operatieve behandeling in deze patiëntengroep niet zinvol is. ${ }^{12,13} \mathrm{Om}$ deze aanbeveling te toetsen evalueerden we 199 patiënten met een geruptureerd AAA die behandeld werden in drie grote, nietacademische ziekenhuizen in Nederland. De resultaten van deze studie worden geëvalueerd in hoofdstuk 5. Drieëntwintig patiënten (11.6\%) met een ruptuur ondergingen geen operatieve behandeling omdat de overlevingskans te klein werd ingeschat, door de aanwezigheid van comorbiditeit of ze waren al overleden voordat een operatie gestart kon worden. In de literatuur worden percentages tot $40 \%$ beschreven van patiënten met een ruptuur die geen operatieve behandeling ondergaan. ${ }^{14}$ Van de 199 geïncludeerde patiënten werden 13 patiënten (7.4\%) gereanimeerd voor het moment van operatie. De meeste patiënten in deze groep werden gereanimeerd in het ziekenhuis (76.9\%). Hiervan ondergingen 11 patiënten open aorta chirurgie (OR) en twee patiënten werden endovasculair behandeld (EVAR). Beide EVAR patiënten overleefden het in tegenstelling tot 8/11 OR patiënten $(p=0.128)$. In tegenstelling tot de in de literatuur gerapporteerde sterfte van $100 \%$, vonden wij een 30 -dagen overleving van $38.5 \%{ }^{12,13}$ Hoewel geen definitieve conclusies kunnen worden getrokken op basis van de lage aantallen in deze studie, suggereren onze resultaten dat succesvolle operatieve AAA behandeling in hemodynamisch zeer instabiele patiënten haalbaar is. EVAR heeft daarbij mogelijk de voorkeur boven open chirurgie.

\section{DEEL DRIE - EVAR in patiënten met complexe aorta anatomie}

De anatomie van de abdominale aorta en het aneurysma verschilt per individu. De anatomische geschiktheid voor EVAR is per stentgraft beschreven in de instructies van de fabrikant. Veel patiënten vallen buiten deze anatomische criteria en dit blijft één van de belangrijkste redenen voor de behandeling van AAAs via open chirurgie. De lengte en angulatie van de proximale infrarenale hals van de aorta zijn hierbij belangrijke anatomische criteria. Uit onderzoek is gebleken dat chirurgen steeds vaker AAAs endovasculair behandelen met kenmerken die buiten de door de fabrikant opgestelde anatomische criteria vallen. Toenemende ervaring met 
EVAR en verbeterde stentgrafts laten dit waarschijnlijk ook toe, maar concreet bewijs is beperkt. Het derde deel van dit proefschrift richt zich op de electieve en spoed EVAR bij patiënten met complexe anatomie van de infrarenale hals.

Ongeveer $80 \%$ van de patiënten met een geruptureerd aneurysma is niet geschikt voor EVAR op basis van de anatomie van de aorta en het aneurysma. ${ }^{15}$ In hoofdstuk 6 worden de resultaten van EVAR vergeleken bij patiënten met een geruptureerd AAA met een niet-complexe (FNA) en complexe (HNA) anatomie van de infrarenale hals. Het onderscheid werd gemaakt op basis van de anatomische criteria van de geïmplanteerde stentgraft. Er werd een behandelstrategie gevolgd waarbij EVAR de voorkeur kreeg boven open chirurgie. In totaal zijn 39 patiënten met een ruptuur geïncludeerd die een primaire endovasculaire behandeling ondergingen. In $43.6 \%$ van de patiënten was sprake van complexe anatomie van de infrarenale hals. Het technisch operatief succes percentage was vergelijkbaar in beide groepen (FNA $100 \%$ vs. HNA $88.2 \%, p=0.184)$. Aan het eind van de procedure werden in beide groepen geen type I endoleaks op de angiografie gezien. Wel waren in de HNA groep meer additionele procedures nodig om peroperatieve type I endoleaks op te lossen ( $0 \%$ vs. $23.5 \%, p=0.029)$. Een jaar na de procedure was er geen verschil in type 1 endoleaks, secundaire endovasculaire procedures en sterfte tussen de groepen. Deze uitstekende resultaten geven aan dat EVAR technisch haalbaar en veilig is bij patiënten met een geruptureerd AAA met complexe anatomie van de infrarenale hals in ervaren endovasculaire centra.

Hoofdstuk 7 beschrijft de invloed van infrarenale hals anatomie op electieve EVAR. Gegevens van 1218 patiënten uit de (ENGAGE) Registry werden gebruikt voor deze analyse. ${ }^{16}$ De patiënten werden verdeeld in drie groepen op basis van de complexiteit van de infrarenale aorta hals; 'regular' (REG), 'intermediate' (INT) en 'challenging' (CHA). De mate van angulatie en lengte van de infrarenale hals bepaalden de mate van complexiteit. Er waren geen significante verschillen tussen de groepen met betrekking tot technisch operatief succes. De incidentie van type I endoleaks was significant hoger in de CHA groep in vergelijking met INT en REG anatomie (REG vs. CHA: OR 0.15, 95\% BI $0.05-0.46$ en INT vs. CHA: OR 0.08\%, 95\% BI 0.01-0.70). Dit verschil resulteerde echter niet tot meer secundaire interventies. De meeste type I endoleaks waren minimaal en verdwenen spontaan. Een jaar na de procedure waren er geen significante verschillen tussen de groepen met 
betrekking tot type I endoleaks, secundaire interventies en sterfte. Op basis van deze resultaten kan geconcludeerd worden dat patiënten met ernstig geanguleerde en korte infrarenale halzen succesvol endovasculair behandeld kunnen worden met de Endurant Stent Graft (Medtronic Vascular, Santa Rosa, Calif).

De uitkomsten van de Endurant Stent Graft in complexe anatomie is al in veel publicaties beschreven, waarin geen significant verschillen worden gerapporteerd met betrekking tot technisch operatief succes en korte termijn resultaten ${ }^{17-19}$ Deze studies bestonden uit (relatief) kleine en retrospectief verzamelde patiëntengroepen waarbij mogelijk sprake is van selectiebias. De 'Endurant for challenging Anatomy: GLobal Experience (EAGLE) Registry' werd geïnitieerd om prospectief 'real-world' data te verzamelen over de Endurant Stent Graft in patiënten met complexe anatomie van de infrarenale hals. Hiermee kunnen de huidige anatomische criteria voor EVAR getoetst worden en de mogelijkheden worden geëvalueerd of meer patiënten middels EVAR behandeld kunnen worden. Hoofdstuk 8 beschrijft het doel en het studie ontwerp van de EAGLE Registry. Deze studie is geïnitieerd door artsen. EAGLE is een prospectieve, niet-interventionele studie met als doel om 250 patiënten met complexe infrarenale hals anatomie te includeren in minimaal 20 ervaren vasculaire centra wereldwijd. Geruptureerde AAAs worden geëxcludeerd in deze studie. Inclusie zal bepaald worden op basis van metingen door een onafhankelijk CORE lab om selectiebias te minimaliseren. De primaire uitkomsten zijn technisch succes op 30 dagen, een jaar en vervolgens jaarlijks tot maximaal vijf jaar na de procedure. Het doel van EAGLE is om inclusie te voltooien in het voorjaar van 2016. 


\section{References}

1. Parodi JC, Palmaz JC, Barone HD: Transfemoral intraluminal graft implantation for abdominal aortic aneurysms. Ann Vasc Surg 1991; 5: 491-9

2. Volodos NL, Karpovich IP, Troyan VI, et al.: Clinical experience of the use of self-fixing synthetic prostheses for remote endoprosthetics of the thoracic and the abdominal aorta and iliac arteries through the femoral artery and as intraoperative endoprosthesis for aorta reconstruction. Vasa Suppl 1991; 33: 93-5

3. Yusuf SW, Whitaker SC, Chuter TA, et al.: Emergency endovascular repair of leaking aortic aneurysm. Lancet 1994; 344: 1645

4. participants Et: Endovascular aneurysm repair versus open repair in patients with abdominal aortic aneurysm (EVAR trial 1): randomised controlled trial. Lancet 2005; 365: 2179-86

5. Prinssen $\mathrm{M}$, Verhoeven EL, Buth J, et al.: A randomized trial comparing conventional and endovascular repair of abdominal aortic aneurysms. N Engl J Med 2004; 351: 1607-18

6. Chaikof EL, Blankensteijn JD, Harris PL, et al.: Reporting standards for endovascular aortic aneurysm repair. J Vasc Surg 2002; 35: 1048-60

7. Torsello GB, Klenk E, Kasprzak B, et al.: Rupture of abdominal aortic aneurysm previously treated by endovascular stentgraft. J Vasc Surg 1998; 28: 184-7

8. Moll FL, Powell JT, Fraedrich G, et al.: Management of abdominal aortic aneurysms clinical practice guidelines of the European society for vascular surgery. Eur J Vasc Endovasc Surg 2011; 41 Suppl 1: S1-S58

9. Ruppert V, Leurs LJ, Steckmeier B, et al.: Influence of anesthesia type on outcome after endovascular aortic aneurysm repair: an analysis based on EUROSTAR data. J Vasc Surg 2006; 44: 16-21; discussion 21

10. Reimerink JJ, Hoornweg LL, Vahl AC, et al.: Endovascular repair versus open repair of ruptured abdominal aortic aneurysms: a multicenter randomized controlled trial. Ann Surg 2013; 258: 24856

11. Investigators IT, Powell JT, Sweeting MJ, et al.: Endovascular or open repair strategy for ruptured abdominal aortic aneurysm: 30 day outcomes from IMPROVE randomised trial. BMJ 2014; 348: f7661

12. Greeven AP, Bouwman LH, Smeets HJ, et al.: Outcome of patients with ruptured abdominal aortic aneurysm after cardiopulmonary resuscitation. Acta Chir Belg 2011; 111: 78-82

13. Johansen K, Kohler TR, Nicholls SC, et al.: Ruptured abdominal aortic aneurysm: the Harborview experience. J Vasc Surg 1991; 13: 240-5; discussion 245-7

14. Karthikesalingam A, Holt PJ, Vidal-Diez A, et al.: Mortality from ruptured abdominal aortic aneurysms: clinical lessons from a comparison of outcomes in England and the USA. Lancet 2014; 383: 963-9 
15. Rose DF, Davidson IR, Hinchliffe RJ, et al.: Anatomical suitability of ruptured abdominal aortic aneurysms for endovascular repair. J Endovasc Ther 2003; 10: 453-7

16. Bockler D, Fitridge R, Wolf $\mathrm{Y}$, et al.: Rationale and design of the Endurant Stent Graft Natural Selection Global Postmarket Registry (ENGAGE): interim analysis at 30 days of the first 180 patients enrolled. J Cardiovasc Surg (Torino) 2010; 51: 481-91

17. Hyhlik-Durr A, Weber TF, Kotelis D, et al.: The Endurant Stent Graft System: 15-month follow-up report in patients with challenging abdominal aortic anatomies. Langenbecks Arch Surg 2011; 396: 801-10

18. Torsello G, Troisi N, Donas KP, et al.: Evaluation of the Endurant stent graft under instructions for use vs off-label conditions for endovascular aortic aneurysm repair. J Vasc Surg 2011; 54: 300-6

19. Georgiadis GS, Trellopoulos G, Antoniou GA, et al.: Early results of the Endurant endograft system in patients with friendly and hostile infrarenal abdominal aortic aneurysm anatomy. J Vasc Surg 2011; 54: 616-27 




\section{Valorisatie addendum}

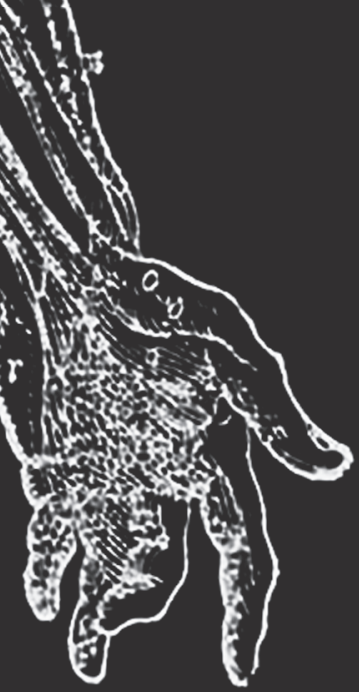





\section{Valorisatie addendum}

Een aneurysma van de abdominale aorta (AAA) is een lokale verwijding van de buikslagader. We spreken van een AAA indien de diameter ten minste 1.5 maal groter is dan de verwachte diameter van het betreffende bloedvat. Een andere definitie is op basis van de bovengrens van de normale diameter van de abdominale aorta die voor mannen en vrouwen $2.9 \mathrm{~cm}$ is. Bij deze definitie is afgesproken dat bij een diameter groter of gelijk aan $3.0 \mathrm{~cm}$ sprake is van een aneurysma.

De prevalentie van een AAA is hoger bij mannen dan bij vrouwen. De prevalentie bij mannen is $1.3 \%$ tot $8.9 \%$ en bij vrouwen $1.0 \%$ tot $2.2 \%$. Belangrijke risicofactoren voor het ontstaan van een AAA zijn leeftijd, geslacht en roken.

Een AAA vormt een levensbedreigend risico als sprake is van een ruptuur. Hierbij ontstaat een scheur in de aorta waardoor een potentieel levensbedreigende bloeding ontstaat. Na een ruptuur overlijdt ongeveer $80 \%$ van de patiënten, hiervan overlijdt de helft voordat ze het ziekenhuis bereiken. Bij vrouwen is de kans op ruptuur groter dan bij mannen.

De behandeling is afhankelijk van de diameter van het AAA en co-morbiditeit van de patiënt. Bij een AAA kleiner dan $5.5 \mathrm{~cm}$ (bij de vrouw kleiner dan $5.0 \mathrm{~cm}$ ) zal het AAA echografisch worden vervolgd met een frequentie afhankelijk van de diameter. In het geval van snelle groei of bij klachten kan overgaan worden tot behandeling. Bij een diameter van $5.5 \mathrm{~cm}$ (bij een vrouw $5.0 \mathrm{~cm}$ ) of bij een snelle groei (meer dan $1 \mathrm{~cm}$ per jaar) zal bij de meeste patiënten worden overwogen om te opereren, omdat vanaf deze diameter het operatierisico kleiner is dan het risico op een ruptuur. In het geval van een ruptuur is directe operatieve behandeling gewenst.

Afhankelijk van onder andere de anatomie van het aneurysma kan een keuze worden gemaakt voor een open operatie of een endovasculaire operatie (EVAR). Gezien de lagere perioperatieve mortaliteit verdient, indien anatomisch mogelijk, EVAR de voorkeur. Bij een EVAR wordt een stentgraft via de lies ingebracht en opgevoerd totdat de stent ter hoogte van het aneurysma ligt. De stentgraft wordt in het aneurysma geplaatst om zo het aneurysma af te sluiten van de normale 
bloedstroom. Deze procedure kan onder lokale anesthesie verricht worden.

Bij een open operatie wordt het AAA van buitenaf benaderd middels een grote incisie in de buik van de patiënt. Het aneurysma wordt vervolgens chirurgisch afgesloten van het hoofddeel van de aorta en vervangen door een kunststof buisprothese, die wordt in gehecht. Dit is een invasieve procedure met een aanzienlijke mortaliteit en morbiditeit. De open operatie wordt altijd onder algehele narcose uitgevoerd.

Dit proefschrift heeft als doel om de mogelijkheden van EVAR te beschrijven en om de anatomische grenzen van EVAR te toetsen. Om dit doel te bereiken werden diverse wetenschappelijke studies verricht.

Een patiënt met een AAA is vaak op leeftijd met soms een uitgebreide comorbiditeit. Onderzoek in dit proefschrift heeft aangetoond dat EVAR uitgevoerd kan worden met behulp van lokale anesthesie. Dit is een groot voordeel ten opzichte van de open chirurgische behandeling die alleen uitgevoerd kan worden onder algehele narcose wat risico's met zich meebrengt. Een minimaal invasieve operatie onder minimaal belastende anesthesie moet een streven worden voor alle patiënten met een AAA in de toekomst.

Na een EVAR procedure kan de patiënt eigenlijk na een paar uur al naar huis. Een EVAR als dagbehandeling wordt in het buitenland al veel toegepast met uitstekend resultaten. Patiënten kunnen vervolgens thuis herstellen en worden zo niet blootgesteld aan de risico's van een ziekenhuisopname. Dit zorgt er uiteindelijk ook voor dat in het ziekenhuis meer bedden beschikbaar zijn voor andere patiënten. Ook kunnen de kosten van een EVAR behandeling gereduceerd worden. Deze vorm van zorg kan in Nederland verzekeringstechnisch helaas nog niet worden uitgevoerd. Vanuit doelmatigheid oogpunt valt hier in de toekomst nog winst te behalen bij de behandeling van het AAA.

De keuze of een AAA patiënt een endovasculaire of open chirurgische behandeling krijgt is niet alleen gebaseerd op anatomische geschiktheid. De ervaring van de vaatchirurg die deze anatomische geschiktheid beoordeelt speelt hierbij een 
grote rol. Uit recente AAA-studies blijkt dat veel centra nog een substantieel deel van hun patiënten middels de invasieve open chirurgie behandelen. In het Catharina ziekenhuis, waar het grootste deel van de patiënten uit dit proefschrift zijn behandeld, wordt nog maar een fractie van de patiënten behandeld met open chirurgie. Er bestaat dus nog veel discrepantie tussen verschillende ziekenhuizen en het is dan ook de vraag of het advies uit de Nederlandse richtlijn om, indien anatomisch mogelijk voor EVAR te kiezen, altijd wordt opgevolgd.

De criteria waaraan de anatomie moet voldoen om voor EVAR in aanmerking te komen is per stentgraft beschreven in de door de fabrikant opgestelde instructies voor gebruik (Engels: Instructions for use [IFU]). Een aanzienlijk aantal AAA patiënten valt buiten deze anatomische criteria en wordt niet geschikt bevonden voor een endovasculaire behandeling. Helaas zijn deze patiënten ook vaak in een dusdanig slechte conditie dat ze geen open operatie aan kunnen. Hierom is de continue doorontwikkeling van stentgrafts essentieel om zo de anatomische criteria te verruimen en meer patiënten met deze minimaal invasieve techniek te kunnen behandelen. Er ligt hier dus een uitdaging voor de medische industrie en de medische wetenschap om het percentage patiënten geschikt voor EVAR zo groot mogelijk te maken.

De Endurant for challenging Anatomy: GLobal Experience (EAGLE) registry heeft als doel om data te verzamelen over een van de laatste generaties stentgraft in patiënten met complexe anatomie van de infrarenale hals (Endurant, Medtronic AVE, Sant Rosa, Ca, USA). Omdat de in deze registry participerende, ervaren endovasculaire centra de IFU regelmatig worden overschreden zonder dat zich hierbij problemen voordoen, worden deze patiënten nu verzameld in de EAGLE registry. Deze registry maakt het mogelijk de anatomische criteria voor EVAR te evalueren en zo de mogelijkheden te toetsen om in de toekomst meer patiënten middels EVAR veilig te behandelen. De EAGLE Registry is uniek omdat zij geïnitieerd is door endovasculaire chirurgen zelf. 



\section{Dankwoord}

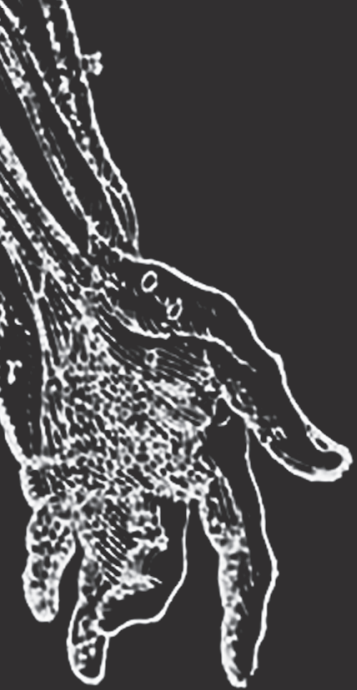





\section{Dankwoord}

Een proefschrift schrijf je niet alleen. Veel mensen hebben direct of indirect een bijdrage geleverd aan de inhoud van dit proefschrift. Een aantal van hen wil ik graag persoonlijk bedanken.

Prof. dr. J.A.W. Teijink, beste promotor, beste Joep, allereerst wil ik jou bedanken. Ik ben je zeer dankbaar dat je mij de mogelijkheid hebt gegeven om te promoveren. Dit proefschrift was niet mogelijk geweest zonder jouw passie voor de vaatchirurgie en de wetenschap. Jouw energie en hoeveelheid aan ideeën zijn ongekend. Hierdoor heb ik mijn promotie snel af kunnen ronden. Niet alleen op het werk maar ook daar buiten was het altijd gezellig. Je stond altijd vooraan bij de vele vaatuitjes en de jaarlijkse congressen met de gehele vaatclub. Al met al was het een fantastische en leerzame tijd! Ik hoop dat ik nog lang betrokken mag blijven bij het AAA onderzoek in het Catharina Ziekenhuis.

Dr. M.R.H.M. van Sambeek, beste copromotor, beste Marc, wat heb ik een geluk met jou als copromotor. Bedankt dat je altijd de tijd hebt genomen om kritisch naar mijn artikelen te kijken. Waar ik vaak totaal de weg kwijt was kon jij mij weer in de juiste richting sturen. Jouw vertrouwen in mijn onderzoek gaf mij de motivatie om door te gaan. De congressen in onder andere Miami en New York waren een geweldige ervaring.

Dr. Ph.W.M. Cuypers, beste copromotor, beste Philippe, bedankt voor al je inzet tijdens mijn promotie. Ik kon altijd aankloppen met vragen en steeds nam je de tijd om de publicaties naar een hoger niveau te tillen. Het is een eer om met iemand samen te mogen werken die zoveel ervaring in de aortachirurgie heeft.. Samen met jou op congres in Miami was geweldig. Wat hebben we een lol gehad. Bedankt!

Alle mede-auteurs, bedankt voor jullie inzet bij mijn publicaties. Zonder jullie geen promotie! In het bijzonder wil ik ook Saskia Houterman bedanken. Bedankt voor je eeuwige geduld. 
Graag zou ik de leden van de beoordelingscommissie, voorzitter prof. dr. M.H. Prins, prof. dr. F.L. Moll, prof. dr. G.W.H. Schurink en prof. dr. H.J.M. Verhagen willen bedanken voor de tijd die jullie hebben genomen voor de kritische beoordeling van mijn proefschrift.

The EAGLE participators. I would like to thank all the doctors and research nurses that are part of the EAGLE Registry. Thank you for your great hospitality during my visits. It was a great and unique experience!

Eric Alberts, beste Eric, fantastisch dat jij tijd vrij wilde maken om de lay-out van dit boekje op je te nemen. Het is mooier geworden dan ik had durven dromen. Ontzettend bedankt!

Toon van der Krieken, beste Toon, geweldig om te mogen leren van iemand die zoveel ervaring heeft met EVAR en beeldvorming. Dit zorgde voor een geweldige bijdrage aan meerdere hoofdstukken in dit proefschrift. Ook bedankt voor je inzet en vertrouwen in de EAGLE Registry.

Gert-Jan Lauret, beste Gert-Jan, goede vriend, collega, trainingsmaatje en paranimf! Fantastisch dat ik jou heb leren kennen. Bedankt voor al je tips en steun bij de afronding van mijn promotie. Wat heb ik met jou vaak hard mogen lachen tijdens alle uitstapjes en congressen. De tripjes naar Budapest en Porto waren veruit hoogtepunten. Nu mijn promotie klaar is kijk ik er naar uit om het oude trainingsritme weer op te pakken. Fel zijn!

Rutger Stokmans, beste Rutger. Als semi-arts heb ik ontzettend veel van jou mogen leren. Jouw oog voor perfectie brengt alles tot een hoger niveau. Samen vormden we al snel de aortaboys, wat onder andere tot de EAGLE Registry heeft geleid. Ook wist jij er altijd een mooi feestje van te maken. De late avondjes in Londen en Budapest waren legendarisch. Bedankt voor de mooie tijd!

Onderzoekers van de chirurgie. Hugo, ontzettende baas, wat hebben we een hoop lol gehad in het kleine onderzoek hok bij de oude poli chirurgie. Wat zitten ze er tegenwoordig luxe bij he! Bedankt dat je altijd bereid was om me te helpen 
met mijn onderzoek. Yannick, mooi dat jij de AAA-trein voortzet. Heel veel succes met jouw proefschrift en de afronding van EAGLE. Ik hoop dat ik nog lang bij het AAA-onderzoek betrokken mag blijven. Thijs, tegelijk begonnen aan het schrijven van een proefschrift. De snelheid waarin jij gepubliceerd hebt is ongekend. Het motiveerde mij om ook zo snel mogelijk dit proefschrift af te ronden. Nu zijn we weer collega's bij de chirurgie. Martin, ik ken niemand die meer bijnamen heeft dan jij. Wat kon ik daar toch altijd hard om lachen. Bedankt voor je gezelligheid en oprechtheid. Hopelijk is jouw proefschrift ook snel af! Geert, een jaartje mijn trouwe buurman in de kelder geweest. Succes met de laatste loodjes van jouw boekje!

De maatschap chirurgie en de arts-assistenten van het Catharina Ziekenhuis. Door jullie heb ik veel plezier in mijn werk. Dit gaf mij iedere keer weer energie om dit boekje af te maken. Bedankt voor jullie steun.

Mijn vrienden. In het bijzonder: Erik, Teun, Thijs, Alex, Ward, Remo en Stijn. Bedankt voor de mooie momenten de afgelopen jaren. Laten we de lijntjes lekker kort houden! Jasper, heel veel succes met het afronden van jouw promotie in Maastricht!

Mijn schoonfamilie, Guido, Godelief, Ben en Kim. Bedankt voor jullie interesse en onvoorwaardelijke steun. Jullie staan altijd voor mij, An en Lola klaar. Ontzettend bedankt!

Lieve Hans, fantastisch dat je paranimf bent! Een grote eer om mijn grote broer naast me te hebben staan tijdens mijn promotie. Ik kan me geen betere broer wensen. Ik kijk ook uit naar de afronding van jouw promotie, zet hem op! Ook wil ik mijn schoonzus Madeleine en neefje Lothar bedanken, jullie maken de familie compleet!

Lieve papa en mama, tijdens mijn promotietraject zijn jullie opa en oma geworden! Bedankt dat jullie altijd voor mij en mijn gezin klaar staan. Het is altijd een feest als ik bij jullie ben! Veel interesse hebben jullie de afgelopen jaren in mijn promotieonderzoek getoond. Dit motiveerde mij om dit boekje af te ronden. Jullie 
zijn de liefste ouders, bedankt!

Tot slot wil ik mijn meisjes bedanken. Lieve An, de grootste overwinning in mijn leven dat ben jij. Wat kunnen wij elkaar toch goed aanvullen. Ik geniet van ieder moment dat ik bij jou ben. Samen op dezelfde dag promoveren, daar ben ik ontzettend trots op. Met jou kan ik heel de wereld aan. Ik zie u heel graag schat! Lieve Lola, ons kleintje. Ons mooiste bezit en de vrolijke noot van de familie! Wat hou ik toch veel van jou. 


Curriculum vitae

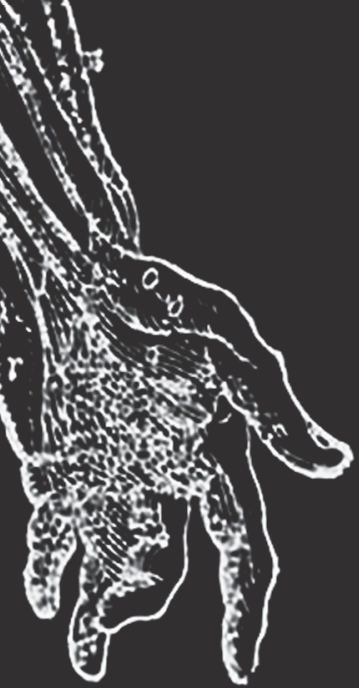





\section{Curriculum Vitae}

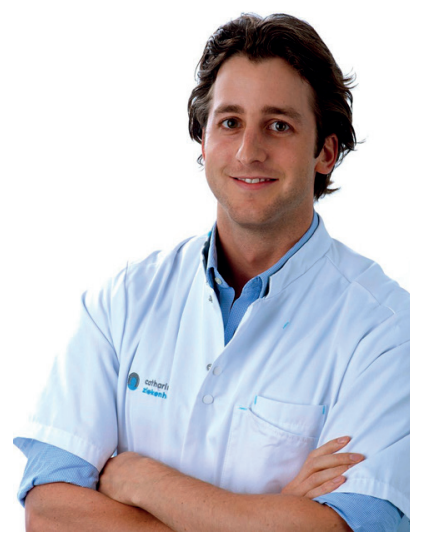

Pieter Petrus Henricus Luciën Broos was born on February 20, 1987, in Oosterhout, the Netherlands. In 2005, he graduated from secondary school at the Mgr. Frencken College in Oosterhout. For three years he studied Molecular Life Sciences at the Maastricht University (2005-2007). Eventually, he started Medical school at the University of Maastricht (20072013). In his last year as medical student he started a vascular research project that resulted in a poster prize at the International Society for Vascular Surgery congress in Miami, Florida, USA. After obtaining his Medical Degree, he started as PhD candidate and research coordinator of the EAGLE Registry at the department of vascular surgery in the Catharina Hospital in Eindhoven. Under the supervision of prof. dr. J.A.W. Teijink, dr. M.R.H.M. van Sambeek and Ph.W.M. Cuypers, he completed this thesis focusing on the treatment of abdominal aortic aneurysms. From February 2015 until August 2015 he worked as a resident at the intensive care department at the Catherina Hospital in Eindhoven. In September 2015 he started as a resident at the department of surgery at the Catharina Hospital in Eindhoven. He is living together with An Deliaert and together they have a beautiful daughter named Lola (2014). Lola is expecting a little brother in January 2016. 



\section{List of publications}

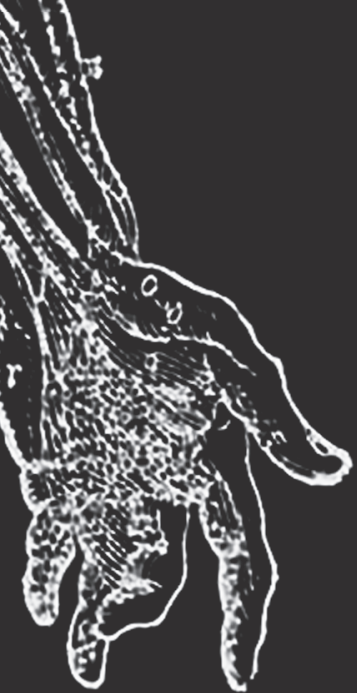





\section{List of publications}

1. van Wijk S, Jacobs L, Eurlings LW, van Kimmenade R, Lemmers R, Broos PP, Bekers $O$, Prins $M H$, Crijns HJ, Pinto YM, van Dieijen-Visser MP, Brunner-La Rocca HP. Troponin T measurements by high-sensitivity vs conventional assays for risk stratification in acute dyspnea. Clin Chem. 2012 Jan;58(1):284-92

2. Nicolaï SP, Kruidenier LM, Bendermacher BL, Prins MH, Stokmans RA, Broos PP, Teijink JA. Gingko biloba for intermittent claudication. Cochrane Database Syst Rev. 2014 Jun;6:CD006888.

3. Broos PP, Stokmans RA, Cuypers PW, Forbes TL, Vahl AC, Swartbol P, van Sambeek MR, Teijink JA. Rationale and design of the EAGLE Registry: EVAR with Endurant ${ }^{\circledR}$ in challenging anatomy. J Cardiovasc Surg (Torino). 2014 Oct;55(5):699-704.

4. Broos PP, Stokmans RA, van Sterkenburg SM, Torsello G, Vermassen F, Cuypers PW, van Sambeek MR, Teijink JA. Performance of the Endurant stent graft in challenging anatomy. J Vasc Surg. 2015 Aug;62(2):312-8.

5. Broos PP, 't Mannetje YW, Cuypers PW, van Sambeek MR, Teijink JA. Endovascular treatment of ruptured abdominal aortic aneurysms with hostile aortic neck anatomy. Eur J Vasc Endovasc Surg. 2015 Sep;50(3):313-9.

6. Broos PP, Stokmans RA, Cuypers PW, van Sambeek MR, Teijink JA. Effects of anesthesia type on perioperative outcome after endovascular aneurysm repair. J Endovasc Ther. 2015 Oct;22(5):770-7.

7. Broos PP, Hagenaars JC, Kampschreur LM, Wever PC, Bleeker-Rovers CP, Koning OH, Teijink JA, Wegdam-Blans MC. Vascular complications and surgical interventions after world's largest $Q$ fever outbreak. J Vasc Surg. 2015 Sep. Epub ahead of print.

8. Broos PP, 't Mannetje YW, Loos MJ, Scheltinga MR, Bouwman LH, Cuypers PW, van Sambeek MR, Teijink JA. A ruptured abdominal aortic aneurysm that requires preoperative cardiopulmonary resuscitation is not necessarily lethal. J Vasc Surg. 2015 Sep. Epub ahead of print. 
